University of Louisville

ThinkIR: The University of Louisville's Institutional Repository

Electronic Theses and Dissertations

$12-2018$

\title{
Lead and crime: an ecological study between lead contaminated topsoil and violent crime.
}

Brian Guinn

University of Louisville

Follow this and additional works at: https://ir.library.louisville.edu/etd

Part of the Epidemiology Commons

\section{Recommended Citation}

Guinn, Brian, "Lead and crime: an ecological study between lead contaminated topsoil and violent crime." (2018). Electronic Theses and Dissertations. Paper 3115.

https://doi.org/10.18297/etd/3115

This Doctoral Dissertation is brought to you for free and open access by ThinkIR: The University of Louisville's Institutional Repository. It has been accepted for inclusion in Electronic Theses and Dissertations by an authorized administrator of ThinkIR: The University of Louisville's Institutional Repository. This title appears here courtesy of the author, who has retained all other copyrights. For more information, please contact thinkir@louisville.edu. 


\title{
LEAD AND CRIME: AN ECOLOGICAL STUDY BETWEEN LEAD CONTAMINATED TOPSOIL AND VIOLENT CRIME
}

\author{
By \\ Brian Guinn \\ MPH, University of Louisville, 2015 \\ BSN, Bellarmine University, 2001

\begin{abstract}
A Dissertation
Submitted to the Faculty of the

School of Public Health and Information Sciences of the University of Louisville in Partial Fulfillment of the Requirements

for the Degree of
\end{abstract} \\ Doctor of Philosophy In Public Health Sciences
Department of Epidemiology and Population Health University of Louisville
Louisville, Kentucky

December 2018 



\title{
LEAD AND CRIME: AN ECOLOGICAL STUDY BETWEEN LEAD CONTAMINATED TOPSOIL AND VIOLENT CRIME
}

\author{
By \\ Brian Guinn \\ MPH, University of Louisville, 2015 \\ BSN, Bellarmine University, 2001 \\ Dissertation Approved on
}

November 19, 2018

by the following Dissertation Committee

Dr. Kristina M Zierold, PhD, MS

Dr. Kathy B. Baumgartner, PhD

Dr. Stephanie Boone, $\mathrm{PhD}$

Dr. Haifeng Zhang, PhD

Dr. Jeremy Gaskins, $\mathrm{PhD}$ 


\section{ACKNOWLEDGMENTS}

It is with great pleasure that I acknowledge my deepest gratitude towards my dissertation committee. A very special thanks to my co-chairs, Dr. Kristina Zierold and Dr. Kathy Baumgartner, who contributed enormously to my academic success and completion of this dissertation. I would like to thank Dr. Zierold, who inspired me with her research which continues to illuminate the relationship between our shared environment and our personal health. I would also like to thank Dr. Baumgartner, who pushed me to be a better researcher in both theory and practice, and who allowed me to study under her tutelage. It is without question that I am a better student of epidemiology because of the unique perspective each of you offered throughout the dissertation process.

I would also like to thank the rest of my dissertation committee, Dr. Jeremy Gaskins, Dr. Haifeng Zhang, and Dr. Stephanie Boone. I would like to thank Dr. Gaskins for expanding my statistical knowledge and pushing me to be a better student of statistics. A special thanks to Dr. Zhang, who generously taught me different ways to analyze geographic information. Finally, I would like to thank Dr. Boone, who has been instrumental in my learning of epidemiology, both as an instructor and as a committee member.

A very special thanks is extended to Dr. Julio Ramirez, Dr. Robert Kelley, Dr. Timothy Wiemken, Dr. William Mattingly, Dr. Ruth Carrico, Kim Buckner, Matthew Grassman, Stephen Furmanek and all my friends at the University of Louisville - 
Division of Infectious Diseases. Each of you has played a pivotal role in my academic success.

A special thanks to Dr. Douglas Lorenz and Dr. Kira Taylor, who have been influential instructors in my learning of statistics. I would like to thank my parents Jeanne Guinn, and Michael and Bonnie Guinn for their support and encouragement. Thank you to my brother Andrew Guinn who has listened to my yammering and yada, yada, yada for the better part of 40 years. Finally, I would like to thank Dr. Emily Tan, my wife and best friend. Emily has been my biggest fan, lovingly cheering me on, and generously supporting me throughout graduate school. 


\title{
ABSTRACT \\ LEAD AND CRIME: AN ECOLOGICAL STUDY BETWEEN LEAD CONTAMINATED TOPSOIL AND VIOLENT CRIME
}

\author{
Brian Guinn
}

November 19, 2018

Lead is a known neurotoxicant. Human exposure to lead comes primarily through environmental exposures, including remnant lead paint, lead contaminated topsoil and lead contaminated water. Prenatal and early life lead exposure has been associated with numerous neurocognitive and neuropsychiatric disorders. This dissertation presents findings from an ecological study which evaluated the geospatial association between topsoil lead content and the incidence of FBI designated violent crime in Jefferson County, Kentucky.

A total of 412 topsoil samples were collected along roadways $(n=300)$ and from Louisville Metro Parks ( $\mathrm{n}=112)$. Jefferson County crime data was obtained from the Louisville Metro Police Department - Crime Information Center. Shared areas of higher than expected rates of FBI designated violent crime was designated as the Study Area. Three Control Areas were established based upon their low to expected rates of violent crime. The Control Areas were located northeast, southeast and southwest of the Study Area. Spatial Error Model was used to compare topsoil lead content between the Study Area and the three Control Areas. A Bayesian sparse spatial generalized linear mixed 
model (SGLMM) was used to evaluate the geospatial association between violent crime and topsoil lead content while controlling for eight pertinent census-tract-level covariates.

Spatial Error Model results showed that the Study Area had an approximate 8-fold increase in topsoil lead content compared to the referent Control Area. Unadjusted SGLMM, found that every 100-unit increase in topsoil lead content was associated with a 62 percent increased risk for violent crime events per census tract $(R R=1.62,95 \%$ CI:1.59, 1.64). The full SGLMM, which controlled for eight census-tract-level covariates, found that every 100-unit increase in topsoil lead content was associated with a 5 percent increased risk for violent crime events per census tract $(\mathrm{RR}=1.05,95 \% \mathrm{CI}: 1.03,1.08)$.

The results of this study are based upon an ecological study and should be interpreted with caution. However, these findings provide a rationale for the design of future studies aimed at exploring the relationship between lead poisoning and subsequent criminality. 


\section{TABLE OF CONTENTS}

\section{ACKNOWLEDGMENTS}

PAGE iii

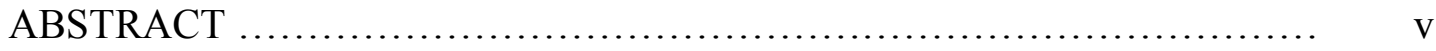

LIST OF TABLES …................................................

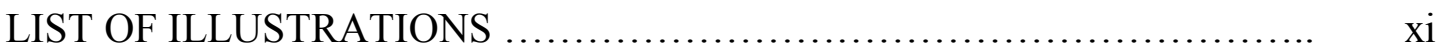

I. RATIONALE, OBJECTIVE, SPECIFIC AIMS, and HYPOTHESES ...... 1

II. Literature Review ..................................................... 6

SECTION A - A Historical Review of Crime Theories and Selected Risk

Factors

1. Defining Violent Crime ................................................... 8

2. Early Theories of Crime - Nature vs. Nurture ……...................... 8

2a. The Classical School ............................................... 8

2b. Biological Positivism .......................................... 9

2c. The Chicago School ............................................. 11

3. Current Approaches to Crime Theory in a Biosocial Milieu ............... 12

3a. Genetic Risk Factors - The Serotonergic System ................... 13

3b. Central Nervous System - Prefrontal Cortex ....................... 16

3c. Prenatal Risk Factors ........................................... 21

3d. Early Life Risk Factors ....................................... 24

SECTION B - The Lead-Crime Hypothesis .............................. 27

4. Lead - A Historical Review from Ancient Egypt to Contemporary

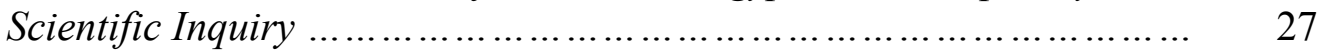

5. Current Standards ....................................................... $\quad 30$

5a. Soil Lead Standards ............................................ $\quad 30$

5b. Blood Lead Standards ........................................ $\quad 30$

6. Lead-Environmental Exposures ……................................... 31

6a. Lead-Based Paint ................................................. 31

6b. Leaded Gasoline ............................................... 33

7. Lead-Lead-Induced Neurotoxicity .......................................

7a. Neurotoxic Pathophysiology ................................... 35

7b. Epidemiological Studies Evaluating Volumetric Effects Associated with Lead Exposure ........................................... $\quad 36$ 
7c. Pediatric Vulnerability in Lead Contaminated Environments

8. The Lead Crime Hypothesis: Epidemiological Studies Evaluating the

Potential Lead-Crime Association

8a. Epidemiological Studies Evaluating the Association between Lead and Crime

8b. Gaps in the Research Exposure Assessment

III. METHODS

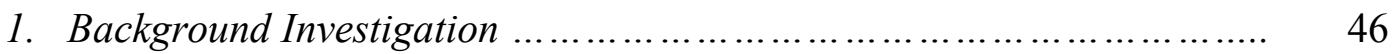

2. Dissertation: Study Design .......................................... 47

3. Methods Specific to Aim 1 .............................................. 48

3a. Crime Map ................................................. 48

3b. Statistical Methods for Cluster Analysis .......................... 48

4. Methods Specific to Aim 2 .............................................. 49

4a. Four Predetermined Collection Areas - Selecting High Crime and .....

Low Crime Clusters for Soil Sampling ...........................

4b. Topsoil Lead Assessment .......................................... $\quad 50$

4c. A Priori Power Calculations ..................................... 52

4d. Statistical Methods for Comparing Soil Lead Content Between Soil Collection Areas ............................................. 54

5. Methods Specific to Aim 3 ................................................ 54

5a. Dependent Variable, Primary Predictor, and Covariates of Interest....... 55

5b. Statistical Methods ......................................... 57

IV. RESULTS ................................................... 59

1. Specific Aim 1 Results: Use Geographic Information Systems (GIS) to Examine the Geospatial Distribution of Violent Crime throughout Jefferson County, KY

2. Specific Aim 2 Results: Quantify and Record Topsoil Lead

Concentrations in Neighborhoods of Jefferson County, KY with High

Crime Rates, and Low to Normal Crime Rates

3. Specific Aim 3 Results: Examine the Statistical Relationship Between the Spatial Distribution of FBI Designated Violent Crime and Topsoil Lead Concentrations, Adjusting for Pertinent Census-Tract-Level Variables in Jefferson County, Kentucky. .......................... 74

4. Summary ......................................................... 77

V. DISCUSSION ................................................ 80

1. The Distribution of Violent Crime in Jefferson County, Kentucky .......... 80

2. The Distribution of Lead Contaminated Topsoil in Jefferson County, Kentucky

3. The Statistical Associations of Topsoil Lead Content and Measures of Socioeconomic Deprivation on the Incidence of FBI Designated Violent Crime in Jefferson County, $K Y$ 
4. Strengths and Limitations ......................................... 87

5. Conclusions ............................................................... 91

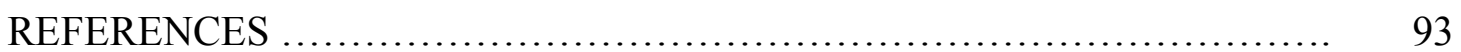

APPENDIX A: SUPPLEMETNAL TABLES .............................. 116

APPENDIX B: SUPPLEMENTAL TABLES ............................... 119

CURRICULUM VITAE ................................................ 126 


\section{LIST OF TABLES}

PAGE

1. Table 1. FBI Violent Crimes per Jefferson County Census Tracts between

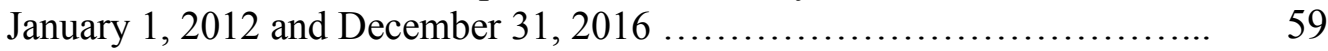

2. Table 2. Edge Zone Topsoil Lead Content by Collection Area ........... 66

3. Table 3. Louisville Metro Parks Topsoil Lead Content by Collection Area 67

4. Table 4. Results Spatial Error Models for Edge Zone and Louisville Metro Parks Soil Samples

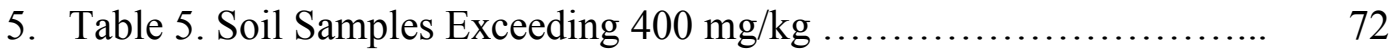

6. Table 6. Results of the marginal Poisson based sparse: All Crime Events 75

7. Table 7. Results of the marginal Poisson based sparse: Sub-analysis by crime type

8. Supplemental Table 1. Serum Lead Data from the Louisville Metro Department of Health and Wellness

9. Supplemental Table 2. Summary of Principle Components Analysis .....

10. Supplemental Table 3. Principle Components Analysis - Rotation Scores

11. Supplemental Table 4. Results Spatial Error Models for Edge Zone and Distance to Urban Core

12. Supplemental Table 5. Results Spatial Error Models for Louisville Metro Parks and Distance to Urban Core

13. Supplemental Table 6. Census Tracts and Pre-1950 Housing 


\section{LIST OF ILLUSTRATIONS}

PAGE

1. Illustration 1. Aggravated Assaults in Jefferson County, Kentucky ...... 61

2. Illustration 2. Robberies in Jefferson County, Kentucky ............... 62

3. Illustration 3. Forcible Rape in Jefferson County, Kentucky ............ 63

4. Illustration 4. Homicides in Jefferson County, Kentucky ............... 64

5. Illustration 5. Soil Collection Areas in Jefferson County, Kentucky ..... 65

6. Illustration 6. Edge Zone Topsoil Lead Content by Soil Collection Area 70

7. Illustration 7. Louisville Metro Parks Topsoil Lead Content by Soil Collection Area .....................................................

8. Illustration 8. Topsoil Lead Levels Greater Than $400 \mathrm{mg} / \mathrm{kg}$ by Soil Collection Area ....................................................

9. Illustration 9. Interpolated Mean Topsoil Lead Levels per Soil Collection Area 79

10. Supplemental Illustration 1. Increased Risk of Elevated Pediatric Blood Lead Levels and Pre-1950 Housing

11. Supplemental Illustration 2. Percent Households Living in Poverty per Census Tract in Jefferson County, Kentucky ..........................

12. Supplemental Illustration 3. Percent Young Males 15-24 Years of Age per Census Tract in Jefferson County, Kentucky ......................

13. Supplemental Illustration 4. Percent Female Head of Households per Census Tract in Jefferson County, Kentucky

14. Supplemental Illustration 5. Percent of the Population with a Bachelor's Degree or Higher per Census Tract in Jefferson County, Kentucky ......

15. Supplemental Illustration 6. Median Household Income per Census Tract in Jefferson County, Kentucky 


\section{RATIONALE, OBJECTIVE, SPECIFIC AIMS, and HYPOTHESES}

The Federal Bureau of Investigation defines violent crime as murder, forcible rape, aggravated assault, and robbery (1). In 1960, the U.S. violent crime rate was 160 per 100,000 (2). Between 1960 and 1991, the incidence of violent crime rose steadily, peaking in 1991 with a rate of 758 per 100,000. Following 1991, the incidence of violent crimes unexpectedly began a stable descent. By 2016, the incidence of violent crimes had fallen to 386 per 100,000 , a rate not seen since $1969(1,3)$.

In 2007, environmental economist Jessica Reyes published a paper which found that reductions in childhood lead exposure in the late 1970's predicted violent crime reduction in the 1990's. Reyes noted that the Clean Air Act regulations concerning leaded gasoline were responsible for a 56\% reduction in violent crime in the 1990's (4). Since the 1990's, numerous epidemiological studies have found associations between lead exposure and subsequent criminality (5-9). The growing body of scientific literature implicating remnant environmental lead as a possible causal mechanism for violence has since garnered the title, the lead-crime hypothesis.

The plausible mechanism behind the lead-crime hypothesis is lead's innate neurotoxic effects. Pre-natal and early life lead exposure have been associated with abnormal development of the serotonergic system and the pre-frontal cortex $(10,11)$. These neurological alterations have been associated with violent behavior and/or criminality $(10,12,13)$ 
This dissertation explored the lead-crime hypothesis by comparing topsoil lead content to the incidence of FBI designated violent crime. To evaluate topsoil lead content, 412 topsoil core samples were extracted using the ESS Lock N' Load ${ }^{\mathrm{TM}}$ system. These topsoil samples were one inch deep and weighed approximately 10 grams. All topsoil samples were collected from four pre-determined areas in Jefferson County, KY; the Study Area and three Control Areas. Inductively Coupled Plasma Mass Spectrometry (ICP-MS) analysis was used to determine topsoil lead content. The geospatial distribution of topsoil lead content was then compared to the geospatial distribution of FBI designated violent crime as documented by the Louisville Metro Police Department's (LMPD) Crime Information Center. All FBI designated violent crimes as recorded by LMPD between January 1, 2012 and December 31, 2016 were used to evaluate the geospatial distribution of violent crime in Jefferson County, KY.

The primary objective of this study was to assess whether there is a geospatial association between lead contaminated topsoil and the incidence of violent crime in Jefferson County, KY, using an ecological study design. The subsequent aims of this study were guided by the following research questions:

1. Is there a non-random pattern in the geospatial distribution of violent crime throughout Jefferson County, KY?

2. Is violent crime more prevalent in areas of Jefferson County, KY, where there is evidence of lead contaminated topsoil?

These research questions were assessed by the following specific aims. 
Specific Aim 1: Use Geographic Information Systems (GIS) to examine the geospatial distribution of violent crime throughout Jefferson County, KY

The following actions were carried out to explore this aim:

a) Obtained the addresses for FBI defined violent crimes committed in Jefferson County, KY, from January 1, 2012 - December 31, 2016.

b) Created pin maps to assess the distributions of each violent crime type in Jefferson County, KY.

c) Used Kulldorff's spatial scan statistic to detect significant clusters of violent crime by type.

Hypothesis: There is a non-random pattern in the distribution of violent crime in Jefferson County, KY. Statistically significant clusters of violent crime will be detected and spatially correlated irrespective of crime specificity.

\section{Specific Aim 2:}

Quantify and record topsoil lead concentrations in neighborhoods of Jefferson County, KY with high crime rates and low crime rates.

The following actions were carried out to explore this aim:

a) Collected residential edge zone topsoil from identified high crime and low crime clusters.

b) Collected topsoil from Louisville Metro Parks located in high crime and low crime clusters.

c) Measured the topsoil lead content in $\mathrm{mg} / \mathrm{kg}$, using Inductively Coupled Plasma Mass Spectrometry (ICP-MS). 
d) Recorded findings in a secure database noting the lead concentration value, as well as the latitude and longitude of each topsoil sample.

e) Assessed the relationship between aggregate topsoil lead content and violent crime.

Hypothesis: Aggregate topsoil lead content sampled from high crime cluster areas will contain statistically significant higher lead content compared to the aggregate topsoil lead content sampled from low crime cluster areas.

\section{Specific Aim 3:}

Examine the statistical relationship between the spatial distribution of FBI defined violent crime and topsoil lead concentrations, adjusting for spatial autocorrelation and pertinent census tract level variables associated with poverty and/or criminality in Jefferson County, KY.

\section{The following actions were carried out to explore this aim:}

a) Collected pertinent census tract level data from The U.S. Census Bureau's 2014 American Community Survey 5-year estimates.

b) Established the best fitting Bayesian sparse spatial generalized linear mixed model (SGLMM) that predicts violent crime in Jefferson County, while controlling for topsoil lead content, and adjusting for pertinent census-tract-level variables.

Hypothesis: Topsoil lead content will be independently geospatially associated with violent crime in Jefferson County, KY, after controlling for median household income, percent female head of household, percent of households living in poverty, percent of 
households with dependents under 18-years of age, percent of households receiving food stamps, percent African American, percent of the population with a Bachelor's degree, and percent of the male population aged 15-24 years of age. 


\section{LITERATURE REVIEW}

This review will evaluate the lead-crime hypothesis, which suggests remnant environmental lead exposure is an important risk factor for violent behavior. Although there is mounting evidence that environmental lead exposure may be an important causal mechanism for violence, the lead-crime hypothesis is only one of many plausible explanations for violence. Therefore, the following sections of this literature review provide an overview of the major theories, biological mechanism, and risk factors associated with violence and/or criminality. This review is divided into two major sections. SECTION A - A Historical Review of Crime Theories and Selected Risk Factors will review other sociocultural and scientific inquires related to violence. This section is subdivided by important criminological philosophies, as well as pertinent genetic, neurological, prenatal, and early life risk factors associated with violence. SECTION B The Lead-Crime Hypothesis will review the sociocultural history of lead and its potential role in violence. This section is subdivided by themes relevant to the natural history of lead both as an ecological service and as a ubiquitous public health hazard associated with violence and/or criminality. 


\section{SECTION A - A Historical Review of Crime Theories and Selected Risk Factors}

\section{Defining Violent Crime}

Codifying criminal behavior has been an element of society from the natural laws of antiquity to the penal codes of modern jurisprudence (14). Formal systems of law endorse cultural expectations, which bring order to society in spite of the persistent deviances of its members $(15,16)$. While there is variation between culture-specific legal codes, most cultures regard certain behaviors as universally wrong. In 1954, E. Adamson Hoebel published The Law of Primitive Man, which noted both early and contemporary societies regarded murder, theft, robbery, and incest as criminal acts (17).

In 1964, Sellin and Wolfgang published their seminal work, The Measurement of Delinquency, which categorized crimes by their relative severity (18). Prior to Sellin and Wolfgang, criminologists had failed to establish methods that adequately defined the relative severity of a crime. The establishment of a crime severity index illuminated the relative deviancy of the offender. Sellin and Wolfgang's findings have since been validated throughout the world, which suggests that there are universal mores which guide cultural jurisprudence (19-21).

In January of 1930, the United States Congress authorized the Federal Bureau of Investigation (FBI) to collect, analyze, and report national crime data. In August of 1930, the FBI published its first Uniform Crime Report (UCR), which described domestic crime statistics. The first generation of the UCR categorized crime as either major or minor (22). Today, the FBI's UCR categorizes most crimes as either violent or property. FBI defined violent crime as murder, forcible rape, robbery, and aggravated assault (23). 
Today, criminal offences can be evaluated in either relative or absolute terms.

Federal, state, and local agencies can monitor violent crimes across different geographic and demographic areas. Although our government can define and monitor trends in violent crime, there is still great debate concerning the origins of violent criminal behavior.

\section{Early Theories of Crime - Nature versus Nurture}

Throughout recorded history many theories have been put forth to explain crime. Prevailing theories of crime can be contextualized by the core beliefs of an underlying philosophy. The major philosophies that have inspired present-day theory include the Classical School, Conflict Theory, Biological Positivism, Sociological Theory, Psychological Theory, and Anthropological Theory (24-28). Each of these philosophical views has provided unique insights into the nature of crime, specifically, whether criminogenesis is a matter of free-will, immutable biology, or the product of social, political, and environmental influences. The following subsections will provide historical context to three major periods in criminology, which have continued to influence contemporary crime theory.

\section{2a. The Classical School}

Understanding the roots of crime in modern society was the endeavor of Jeremy Bentham and Cesare Beccaria, two influential 18th century philosophers. Bentham and Beccaria's work on legal reform and criminality took the position that people have free will and are therefore rational agents in their criminal behavior. Bentham suggested that, 
"man is a calculating animal" who naturally considers the potential cost to the potential benefit of a crime. Because of this, Bentham argued that the punishments for crime should match the severity of the infraction. Bentham, a Utilitarian philosopher, believed that severe punishments for relatively minor crimes motivated criminals to take severe measures to avoid being caught, thereby creating more crime $(29,30)$.

Cesare Beccaria, a social-contract philosopher, argued that remediating harsh punishments for minor crimes would improve detection and successful prosecution of the offender. Beccaria posited that swift prosecution, societal shaming, and criminal embarrassment would be an effective deterrent to crime (31). The underpinnings of Bentham and Beccaria's beliefs regarding criminogenesis were the immutable characteristics of free will and rationality. This was a progressive position compared to earlier systems of justice that engaged in severe retribution for what was considered the demonic nature of the criminal. Bentham and Beccaria's work has since garnered the title the Classical School and has become a major early period in the annals of criminology (32).

\section{$\underline{\text { 2b. Biological Positivism }}$}

The advent of the printing press in Europe towards the end of the Middle Ages provided a novel medium to disseminate new ideas. The social and academic environment of the Enlightenment was replete with printed material that often challenged contemporary systems of belief (33). Biological Positivism, a new philosophy that challenged the Classical School's "free will" model offered an opposing view. Biological 
Positivism considered criminogenic behavior the product of inherited or innate psychological and/or biological characteristics (34).

An early challenger to the Classical School was Dr. J.C. Prichard, an English physician in the 19th century. Prichard noted that some individuals, while intellectually intact, were simultaneously depraved and often incapable of controlling their behavior to the standards of civilized society. A diagnosis of "moral insanity", a term coined by Prichard, and the precursor to the modern diagnosis of psychopath, was ascribed to these individuals. The morally insane lacked some degree of free will, and therefore often acted irrationally $(35,36)$. Prichard's morally insane doctrine removed the immutable "free will" that characterized criminal behavior under Classical School dogma (37). In 1871, while performing a routine autopsy, Cesare Lombroso found an atypical indentation in the skull of Giuseppe Villella, an infamous criminal. Lombroso assumed that the indentation was evidence of an underdeveloped cerebellum. From this singular observation, Lombroso hypothesized that criminals had underdeveloped brains, and were therefore evolutionary laggards. Lombroso hypothesized that you could identify criminals by the physical characteristics of their skull. Lombroso called these physical characteristics "atavistic stigmata" $(38,39)$. Although Lombroso's atavistic stigmata was ultimately disproven, he introduced the hypothesis that brain anatomy could be related to criminal behavior. Cesare Lombroso is considered the father of criminology and is remembered as an important protagonist of Biological Positivism $(39,40)$. 


\section{2c. The Chicago School}

In the early part of the 20th century, sociologists Ernest Burgess and Robert Park of the University of Chicago studied the distribution of social groups in the urban environment. Their work concluded that as a city grew, there would be a zone of transition near the urban center that would include a high degree of social breakdown and disorder. Burgess and Park's work would become known as the Chicago School, and would inspire numerous sociological theories of crime $(41,42)$.

In the 1940's, Clifford Shaw and Henry McKay of the Chicago School developed the Social Disorganization Theory, which is considered an important extension of Burgess and Park's original work. Shaw and McKay hypothesized that criminality was not created at the individual level, but rather occurred as a consequence of an individual's abnormal living conditions (43). The Social Disorganization Theory was undoubtedly influenced by two important observations from the Chicago School. First, that crime is often spatially correlated with poverty, and second, crime persists in neighborhoods irrespective of shifting racial and ethnic demographics (44).

The Social Disorganization Theory suggests that interpersonal cohesion and social organization create common social values and goals, which are necessary for a community to remediate unwanted criminal activity. In this model, community members engage in the informal surveillance of their surroundings, and if required, intercede suspicious activity and/or unwanted social behavior. This theory suggests that cohesive neighborhoods which share common goals can produce social norms that perpetually oppose criminality. An important construct of this theory is that the social, political, and 
physical environment can produce a criminogenic niche, irrespective of societal demographics (44).

Theories of crime inspired by the Classical School, Biological Positivism, and the Chicago School have introduced varying positions regarding the nature of criminogenesis. While these three philosophies of crime do not represent the entire corpus of criminology, they highlight two conflicting opinions in the early history of criminological philosophy. The Classical School and Biological Positivism both suggest that crime is a construct of the individual, either by volition or innate defects. In contrast, the Chicago School suggests that crime is a consequence of social, political, and environmental influences $(45,46)$.

\section{Current Approaches to Crime Theory: Risk Factors in a Biosocial Milieu}

While many unique theories of crime have been established, present-day academicians have yet to produce an accepted unified model that integrates the taxonomic architecture of criminological philosophy. Although a unified model has yet to be accepted, a review of the scientific literature supports the notion that criminogenesis is a multifactorial process, which includes biological, social, and environmental risk factors (45). Adriane Raine (2013) has suggested that crime should be viewed on a dimensional probabilistic plane that exists in a biosocial milieu, wherein the innate or inherited characteristics of people interact in their social and physical environments (47).

For this review, risk factors will be classified into subsections that share common themes but not necessarily by their modifiable or non-modifiable nature. It is also worth mentioning that there are far too many risk factors associated with crime to be evaluated 
in this review. Therefore, risk factor selection was based upon relevancy to contemporary crime theory and/or associations pertinent to the lead crime hypothesis.

\section{3a. Genetic Risk Factors - The Serotonergic System}

Genetic studies evaluating the role of genes and behavior have provided insight into the heritability of violent behavior. Polymorphisms of serotonergic genes are known to alter the availability of serotonin in the central nervous system $(48,49)$. Early research into the effects of altered serotonergic processing found associations between serotonin and violent or aggressive behaviors $(50,51)$. These associations were found in both animal and human models (52-54). The two most commonly studied genes with serotonergic implications are the Monoamine Oxidase-A gene (MAOA), and the Serotonin Transporter gene $(5-\mathrm{HTT})(51,52)$.

\section{Monoamine Oxidase -A}

In 1993, Hans Brunner and colleagues published a landmark study, which showed an association between a variant of the MAOA gene, and familial male patterns of violence. Brunner and colleagues, genetically sequenced specimens from an extended family, and found that the violent male members had a genetic mutation of the MAOA gene. This genetic mutation resulted in an absence of MAOA, which is an enzyme primarily responsible for the breakdown of serotonin, a neurotransmitter associated with emotion and stress regulation(55). Disruptions in the serotonergic processing have been associated with reactive aggression, alcoholism, and risk-taking behaviors. For Brunner's study subjects, the absence of MAOA was strongly correlated with low IQ, substance abuse, aggravated assaults, domestic violence, and homicide (56). 
Subsequent mouse studies identified mice with naturally occurring mutations of the MAOA gene, similar to Brunner's MAOA-deficient subjects. Cases and colleagues (1995) showed that mice with absent MAOA had elevated levels of serotonin. The MAOA-deficient mice were found to be excessively aggressive compared to mice without the MAOA gene mutation (53). Scott and colleagues (2008) also showed that MAOA-deficient mice, through artificial knock-out of the MAOA gene, had reduced response times to aggressive behavior, as well as increased combative behavior (57).

The genetic variant of the MAOA gene first identified by Brunner is now believed to be exceedingly rare. However, further investigation of the MAOA gene has identified low activity variants of MAOA-uVNTR, a polymorphism of the MAOA gene. Manuck and colleagues (2000) found that the study participants with low expressing allelic variants of MAOA-uVNTR had significantly higher dispositional aggressiveness and impulsivity compared to participants with higher expressing alleles (58). Kuepper and colleagues (2013) also found that study participants with low expressing variants of MAOA-uVNTR had significantly more reactive aggression as compared to participants with higher expressing alleles of MAOA-VNTR (59). Stetler and colleagues (2014) casecontrol study of subjects in a correctional facility found a robust association between low expressing allelic variants of MAOA-uVNTR and violent prisoners (60).

\section{$\underline{5-\mathrm{HTT}}$}

Variations of the MAOA gene first implicated the serotonergic system as a possible mechanism for violent and aggressive behavior. While the MAOA gene, dubbed the warrior gene, has received considerable attention by the mainstream media, it is not the only gene with serotonergic implications (61). The serotonin transporter gene (5- 
HTT) is responsible for synaptic transport of serotonin, and similar to the MAOA gene, has a naturally occurring polymorphism (5-HTTLPR) with a long and short allelic variant. The short variant is associated with less transcriptional activity and lower serotonin uptake (62).

Hallikainen and colleagues (1999) hypothesized that the short allelic variant of the 5-HTT gene would be more prevalent among violent alcoholics compared to nonviolent alcoholics. Hallikainen's study found a statistically significant association between the short variant of 5-HTT and early onset alcoholism with habitually violent behavior (63). Retz and colleagues (2004) also found an association between the short allelic variant of the 5-HTT gene and violence. Retz's study found a significant association between criminally violent participants who had intentionally harmed another person and the short allelic variant of the 5-HTT gene (64).

The low expressing allelic variant of the 5-HTT gene has also been implicated in aggressive behavior in a pediatric population. Haberstick and colleagues (2006) found a significant association between the low expressing allelic variant of 5-HTT and aggressive behavior in middle childhood (65). Beitchman and colleagues (2006) conducted a matched case-control study to evaluate the association between the low expressing allelic variant of 5-HTT and children aged 5-15 years who had clinically evaluated for extreme aggressive behavior. Beitchman's study found a significant association between low expressing 5-HTT variants and extreme aggression in children (66).

It is important to note that not all MAOA and 5-HTT gene studies have found positive associations between low expressing polymorphisms and aggressive or violent 
behavior (67-70). However, several recent meta-analyses have implicated MAOA and 5HTT with aggressive and violent behavior, albeit with cautious interpretation $(49,71)$.

\section{3b. Central Nervous System - Pre-fontal Cortex}

Neuroscience has yet to produce a complete neural framework that explains human cognition and behavior. Current neuroscientific understanding suggests that the consciousness arises from a complex interactive network of neuronal inputs that includes deep brain structures and the cerebral cortex (72). Throughout the $20^{\text {th }}$ century, criminology and psychiatry has employed numerous neuropsychiatric and neuroimaging techniques to further understand the neurological roots of violence. Recent neuroimaging studies have found associations between the frontal lobe and violent behavior (73-76).

The frontal lobe makes up the front half of the brain and can be anatomically divided into the primary motor cortex, pre-motor cortex, and the pre-frontal cortex. Of particular interest to the lead crime hypothesis is the pre-frontal cortex, which can be further subdivided into the lateral, medial, and orbitofrontal regions $(77,78)$. The prefrontal cortex is believed to process various neuronal inputs which give rise to selfawareness, social perception, and the cognitive control of emotions, impulses, empathy, and moral judgements (78-80).

The simultaneous multimodal properties of the pre-frontal cortex make it difficult to subdivide the scientific literature into distinct classifications of criminogenic risk factors, as there is frequent overlap in findings between structural and functional research. Therefore, this subsection will be dichotomized by theme. The first section, Pre-frontal Cortex and Studies of Violence, will review literature, which has found 
associations between the pre-frontal cortex and violence. The second section, Pre-frontal Cortex and Studies of Violence Inhibition, will review literature that has found associations between the pre-frontal cortex and regulation of emotion, empathy, and moral judgement, each of which has been associated with violent behavior (81-83).

\section{Pre-frontal Cortex and Studies of Violence:}

The story of Phineas Gage is perhaps the first well-known case-study associating brain injury and violent behavior. In 1848, while Gage was working on a railway, an explosion blew a tamping rod through his left cheek and out the frontal aspect of his skull. Remarkably, Gage recovered from this accident. Although Gage survived with his intellect intact, he became violent, vulgar, and irresponsible; personality traits completely foreign to Gage before the accident. John Harlow, a local physician who treated Gage over the course of his recovery, believed that Gage's behavior changes were the result of brain damage to the frontal lobe (84). It would be another century before medical science would develop techniques to explore the relationships between violent behaviors and the anatomy and physiology of the brain.

Volkow and Tancredi (1987) published their seminal study which was the first to use positron emission tomography (PET) to evaluate the brains of violent psychiatric patients with histories of recidivism. Volkow's study participants showed moderate to severe metabolic disruption of the pre-frontal cortex. Volkow noted that patients with severe metabolic disruption of the pre-frontal cortex lacked regret for their violent actions, unlike study participants with less severe metabolic disruption of the pre-frontal cortex (85). Raine and colleagues (1997) showed that PET scans from a group of 41 
murderers had significantly less glucose metabolism in their lateral and medial prefrontal cortex, angular gyrus, and corpus callosum compared to their matched controls. Raine's study also found that murderers had asymmetric activity of the amygdala, thalamus, and hippocampus (86).

The use of PET was a novel approach to evaluating behavior. At the time of Volkow and Tancredi's study, prior neuropsychological studies had already found associations between lesions of the pre-frontal cortex and violent behavior $(87,88)$. The addition of PET provided new objective evidence for similar associations in people with less obvious pre-frontal cortex dysregulation. Although early computed tomography provided better visualization of brain anatomy, PET found physiological differences in neuronal metabolism which extended the utility of nuclear medicine in psychiatry and criminology (89).

Contemporary imaging techniques also employ Single-Photon Emission Computed Tomography (SPECT), and variations of Magnetic Resonance Imaging (MRI). These imaging techniques provide a more robust visualization of the anatomy and physiology of the brain. These modern imaging techniques have revealed structural and functional abnormalities of the frontal lobe and the limbic system, which have been associated with violence and criminality $(89,90)$. Amen and colleagues (1996) compared SPECT scans between 40 violent study participants and 40 non-violent controls. Amen's study, similar to Volkow and Tancredi, showed decreased activity in the pre-frontal cortex of the violent cases, as compared to the non-violent controls (91).

Raine and colleagues (2000) used structural MRI to compare study participants with antisocial personality disorder (APD) to participants without APD. Raine's study 
showed structural differences in the brain anatomy of APD cases compared to non-APD controls. Study participants with APD had an 11 percent reduction in grey matter volume of the pre-frontal cortex compared to the study controls. Additionally, APD cases had committed significantly more violent crimes, with 42.9 percent reporting having raped someone, and 38.1 percent reporting having fired a gun at someone (13).

Raine and colleagues (2000) also evaluated how the study participant's autonomic nervous system (ANS) responded to stress. Prior research had shown positive associations between hypoactive stress responses of the ANS and violence (92). To measure ANS performance, skin conductance testing was employed. Cases in the bottom $50^{\text {th }}$ percentile for pre-frontal grey matter volume were found to have significantly reduced skin conductance during periods of stress compared to cases in the top $50^{\text {th }}$ percentile for pre-frontal grey matter volume (13).

Raine's study was the first to show reduced grey matter volume of the pre-frontal cortex of non-institutionalized study participants with a diagnosis of APD. Additionally, the positive relationship between reduced pre-frontal grey matter volume and reduced skin conductance in APD cases suggests a possible relationship between structural deficiencies of the pre-frontal lobe and poor fear conditioning, a characteristic associated with psychopathic behavior $(13,93)$.

\section{Pre-frontal Cortex and Studies of Violence Inhibition:}

The dysregulation of the cognitive control of emotions has been shown to be an important risk factor for violent behavior $(82,94)$. Research has suggested that the prefrontal cortex regulates emotions through cognitive reappraisal and expressive 
suppression. Cognitive reappraisal is the cognitive transformation of an emotional experience, while expressive suppression is the regulation of behavior from an emotion eliciting event (95). Ochsner and colleagues (2002) first used functional MRI to examine the cortical structures associated with cognitive reappraisal. Ochsner's study found that the lateral and medial pre-frontal cortex are involved in the reappraisal of negative emotional experiences (96). More recently, Vanderhasselt and colleagues (2013) found that cognitive reappraisal, as well as expressive suppression, involved activation of a prefrontal cortex - cingulate network (97).

Empathy is the ability to understand and share emotions of other people (98). Incompetent empathetic responsiveness is another risk factor associated with violence (99). Baez and colleagues (2015) found that atrophy of the orbitofrontal cortex was associated with deficits in empathetic concern related to intentional harm (100). Following Baez's study, Pera-Guardiola and colleagues (2016) found that the ability to correctly identify emotional facial expressions was correlated to the orbitofrontal, inferior frontal, and dorsomedial prefrontal cortices (101). Kral and colleagues (2017) found that the medial pre-frontal cortex was involved with empathetic accuracy (80).

The dysregulation of moral decision making is a well-known risk factor for violence $(102,103)$. Moll and colleagues (2001) published one of the first neuroimaging studies evaluating the neural correlates of moral decision-making. Moll's study showed that the medial orbitofrontal cortex was involved in moral-decision making (78). Following Moll's study, Heekeren and colleagues (2003) found that the left lateral prefrontal cortex and the left posterior temporal lobe were involved in unambiguous moral decision making (83). Cameron and colleagues (2018) found that damage to the 
ventromedial pre-frontal cortex impaired judgement of moral transgressions, which has been associated with dysregulation of impulse control $(12,104)$.

\section{$\underline{\text { 3c. Prenatal Risk Factors }}$}

There are multiple prenatal exposures that harm the developing fetus (105). Of

these exposures, the ill effects related to prenatal alcohol exposure and prenatal exposure to cigarette smoke are well established in the medical literature $(106,107)$. Prenatal alcohol exposure is known to cause alcohol spectrum disorders (108). Prenatal exposure to cigarette smoke has been associated with low birth weight, childhood asthma, Attention Deficient Hyperactivity Disorder, and other neurobehavioral effects (109-113). Although these exposures are well represented in the medical literature, there is growing concern that they may harm fetal brain organogenesis, resulting in permanent structural and functional abnormalities (114-116). Alterations in brain structure and function have previously been associated with criminality and/or behavioral phenotypes associated with criminality $(13,104,117)$.

\section{Prenatal Exposure to Maternal Alcohol Use}

The teratogenic effects of prenatal alcohol exposure (PAE) are well established $(118,119)$. These effects are believed to be caused by the differences between prenatal and postnatal alcohol metabolism. Postnatal metabolism of alcohol relies on two hepatic enzymes, alcohol dehydrogenase (ADH) and aldehyde dehydrogenase. These two enzymes bio-transform alcohol into acetaldehyde and then into acetate for elimination (120). During heavy alcohol consumption, the CYP2E1 enzyme helps the body 
metabolize alcohol into acetaldehyde (121). Prenatal metabolism of alcohol has a different metabolic pathway. Fetal metabolism of alcohol relies on placental CYP2E1, which generates hydroxyethyl or superoxide radicals. These radicals are believed to directly damage fetal brain development (122). There is also evidence that prenatal alcohol exposure may permanently damage the serotonergic system by causing serotonergic neuronal death (123).

Fetal alcohol spectrum disorders (FASD) is an umbrella term used to describe adverse outcomes related to PAE. Donald and colleagues (2015) published a literature review of neuroimaging studies that evaluated the effects of PAE on the brain. Donald's review showed that people with FASD had smaller total brain volumes, in both white and grey matter, as well as altered frontal cortical activity (124).

Fast and colleagues (1999) published the first study that investigated the prevalence of FASD in the juvenile justice system. Fast's study found that 23 percent of youth in the juvenile justice system had a diagnosis of a FASD (125). Streissguth and colleagues (2004) found that 50 percent of study participants with a diagnosis of a FASD had been previously arrested for a crime (126). Streissguth's results showed that children with a diagnosis of a FASD had significantly reduced IQ, which is a well-known risk factor for crime (127). A systematic literature review by Popova and colleagues (2011) found that juveniles with a diagnosis of a FASD were 19 times more likely to be incarcerated than youths without a diagnosis of FASD (128). 


\section{Prenatal Exposure to Maternal Cigarette Smoke}

Prenatal exposure to cigarette smoke can harm fetal brain organogenesis by disrupting the normal transfer of nutrients and oxygen across the placenta (129). Additionally, prenatal exposure to cigarette smoke can introduce numerous neuroteratogens to fetal circulation (107). Nicotine, a constituent of tobacco smoke, crosses the placenta and fetal blood brain barrier (130). Research has suggested that prenatal exposure to nicotine permanently alters the sensitization to serotonin by damaging presynaptic and postsynaptic bodies necessary for neurotransmission (131).

Cigarette smoke also contains numerous neurotoxic heavy metals which can enter fetal circulation (132-134). Prenatal exposure to mercury, cadmium and lead from maternal cigarette smoke has been associated with low birthweight, reduced head circumference and abnormal cognitive development (134). Additionally, prenatal exposure to lead from maternal cigarette use has been associated with anti-social behavior (135).

Toro and colleagues (2008) found that prenatal exposure to maternal cigarette smoke (PEMCS) was associated with anatomically thinner orbitofrontal, middle frontal, and parahippocampal cortices, as compared to children without PEMCS (114). Of particular interest to risk factors associated with violence is the attenuation of the orbitofrontal cortex, which is thought to be a neural substrate of empathy and moral judgment (136).

Weitzman and Gortmaker (1992) conducted one of the first studies which evaluated the effects of PEMCS and behavioral problems in children. Their findings showed that behavioral problems in children, including issues with conduct, were 
associated with PEMCS (137). These findings were subsequently supported by Fergusson and colleagues (1993), who found that children with PEMCS were more likely to have conduct issues compared to children without PMECS (138). Wakschlag and colleagues (1997) found that children with PEMCS that exceeded a half pack-per-day had significantly more diagnoses of conduct disorder compared to children without PEMCS (139). Conduct disorder in children has been associated with later life diagnoses of antisocial personality disorder, which is a well-established risk factor for violence $(140,141)$. Brennan and colleagues (1999) found a dose-response between PEMCS and adult recidivism for violent and non-violent crimes (142). A meta-analysis by Pratt and colleagues (2006) found a significant association between PMECS and criminal behavior in children (143). A review of the literature by Zhou and colleagues (2014) concluded that PEMCS and post-natal secondhand smoke were associated with conduct disorder in children (144).

\section{$\underline{\text { 3d. Early Life Risk Factors }}$}

The Social Determinants of Health is a partitioned framework that identifies similar risk factors for adverse health outcomes. Categories of risk factors typically include: economic stability, the physical environment, education, food, social support, and healthcare (145). Current research has begun to evaluate how deprivation within the social determinants' milieu can produce or promote violent behavior. Classifying the scientific literature into distinct subcategories is challenging, as there is considerable overlap between social determinant risk factors and violence. Therefore, this section is subdivided by Early Life Stress and Intelligence. 


\section{Early Life Stress}

Early life stress from the biosocial environment can have deleterious effects on childhood development. Although stress can be a nebulous construct, its effects can have measurable physiological and behavioral consequences $(146,147)$. Côté and colleagues (2006) published findings from their evaluation of the Canadian National Longitudinal Survey of Children and Youth (NLSCY). Côté's study found that later life physical aggression was significantly associated with early life poverty and hostile or ineffective parenting strategies (148). Rylands and colleagues (2012) found that childhood abuse and neglect was correlated to abnormal development of the serotonergic system, which has been previously associated with impulsive and aggressive behavior (48). Wallinius and colleagues (2016) found that early life exposure to inter-parental violence and parental substance abuse were associated with both aggressive antisocial behaviors and criminality (149). Afifi and colleagues (2017) found that children exposed to harsh physical punishment or maltreatment were more likely to be involved in intimate partner violence, either as the perpetrator or the victim (150).

\section{Intelligence}

Alfred Binet and Theodore Simon produced the first modern intelligence test in 1904 (151). Since the introduction of intellectual ability as a psychometric measure, numerous models of intelligence (IQ) have emerged (152). Although there are conflicting models for intelligence, IQ has proven to be an important index of normal neurocognitive development, academic success, socioeconomic position, and criminality $(127,153,154)$. 
In 1977, Hirschi and Hindelang published their seminal paper regarding IQ and delinquency. In the decades prior to Hirschi and Hindelang's paper, the contemporary opinion was that IQ was independent of criminality, and that any perceived association was spurious, given unmeasured confounders. Hirschi and Hindelang found that IQ was associated with delinquent behavior after controlling for important confounders, primarily socioeconomic position (155).

Wilson and Herrnstein (1985) published Crime and Human Nature, which claimed that criminals on average have an IQ that is 10 points lower than non-criminals. Wilson and Herrnstein also reported that low IQ criminals committed more serious forms of crime, relative to normal or high IQ criminals (156). Koolhof and colleagues (2007) also found that low IQ criminals had committed significantly more serious crimes compared to high IQ criminals. Additionally, Koolhof found that low IQ criminals had significantly less impulse inhibition compared to high IQ criminals, which may explain differences seen between IQ groups and the seriousness of the offense (157).

Satterfield and colleagues (2007) published the results of their 30-year prospective follow-up on boys with conduct problems. Satterfield's study found that IQ was inversely related to adult criminality. This inverse relationship was found among all socioeconomic classes, including the highest socioeconomic class. Satterfield's findings underscore the significance of intelligence as a plausible etiological mechanism for criminality regardless of socioeconomic position (158).

Ttofi and colleagues (2016) published a meta-analysis of prospective longitudinal studies which evaluated the protective effect of intelligence on criminal offending. Ttofi's study found that high IQ was protective against criminality even among high at-risk 
populations. Ttofi and colleagues suggested that the scholastic aptitudes enable better resiliency towards adversity, which may explain why high IQ has a protective effect against criminal offending (127).

\section{$\underline{\text { SECTION B - The Lead-Crime Hypothesis }}$}

Several hypotheses have been put forth to explain the temporal variation of violent crimes since 1960. These hypotheses include gun ownership, the legalization of abortion, the War on Drugs, fluctuation in age demographics, and increasing rates of criminal imprisonment (159). Recently, a new hypothesis has suggested that environmental lead exposure might be a cause of criminal behavior. This lead crime hypothesis suggests that the downward trend in violent crimes in the United States in the mid-1990's is partially explained by the phasing out of domestic leaded gasoline between 1985 and $1995(160,161)$.

\section{Lead - A Historical Review from Ancient Egypt to Contemporary Scientific Inquiry}

Lead is a naturally occurring heavy metal most often found in different ores.

Leaded ores have been refined to produce useful lead compounds since at least $4000 \mathrm{BCE}$ (162). From ancient Egypt to the technologies of modernity, lead has been a useful ecological good. However, as history has shown, the industrial production and indiscriminate use of lead can have dire public health consequences (161).

The earliest surviving document linking lead exposure to illness dates back to $2^{\text {nd }}$ century BCE, when Greek physician Nikander of Colophon documented the ill effects of lead ingestion in his Alexipharmaca (163). The first well-documented description of 
harmful lead ingestion was colica Pictonum, a severe abdominal pain, sometimes followed by paralysis and death. Colica Pictonum was periodically epidemic from ancient Rome until $17^{\text {th }}$ century Europe. In 1696, Eberhard Gockel discovered that colica Pictonum was associated with wine preparation, which following Roman tradition, used lead vessels to produce sapa, an artificial sweetener adulterated with lead. Gockel's discovery showed that lead exposure could be incidental and affect the general population, beyond the occupational milieu (164).

In 1839, French physician Tanqueral des Planches conducted one of the first occupational health studies, which documented adverse neuropsychiatric outcomes associated with lead exposure (165). Tanqueral des Planches called the lead associated encephalopathy encéphalopathie saturnine, a homage to the Roman god Saturn, who was known as a violent ghoulish deity $(166,167)$. These early reports provide important historical context for occupational and incidental lead exposure in the adult population. Evidence of lead poisoning in a pediatric population would not come until the 20th century.

J. Lockhart Gibson (1904) published the first report on lead poisoning in a pediatric population. This seminal report described an epidemic of pediatric lead poisoning in Brisbane, Australia. Gibson correctly hypothesized that his lead poisoned patients were being exposed to lead-based paint found in and around their respective homes (168). The first report of pediatric lead poisoning in the United States was authored by Kenneth Blackfan (1917), who published a case-series study of children treated for lead poisoning. Blackfan, aware of Gibson's report, called for prophylactic 
measures to prevent children from accidentally or purposefully consuming lead-based paint (169).

Around the turn of the $20^{\text {th }}$ century, most of the known adverse health outcomes associated with lead poisoning occurred in the occupational setting (161, 170). Classic signs of adult occupational lead poisoning included peripheral neuropathy, paralysis in the wrist or foot, weakness, confusion, colic, and reproductive issues for both men and women $(161,171)$. The dangers associated with occupational lead poisoning were understood and accepted by most plant workers and plant operators. As historian David Montgomery pointed out, industrial America accepted a "culture of plumbism" built on denial, fatalism, and individual responsibility (172). This "culture of plumbism" which embodied the philosophy of $19^{\text {th }}$ century industry, helped embolden early American industrial hygienists, who would in the $20^{\text {th }}$ century bring about sweeping public health reforms (173). While these reforms lead to stringent environmental regulations, they could not assuage the ill effects from the millions of tons of lead already released into the environment (163).

Contemporary lead poisoning research categorizes exposures as acute or chronic, high dose or low dose, and by exposure type, occupational, environmental, or pediatric $(174,175)$. Additionally, the advent of serum lead testing illuminated for the first-time dose-response relationships between severity of lead exposure and adverse health outcomes $(161,176)$. The nuanced approach to exposure classification, as well as the dose-response paradigm, has been instrumental for deconstructing lead's toxic effects. 


\section{Current Standards}

Lead does not naturally occur in the human body. Therefore, there is no physiological level of lead. Research on skeletal lead content has suggested that contemporary people contain up to 500 times more bone lead content compared to ancient populations. This suggests that anthropogenic lead use has amplified the bioavailability of lead in the environment (177).

\section{5a. Soil Lead Standards}

Lead naturally exists in most soils at very low levels. The U.S. Geological Survey has estimated that the median background soil lead content in the United States is 16 milligrams per kilogram (mg/kg) (178). However, the release of lead from lead-based products has contaminated some residential soils many times beyond normal background levels. In 2001, the Environmental Protection Agency (EPA) issued its Final Rule, which established two hazard standards for residential soil lead content. In its Final Rule, the EPA set the hazardous lead content for bare soil in play areas at $400 \mathrm{mg} / \mathrm{kg}$ or higher; the hazardous level for non-play areas was set at 1,200 mg/kg or higher (179).

\section{$\underline{\text { 5b. Blood Lead Standards }}$}

In the 1960's, pediatricians considered blood lead levels toxic if they were $\geq 60$ micrograms per deciliter (mcg/dL). In 1975, the CDC defined elevated blood lead levels as $\geq 30 \mathrm{mcg} / \mathrm{dL}$. Ten years later, in 1985 , the CDC reduced this threshold to $\geq 25$

$\mathrm{mcg} / \mathrm{dL}$. In 1991, the CDC lowered the reference level to $\geq 10 \mathrm{mcg} / \mathrm{dL}$. In 2012, the CDC lowered the reference level to its current threshold of $\geq 5 \mathrm{mcg} / \mathrm{dL}$ (180). Although the 
CDC has set a threshold for what constitutes an elevated blood lead level, contemporary theory suggests that there is no safe blood lead level (181). Additionally, some research has suggested that blood lead levels as low as $2 \mathrm{mcg} / \mathrm{dL}$ can result in measurable adverse effects on cognitive performance (182).

\section{Lead - Environmental Exposures}

The mass production of lead-based paint and the introduction of tetraethyllead in the early $20^{\text {th }}$ century were a boon for the domestic industrial lead economy (161). However, the mass production of lead-based products carried with them dire economic externalities which have been associated with numerous adverse health outcomes (183). This section will focus on the history of lead use in the United States throughout the $20^{\text {th }}$ century; specifically, on a review of lead-based paint and leaded gasoline, the two most common sources of remnant lead in the environment (183).

\section{6a. Lead-Based Paint}

The addition of lead in paint served many purposes. Different lead ores provided different lead pigments. Lead chromate, lead oxide, and lead carbonate were used to produce yellow, red, and white lead-based pigments (184). These pigments when added to oil substrates produced vibrant, durable, and water-resistant paints (161). The Renaissance that swept across Europe ushered in a new era for lead-based paints. Michelangelo, Caravaggio, Van Gogh, and many others incorporated white lead and yellow lead into their works. The durability of leaded-paint was also a favorite in the 
maritime industries (185). When Europeans colonized North America, they brought with them a desire for lead-based paints (161).

The first large scale production of white lead-based paint in the United States began in 1809, when Samuel Wetherill \& Sons began extracting white lead from lead carbonate. The Louisiana Purchase in 1803 helped bolster lead paint production through the acquisition of lead mines. In the decades that followed, numerous high-grade lead ores were found throughout present-day Arkansas, Iowa, Colorado, and Kansas (186). The influx of lead ore increased domestic lead paint production and lowered prices. By the 1920's, white lead paint accounted for 30-40 percent of domestic lead use. Between 1910 and 1977, approximately 400,000 tons of lead paint were applied to homes in the United States (161).

Although the domestic use of lead paint was officially banned in 1978, remnant lead from its use remains a pervasive environmental hazard (187). After lead sinks into the soil, it is expected to stay there for hundreds of years due to its immobility (188). The Environmental Protection Agency (EPA) (1998) published a Final Report on the sources of lead in the soil. The EPA's Final Report concluded that deteriorating lead-based paint from exterior surfaces, industrial point source pollution, and remnant lead from the leaded-gas era were the primary sources for lead contaminated soil (189).

Bernard and McGeehin (2003) published their findings on elevated blood lead levels from the Third National Health and Nutrition Examination Survey (NHANES III), 1988-1994. Bernard and McGeehin found that 42.5 percent of children living in pre-1946 housing, and 38.9 percent of children living in housing built between 1946 and 1973, had blood lead levels exceeding $5 \mathrm{mcg} / \mathrm{dL}$ (190). Following Bernard and McGeehin's study, 
Jones and colleagues (2009) published their findings from annual NHANES survey data, collected between 1999 and 2004. Jones and colleagues found that pre-1950 housing and housing built between 1950 and 1977, were significantly associated with blood lead levels greater than $10 \mathrm{mcg} / \mathrm{dL}(191)$.

\section{$\underline{\text { 6b. Leaded Gasoline }}$}

Automobiles in the first two decades of the $20^{\text {th }}$ century suffered from engine knock, a phenomenon where cylinder combustion occurs outside the normal temporal envelope for proper piston stroke timing. Premature combustion within the cylinder caused a shockwave which knocked the engine, hence the term engine knock. Early engineers recognized that controlling combustion timing required the addition of an oxygenate, which would delay ignition before proper cylinder compression. In 1921, Thomas Midgley Jr, an engineer at General Motors, discovered that the addition of tetraethyllead to gasoline was an adequate octane booster which eliminated engine knock (192).

The introduction of tetraethyllead in the United States was a windfall for domestic lead production (161). The first filling station in the United States began using leaded gasoline in 1923. By 1929, demand from the automotive industry had doubled domestic production of lead (161). A total ban of leaded gasoline did not take place until 1995, when amendments to the Clean Air Act of 1990 took effect (193). The lead gas era lasted for approximately 70 years, during which time American consumers burned hundreds of millions of tons of leaded gas, which released an estimated 7 million tons of lead into the atmosphere (194). 
Lead from automobile exhaust has been found in arctic ice fields, surface ocean water, and most prominently along properties adjacent to roadways in urban environments $(161,195,196)$. Urban soil lead content has a well-established doseresponse related to roadside proximity. Average soil lead content is the highest within 10 meters of the roadside, and decays exponentially every 10 meters thereafter. Additionally, the concentration of lead in roadside soils is proportionally related to traffic volume during the lead gas era (197).

Mielke and Reagan (1998) published a literature review which compared sources of environmental lead exposure, specifically leaded-paint and lead contaminated soils. Mielke and Reagan's review noted that lead contaminated soil has more bioavailable lead than leaded paint chips. It was also noted that leaded house dust, a known pathway for lead exposure, had a dose-response associated with traffic density. This association between level of leaded house dust and traffic density is believed to be due to the leaded exhaust-soil-dust pathway, wherein leaded-soils contaminated from leaded automobile exhaust get tracked into the house, where it becomes a primary constituent of house dust $(195,198)$

Mielke and colleagues (2007) published a five-year review of median blood lead levels from children living in New Orleans, Louisiana. Study results found a significant curvilinear relationship between soil lead concentrations and median blood lead levels. The predicted median blood lead level for soil lead concentrations of $400 \mathrm{mg} / \mathrm{kg}$, is 5.5 $\mathrm{mcg} / \mathrm{dL}$. Soil lead concentrations of $1,200 \mathrm{mg} / \mathrm{kg}$ predict a blood lead level of $8 \mathrm{mcg} / \mathrm{dL}$. Mielke and colleagues concluded that 92.8 percent of children living in New Orleans have elevated blood lead levels $\geq 2 \mathrm{mcg} / \mathrm{dL}$ (199). If health effects research continues to 
find blood lead exposures of $\leq 5 \mathrm{mcg} / \mathrm{dL}$ then the amount of lead accumulated in cities such as New Orleans support the prediction by the late Claire Patterson (1980), that millions of tons of lead have virtually made older U.S. cities uninhabitable (200).

\section{Lead - Lead-Induced Neurotoxicity}

Lead is a persistent environmental toxicant, which can theoretically affect every organ system through direct or indirect pathways. Although lead is a systemic toxicant, its neurotoxic effects on the developing brain are of primary concern. Lead-induced neurotoxicity involves numerous complex mechanisms, most notably, the calcium mediated signaling pathways $(10,11)$. This section will review the basic pathophysiological mechanisms of lead-induced neurotoxicity, as well as review epidemiological literature detailing the consequences of early-life lead exposure.

\section{7a. Neurotoxic Pathophysiology}

The movement of calcium ions across cellular calcium channels is a normal physiological process. However, dysregulation of calcium kinetics can cause cell death from excessive intracellular calcium. Lead, which mimics calcium, can invade the intracellular space and damage mitochondria. Normally, mitochondria regulate intracellular calcium. However, lead-induced mitochondrial damage can cause dysregulation of calcium kinetics, leading to a state of neuronal excitotoxicity which can damage or kill neurons. Lead-induced dysregulation of calcium kinetics also causes the intracellular production of reactive oxygen species (ROS). Neurons, by their nature, have 
a reduced capacity for detoxifying ROS. Oxidative stress from ROS can cause cellular apoptosis via a protein-gene pathway $(10,201)$.

\section{7b. Epidemiological Studies Evaluating Volumetric Effects Associated with Lead}

\section{$\underline{\text { Exposure }}$}

Review of the medical literature suggests that lead exposure may be responsible for CNS dysfunction and related neuropsychiatric effects, which have been associated with violence $(202,203)$. Prenatal and pediatric lead exposure may disrupt brain organogenesis. The medical literature suggests that there is an association with early-life lead exposure and atrophy of the pre-frontal cortex, which has been associated with conduct disorder, impulse inhibition, cognitive reappraisal, empathetic concern, moral decision making, and intelligence; all risk factors for violence (204). Brain atrophy and reduced cognitive functioning have also been associated with occupational lead exposure (205).

Cecil and colleagues (2008) examined the relationship between early-life blood lead levels and adult brain volume in 157 participants from the Cincinnati Lead Study. Volumetric whole brain analysis from MRI data found a significant association between early-life lead exposure and reduced brain volume in the anterior cingulate cortex and the ventrolateral prefrontal cortex (202). The anterior cingulate cortex has been associated with processing cognitive and emotional information, behavior modification, assessing for potential conflicts, and decision-making based upon reward seeking $(206,207)$. The ventrolateral prefrontal cortex has been associated with the cognitive control of emotions and subsequent mood regulation (208). 
Brubaker and colleagues (2009) also analyzed study participants from the Cincinnati Lead Study. This study used Diffused Tensor Imaging to evaluate whether childhood lead exposure was associated with later life alterations in white matter microstructures, specifically axonal myelination and integrity. Brubaker's study found a significant dose-response between childhood lead levels and white matter organization and myelination. These lead-associated alterations in white matter were found throughout the frontal, temporal, parietal, and occipital lobes, even after controlling for prenatal maternal alcohol use, prenatal tobacco use, and maternal IQ (209).

Following their 2009 study, Brubaker and colleagues (2010) again analyzed study participants from the Cincinnati Lead Study. The purpose of this study was to evaluate whether later childhood blood lead levels were a better predictor of neuroanatomical changes compared to average or maximum blood lead levels seen in early childhood. Brubaker's results showed elevated blood lead levels collected at five and six years of life were stronger predictors for brain volume loss compared to maximum elevated blood lead levels taken earlier in life. These results remained significant after controlling for pertinent confounders. This study also found that grey matter volume loss was most pronounced in the frontal lobes. These findings suggest that while maximum elevated blood lead levels usually seen during peak hand-to-mouth activity are significantly associated with reduced brain volume, ongoing low-level lead exposure identified between ages five and six have a greater effect on total brain volume loss (204). This association may be explained by the timing of synaptogenic overproduction in the frontal lobe, which is not completed until the third or fourth year of life $(210,211)$. 
Not all lead-associated volumetric brain studies have been based on pediatric blood lead levels as a metric of exposure. Stewart and colleagues (2006) evaluated 532 former employees at a chemical plant, which produced tetraethyllead. Stewart's study found that there was a significant association with the amount of tibial lead, a metric for prior lead exposure, and reductions in total brain volume, including the frontal lobe. Stewart's findings showed that occupational lead exposure is associated with cognitive decline, and that a dose-response exists between lead exposure and total brain volume (205).

\section{7c. Pediatric Vulnerability in Lead Contaminated Environments}

There is an old axiom in pediatric medicine that children are not little adults (212). This axiom emphasizes important physiological and behavioral differences between pediatric and adult populations. While children and adults are both vulnerable to the adverse effects of a lead contaminated environment, children are especially vulnerable given their greater propensity for incidental lead exposure and gastrointestinal absorption (213).

Children have higher respiration rates compared to adults (212). Because of this children breath in more volume of air per pound (214). This difference in respiration can increase exposure to aerosolized lead. Additionally, young children are typically shorter than adults which puts them closer to the ground, thereby increasing their exposure to aerosolized lead contaminated dust or soil (215).

Children also ingest more lead than adults. Normal neurocognitive development relies on hand-to-mouth activities during the first few years of life. Because of this, 
children have incidental lead ingestion from remnant lead found in house dust and/or residential soils (216). Children also exhibit more pica than adults. It is estimated that 50 percent of children aged 18-36 months engage in pica-like behavior. By 12 years of life the incidence of pica-like behavior is approximately 10 percent (217). Pica behavior is a well-established risk factor for lead intoxication in children (195). Conversely, lead intoxication in adults due to pica behaviors is exceedingly rare, and is considered a psychiatric condition (218).

The adverse effects of lead ingestion are heavily influenced by gastrointestinal absorption. It is estimated that children absorb 5 times more lead than adults after ingestion (219). Additionally, lead absorption rates are influenced by dietary deficiencies of ascorbate, calcium and iron; deficiencies that are also associated with poverty related food insecurity $(175,220,221)$.

Special consideration for the pediatric population should be made when evaluating public health hazards associated with remnant environmental lead. The pediatric population has a greater propensity for incidental environmental lead ingestion and absorption compared to the adult population (214). Early life lead absorption can cause permanent brain damage, diminished IQ, and other deficiencies associated with normal neurocognitive development (11).

\section{The Lead Crime Hypothesis: Epidemiological Studies Evaluating the Potential Lead-Crime Association}

Lead associated damage to the serotonergic system, as well as the pre-frontal cortex has been associated with criminality and/or violent behavioral phenotypes (10, 
11). These neurotoxic effects provide a credible biological mechanism that underpins the lead crime hypothesis. This section will review the epidemiological literature that has evaluated the association between lead exposure and criminality. Additionally, this section will demonstrate important gaps in the biomedical literature that are fundamental to the thesis of this research project.

\section{8a. Epidemiological Studies Evaluating the Association between Lead and Crime}

The first study published regarding lead and violent behavior was Byers and Lord's (1943) seminal case-series, which noted 95\% of children previously hospitalized for lead poisoning subsequently developed persistent cruel and impulsive behavior. Byers and Lord were the first to document that the saturnine effects of childhood lead exposure could persist $(171,222)$. Prior to Byers and Lord's publication, it was widely believed that acute lead poisoning resulted in death or recovery without sequela $(171,223)$.

Pihl and Ervin (1990) published a case-control study, which evaluated hair-lead levels from an incarcerated study population. Cases were defined as having a history of a violent offense. Controls were defined as non-violent offenders. Analysis of variance found that violent offenders had more than a two-fold increase in hair-lead levels compared to the non-violent controls $\left(F_{1,48}=28.83, p<0.0001\right)(9)$.

Needleman and colleagues (1996) conducted a retrospective cohort study that compared early life lead exposure to Child Behavioral Checklist scores (CBCL), a measure of behavioral or emotional problems. Needleman's study enrolled participants who were already taking part in the Pittsburgh Youth Study, a prospective study aimed at evaluating life-course delinquency. Needleman's study found that children in the top $50^{\text {th }}$ 
percentile of bone-lead levels had a two-fold increase in the odds of being classified as aggressive compared to participants in the bottom $50^{\text {th }}$ percentile (Odds Ratio: $2.18,95 \%$ CI: 1.03-4.6). Analysis of covariance showed that study participants in the top $50^{\text {th }}$ percentile for bone-lead levels had clinically significant issues with attention, aggression, and delinquency, as evidenced by CBCL stratum scores, compared to study participants in the top $50^{\text {th }}$ percentile. Model covariates included: maternal IQ, maternal scholastic achievement, SES, race, age of study participant, and Family Function, an index that includes presence or absence of both parents, mother's age at participant's birth, and number of children in the home (5).

Stretesky and Lynch (2001) published an ecological study that compared estimated county-level air lead concentrations in the United States to the incidence of county-level homicide. Negative binomial models adjusted for nine other environmental pollutants, as well as six sociological variables associated with homicide. Of the ten environmental pollutants included in the model, only lead was found to be statistically associated with county level homicide, after controlling for pertinent sociological variables (Incidence Rate Ratio: 4.11; 95\% CI: 1.02-16.61) (6).

In 1979 the Dietrich and colleagues began enrolling mother-infant pairs into the Cincinnati Lead Study, an ongoing longitudinal study designed to evaluate the effects of prenatal and postnatal lead exposure on growth and neurodevelopment. To date, more than 300 mother-infant pairs have been enrolled in the Cincinnati Lead Study. Dietrich and colleagues' (2001), was the first published prospective cohort study that evaluated the Lead Crime hypothesis using data from the Cincinnati Lead Study. Multiple linear regression was used to predict delinquent acts by prenatal or post-natal lead exposure, 
after controlling for birth weight, SES, HOME score, and parental IQ. Model results found that prenatal and postnatal lead exposure predicted delinquent behavior $(\beta=0.192$, $\left.R^{2}=0.049, p<0.002 ; \beta=0.193, R^{2}=0.055, p<0.002\right)$. Analysis of covariance showed that children classified with the highest levels of prenatal or post-natal lead exposure had committed 2.3 - 4.5 more delinquent acts over the preceding 12-months, compared to subjects in the lowest category, after controlling for birth weight, SES, HOME score, and parental IQ $(p \leq 0.02 ; p \leq 0.0007)(224)$.

Wright and colleagues (2008), using data from the Cincinnati Lead Study, were the first to find a dose-response relationship between early life lead exposure and adult criminality. Negative binomial regression was used to predict adult criminality associated with prior childhood blood lead levels, after controlling for maternal IQ, sex, SES, and maternal education. Model results found that for every $5 \mathrm{mcg} / \mathrm{dL}$ increase in early-life blood lead levels, there was a 30 percent increased risk for being arrested for a violent crime as an adult (Rate Ratio 1.30; 95\% CI: 1.03, 1.64). Additionally, it was found that for every $5 \mathrm{mcg} / \mathrm{dL}$ increase in blood lead levels taken at 6 years of age, there was a 48 percent increased risk for being arrested for a violent crime as an adult (Rate Ratio 1.48; 95\% CI: $1.15,1.89)(203)$.

Needleman and colleagues (2002) published a case-control study that compared early life lead exposure to youth who had been criminally convicted, in Allegheny County, PA. Cases were defined as having been arrested and adjudicated through the Juvenile Justice System. Controls were non-delinquent high school students. Logistic regression controlled for race, parental education, parental occupation, number of parents in home, number of siblings in home, and neighborhood crime rate. After removing non- 
influential covariates, it was shown that criminally convicted youths had a 4-fold increase in the odds of having elevated bone-lead levels (OR: 4.0; 95\% CI: 1.4, 11.1).

Needleman's study also showed that criminally convicted youth had mean bone lead levels seven times higher compared to non-criminally convicted youths $(11.0 \pm 32.7 \mathrm{vs}$. $1.5 \pm 32.1 \mathrm{ppm}, p=0.007)(225)$.

Nevin (2007) published a cross-sectional study which compared childhood lead exposure from leaded-gasoline to temporal trends in international crime rates. Nevin's study showed that there was an approximate 18-23 year lag between the removal of leaded gasoline and a significant reduction in violent crime. For example, a reduction in pre-school lead levels in the United States, United Kingdom, Canada, Australia, New Zealand, and West Germany statistically correlated to a reduction in murder rates 18 years later $\left(\mathrm{R}^{2}=0.137, p<0.0001\right)(226)$.

Braun and colleagues (2008) published a case-control study, using data from NHANES, which compared childhood lead levels to symptoms consistent with a diagnosis of conduct disorder. Logistic regression controlled for study subject's age, maternal age at birth, maternal cotinine levels, poverty-to-income ratio, subject sex, subject race, and prenatal exposure to cigarette smoke. Blood lead levels were categorized by quintiles. Model results showed that study subjects with symptoms consistent with conduct disorder had increased odds of having early life elevated blood lead levels, compared to study subjects without symptoms of conduct disorder (Odds Ratio: 8.64; 95\% CI: 1.87, 40.04) (226).

Mielke and Zahran (2012) published an ecological study which compared average city lead air emissions to latent aggravated assault rates in six major US cities. Least 
squares dummy variable regression was used to predict aggravated assault rates by average air lead emissions measured in metric tons. Statistical models controlled for income per capita and percent of the population between 15 and 24 years of age. Model results found that for every metric ton of lead released into the air, twenty-two years later there was a $0.46 \%$ increase in aggravated assaults. Additionally, the model explained $90 \%$ of the variation in the temporal trend of aggravated assaults over a twenty-two-year period $\left(\beta=0.458, \mathrm{R}^{2}=0.903, p<0.001\right)(7)$.

Boutwell and colleagues (2016) published an ecological study which compared the geographic distribution of blood lead levels per census tract to FBI designated violent crime. Poisson regression was used to predict violent crime by percentage of elevated blood lead levels per census tract. The model adjusted for a novel deprivation index, which included pertinent measures of SES disadvantage. The final model found that census tracts with the highest proportion of blood lead levels greater than $5 \mathrm{mcg} / \mathrm{dL}$, had an increased incidence of violent crime compared to census tracts with lower proportions of elevated blood lead levels (Risk Ratio: 6.57; 95\% CI: 2.89,17.18) (227).

\section{8b. Gaps in the Research Exposure Assessment}

Evidence from the biomedical literature suggests lead exposure may have a causal relationship to violence. Lead is a persistent environmental neurotoxicant, that can damage or destroy neurons through a variety of complex genetic and cellular pathways $(10,201)$. Prenatal lead exposure may also damage fetal development of the serotonergic system, which has been associated with violent behavior $(10,228)$. Nuclear imaging studies have illustrated relationships between pediatric and occupational lead exposure, 
and reductions in brain volume, especially the prefrontal cortex $(202,204,205)$. Nuclear imaging studies have also associated abnormalities of the prefrontal cortex to numerous psychiatric and cognitive effects as well as criminal activity $(12,13,203)$.

Since the 1990's there have been numerous epidemiological studies exploring early life lead exposure and subsequent criminality. However, as of this date, none of these studies have evaluated whether neighborhood trends in violent crimes are geospatially correlated to soil lead content, a major risk factor for pediatric lead exposure $(195,199)$. Additionally, there has been limited use of the Kulldorff spatial scan statistic a validated method for cluster analysis, to detect neighborhoods with increased risk for violent crimes (229-231). Given the innate neurotoxic effects of lead and its association to crime, it may be of interest to determine if neighborhoods with identified clusters of violent crime also have disproportionate levels of lead in the soil. 


\section{METHODS}

\section{Background Investigation}

A preliminary investigation into the geospatial distribution of elevated blood lead levels in children aged 0 to 17 years was conducted prior to the assessment of topsoil lead content. Approval for this preliminary investigation was received from the University of Louisville's Institutional Review Board; IRB \#: 17.1133. Following IRB approval, a blood lead dataset was received from the Louisville Metro Department of Health and Wellness. The blood lead dataset $(n=26,027)$ covered the years 2007 through 2016, and contained street address and zip code, date of blood draw, and blood lead level reported as $\mathrm{mcg} / \mathrm{dL}$.

This background investigation hypothesized that there would be a clustering of elevated blood lead levels geospatially correlated to Jefferson County census tracts $(n=191)$ that have a high proportion of pre-1950 housing. A pin map was created using Esri ArcGIS v.10.4. Shapefiles of Jefferson County, KY were downloaded from the U.S. Census Bureau's Topographically Integrated Geographic Encoding and Referencing Line database (TIGER/Line). Pre-1950 housing data was downloaded from the U.S. Census Bureau's American Community Survey. Pre-1950 housing data was classified by quantiles for choropleth mapping. Cluster analysis of elevated blood lead levels was assessed by the Kulldorff spatial scan statistic, a Poisson-based space-time scan statistic employed by SaTScan v.9.1.1 
Data procured from the Louisville Metro Department of Health and Wellness between the years 2007 and 2016 included 26,027 blood lead levels from children residing in Jefferson County. Of these 26,027 data points, 2,244 (8.62\%) exceeded the current CDC standard for acceptable blood lead levels which is $5 \mathrm{mcg} / \mathrm{dL}$ (Table 1 Appendix A).

While the majority of serum lead testing were below the current CDC guidelines, a non-uniform distribution of elevated pediatric blood lead levels was found in Jefferson County. An area of increased risk in the northwestern census tracts of Jefferson County was identified by the Kulldorff spatial scan statistic (Relative Risk: 8.55). This area of increased risk appears to be spatially correlated to percent pre-1950 housing per census tract. The pin map used for analysis via the Kulldorff spatial scan statistic is not included in the appendix given the map is based on specific geographic locations; only those areas of increased risk identified by the Kulldorff spatial scan statistic are portrayed on a choropleth map of percent pre-1950 housing per Jefferson County census tracts (Illustration 1 - Appendix B).

\section{Dissertation: Study Design}

Following the background investigation, an ecological study was conducted to evaluate the geospatial association between topsoil lead content and the incidence of FBI designated violent crime. University of Louisville IRB waived review of this study's protocol as the methods described herein do not meet the legal requirements for IRB review defined under 45 CFR 46.101. 


\section{Methods Specific to Aim 1}

\section{3a. Crime Map}

To evaluate the distribution of violent crimes in Jefferson County, a series of pin maps and kernel density heat maps were created using Esri ArcGIS v.10.4. Shapefiles of Jefferson County, KY were downloaded from the U.S. Census Bureau's Topographically Integrated Geographic Encoding and Referencing Line database (TIGER/Line). The latitude and longitude of violent crimes reported during calendar years 2012 through 2016 were obtained from the Louisville Metro Police Department - Crime Information Center.

\section{$\underline{\text { 3b. Statistical Methods for Cluster Analysis }}$}

Cluster analysis of violent crimes was assessed by the Kulldorff spatial scan statistic, a Poisson-based space-time scan statistic employed by SaTScan v.9.1.1. Multiple cluster analyses were completed for each violent crime type. To control for the background population, the estimated census-tract-level population was downloaded from the U.S. Census Bureau's 2014 American Community Survey 5-year estimates. Clusters of increased risk as defined by the Kulldorff spatial scan statistic were then overlaid as hollow-filled buffers in ArcGIS. For the purposes of this dissertation, only statistically significant clusters of increased risk, defined as p-values $\leq 0.05$, were illustrated. 


\section{Methods Specific to Aim 2}

To investigate the geospatial association between topsoil lead content and violent crime, soil was collected from high crime and low crime neighborhoods in Jefferson County, Kentucky. All topsoil samples were collected from four predefined collection areas. Within each collection area, topsoil samples were collected along the Edge Zone (i.e. utility strip), and from play areas within predetermined Louisville Metro Parks.

\section{4a. Four Predetermined Collection Areas - Selecting High Crime and Low Crime}

\section{Clusters for Topsoil Sampling}

All soil samples were collected from four predefined collection areas. High crime areas were identified using the Kulldorff spatial scan statistic. The highest risk areas for each violent crime classification were concentrated in the northwest neighborhoods of Jefferson County. The shared geographical area of these high crime clusters was designated as the Study Area, which served as the first soil collection area.

The three Control Areas were established based upon their low to expected rates of violent crime as identified by the Kulldorff spatial scan statistic. All control areas had equal geospatial diameters of 6.02 kilometers, which equals the diameter of the cluster of homicides associated with the Study Area. The three control areas were also selected for differing cardinal directions, relative to the Study Area. The three control areas are designated the Northeast Control Area, Southeast Control Area, and the Southwest Control Area (henceforth collectively referred to as Control Areas, when applicable). The Control Area diameters of 6.02 kilometers allowed for adequate selection of Louisville Metro Parks. 


\section{4b. Top Soil Lead Assessment}

One-inch cores, approximately 10 grams of topsoil, were extracted using the ESS Lock N' Load ${ }^{\mathrm{TM}}$ system produced by AMS Incorporated. After extraction, the soil syringe, a disposable component of the Lock N' Load $^{\mathrm{TM}}$ system, was capped and labeled with a pre-stablished study identification number. Topsoil that had been recently sodded and/or excavated was not considered for collection. Soil sampling was conducted over a two-month period in June and July of 2018. All soil samples were shipped to Elemental Analysis Inc. in Lexington, Kentucky for further analysis.

Soil lead content was determined by Inductively Coupled Plasma Mass Spectrometry (ICP-MS), a geochemical instrument used to detect analyte elemental components (232). ICP-MS is a multistage process that begins with introducing an aerosolized analyte into an argon plasma torch. The plasma torch deconstructs the analyte into component ions. These singularly charged component ions are then filtered in a mass spectrometer, which identifies the ions based upon their mass-to-charge ratio. The ions, separated by their respective atomic masses enter an electron multiplier. The electron multiplier creates a cascade of measurable electrons, which is evaluated by software to determine elemental concentrations, based upon pre-established calibration measures (233).

\section{Edge Zone Soil Sampling}

Topsoil extraction was taken from Edge Zone areas within each census tract from the four collection areas. Edge zones, sometimes referred to as utility strips, are defined as the government owned non-paved property directly adjacent to paved roads. Topsoil 
samples from the Edge Zones were extracted between 12-36 inches from the street curb.

All samples were taken along pre-identified streets from the U.S. Census Bureau's TIGER/Line Roads shapefile. A random sampling of streets was conducted for each census tract located within each collection area. After street selection, Edge Zone locations were identified based upon a random selection of available locations suitable for topsoil collection. Randomization was carried out using the sample function in $\mathrm{R}$ version 3.3.1 (R Foundation for Statistical Computing, Vienna, Austria)(234).

A total of 300 topsoil samples were collected, 120 from the Study Area, and 60 from each Control Area. Collecting twice as many soil samples from the Study Area is an unbiased method to better evaluate the soil lead content within our primary area of concern (high crime neighborhoods), as well as account for the anticipated higher variability in this region, relative to the Control Areas.

\section{Louisville Metro Parks Soil Sampling}

Topsoil was also extracted from Louisville Metro Parks found within each collection area. A total of 28 parks was selected for soil sampling. A random selection of 10 parks was made from the 36 parks located in the Study Area, using the sample function in R (234). Additionally, the Northeast Control Area, Southeast Control Area, and the Southwest Control Area contributed 10, 3, and 5 parks respectively, which were the total number of Louisville Metro Parks in these collection areas. A total of 112 soil samples, 4 from each of the 28 parks, were collected for this specific analysis. Topsoil was extracted from play areas identified as bare topsoil from high foot traffic areas, or the presence of play equipment (e.g. swing set, jungle gym). 


\section{4c. A Priori Power Calculations}

A priori power calculations for one-way, fixed effects analysis of variance (ANOVA) was conducted using G*Power v.3.1. Sample size $n$ was calculated as a function of the power $(1-\beta)$, the significance level $(\alpha)$, and the estimated effect size $f$ from Cohen (1988) (235). The subsequent power analyses specified a $\beta$ of 0.20 , and an $\alpha$ of 0.05 . The effect size $f$ was calculated given our assumptions concerning the mean and standard deviation of the soil lead content; these assumptions are described below.

The first assumption is that there is a diffusion pattern in soil lead content from the Study Area, which exists in the urban core, to the suburban Control Areas. This first assumption is based on a review of the scientific literature, which has documented diffusion patterns of soil lead content from urban and suburban locations (236-238).

A second assumption was that the Study Area would have an approximate mean soil lead content three times higher than the Control Areas (e.g. $300 \mathrm{mg} / \mathrm{kg}$ vs. 100 $\mathrm{mg} / \mathrm{kg}$ ); and that the estimated overall standard deviation would be $300 \mathrm{mg} / \mathrm{kg}$. This second assumption is a conservative estimate given a review of the soil-lead literature, which has found that mean urban soil lead levels are 2-10 times higher than their suburban counterparts (239).

\section{Edge Zone}

Given the aforementioned assumptions, as well as using an uneven sampling scheme (twice as many samples from the Study Area as each Control Area), the estimated effect size $f$ is 0.3265 . Cohen (1988) suggests that an effect size of 0.3265 is a medium to moderate effect size; that is, the standard deviation of the overall population is 
0.3265 , the size of the standard deviation of observations within the populations. From this, an $\eta^{2}$, a generalization of Pearson's $r^{2}$, of 0.0963 is theoretically detectable (235).

Using G*Power v.3.1, fixed effects ANOVA, where $\alpha=0.05, \beta=0.20$, and an effect size of 0.3265 , a total sample size of 108 would achieve a power of $80.75 \%$. For this analysis, a total of 300 edge zone soil samples were collected.

\section{Louisville Metro Parks}

Given the aforementioned assumptions, as well as an unequal sample sizes between the Study Area $(\mathrm{n}=40)$ and the Control Areas $\left(\mathrm{n}_{\mathrm{i}}=40,12,20\right)$, the estimated effect size $f$ is 0.3194 . Cohen (1988) suggests that an effect size of 0.3194 is a medium to moderate effect size; that is, the standard deviation of the overall population is 0.3194 the size of the standard deviation of observations within the populations. From this, an $\eta^{2}$ of 0.0925 is theoretically detectable (235).

Using G*Power v.3.1, fixed effects ANOVA, where $\alpha=0.05, \beta=0.20$, and an effect size of 0.3194 , a total sample size of 112 would achieve a power of $80.47 \%$. For this analysis, a total of 112 were collected from the Louisville Metro Parks.

Upon review of the park topsoil collection locations, it was determined that the four samples from the Northeast Control Area (E.P. Tom Sawyer Park) were collected outside of the official study boundary. Because of this, these four topsoil samples were not included in any statistical analysis. A revised power analysis based upon an updated effect size of 0.3219 showed that a total sample size of 108 would achieve a power of $81.14 \%$. 


\section{4d. Statistical Methods for Comparing Soil Lead Content Between Soil Collection}

$\underline{\text { Areas }}$

A systematic multi-stage approach was used to evaluate soil lead content between the soil collection areas. Because the soil lead data was intractably linked to a spatial location, concern for spatial dependence (i.e. spatial autocorrelation) was observed. To evaluate for spatial dependence, a spatially weighted Moran's I test was employed (240). Residual spatial dependence was identified in both Edge Zone and Louisville Metro Parks soil samples. Therefore, the independence assumption of ANOVA was not met. To evaluate soil lead content between soil collection areas spatially weighted linear models were used. Model specification was determined by the Lagrange Multiplier test (241). Based on the results from the Lagrange Multiplier test a spatial error model was used to evaluate Edge Zone, and Louisville Metro Parks topsoil lead content between the four soil collection areas.

Both the spatially weighted Moran's I test and the Lagrange Multiplier test, lm.morantest and lm.LMtests respectively, were employed using the 'spdep' package in $\mathrm{R}$ (242, 243). Since the dependent variable 'Soil Lead Content' was not normally distributed it was log transformed in the analysis. Regression coefficients and confidence intervals were back transformed using the exponential function to return effects to their original measurement scale.

\section{Methods Specific to Aim 3}

To further explore the geospatial association between topsoil lead content and FBI designated violent crime, a spatially weighted Poisson regression model was constructed 
using census-tract-level variables. For this analysis census-tract-level data were constrained to Jefferson County census tracts within each of the four topsoil collection areas. Therefore, 108 of the 191 census tracts were retained for this analysis.

\section{5a. Dependent Variable, Primary Predictor and Covariates of Interest}

The latitude and longitude of FBI designated violent crime events reported during calendar years 2012 through 2016 were obtained from the Louisville Metro Police Department - Crime Information Center. A total of 21,097 violent crime events were mapped using Esri ArcGIS v.10.4 onto the 191 census tracts that make up Jefferson County, KY. For the response variable, violent crime events, only those events which occurred in one of the 108 census tracts that made up the four topsoil collection areas were considered. This spatial reduction retained a total of 12,710 violent crime events for inclusion in this analysis.

The primary predictor for this analysis was topsoil lead content. To evaluate the predictive effect of topsoil lead content on the incidence of violent crime, an interpolated topsoil lead content variable was created by Empirical Bayesian Kriging, within Esri ArcGIS v.10.4. This method used the 300 edge-zone topsoil lead measurements collected in Aim 2 to model the soil lead level at all locations within the four soil collection areas. Within each census tract, these were averaged across all locations to produce an estimate for the mean topsoil lead level of that census tract. The interpolated mean topsoil lead content was then used as the primary predictor for this analysis.

A review of the literature showed that median household income, percent female head of household, percent of households living in poverty, percent of households with 
dependents under 18-years of age, percent of households receiving food stamps, percent black population, percent of the population with a bachelor's degree, and percent of the male population 15-24 years of age were important census-tract-level predictors of crime and/or socioeconomic deprivation (244-248). Jefferson County census-tract-level data for these eight variables were downloaded from the 2014 American Community Survey 5year estimates. Principal components analysis was then used to create a census-tract features index from the aforementioned census-tract-level variables, excluding percent of the male population 15-24 years of age. This exclusion was based on evidence from the literature, which indicates that percent of the male population between 15-24 years of age is an important predictor of violent crime $(247,249)$. Therefore, this variable was included in the final model as an independent covariate separate from the census-tract features index.

The inclusion of a census-tract features index via principal components analysis reduced the number of variables for inclusion into a full model, while simultaneously retaining a preponderance of census-tract-level covariate information. Additionally, the use of principal component analysis accounted for any multicollinearity between the census-tract-level variables. The final census-tract features index included in the full model was constrained to the first three principal components, which explained $90 \%$ of the variance within the seven variables (Table 2 - Appendix A).

It is worth considering which variables load on each principal component of the census-tract features index. The rotation scores of the retained principal components (PC) guided the interpretation of these summaries. The first PC (PC1) was associated with high median household income, high percentage of bachelor's degrees, low percentage of 
black population, low percentage of female head of household, low percentage of household receiving food stamps, and low percentage of household living in poverty (all in roughly equal weight). Because of this, $\mathrm{PC} 1$ is referred to as neighborhood advantage. The majority of variance in the second principal component (PC2) was explained by high median household income and high percentage of households with children less than 18 years of age. Because of this, PC2 is referred to as family neighborhoods. Finally, the majority of the remaining variance in principal component 3 (PC3) was explained by percent of the population without a bachelor's degree, therefore PC3 is referred to as low college graduates (Table 3 - Appendix A).

\section{5b. Statistical Methods}

A Bayesian sparse spatial generalized linear mixed model (SGLMM) was used to examine the statistical relationship between FBI designated violent crimes and topsoil lead content, while adjusting for the census-tract-level census-tract features index and spatial confounding (250). A sparse SGLMM included an adjacency matrix which accounted for the inherent spatial dependence within the four topsoil collection areas. Spatial adjacency was defined by queen contiguity, which defined census tracts as neighbors in the presence of a shared boarder (251).

For this analysis a Poisson based sparse SGLMM was used with an offset, where the offset was defined as 2014 American Community Survey 5-year estimates censustract-level population data. This offset effectively transformed the response variable, violent crime events per census tracts, into per capita rates of violent crimes. To evaluate the predictive effect of the interpolated mean topsoil lead levels and on violent crime rate, 
two models were used: a marginal model and a full model. Both models used the interpolated mean topsoil lead level as the primary predictor, however the full model included the census-tract features index and the percentage of young males 15-24 years of age per census tract, to account for confounding between topsoil lead, crime, and other neighborhood features.

Both the marginal and full model were used to examine the predictive effect of topsoil lead content on violent crime events. Additionally, both models were used to predict each violent crime type: aggravated assault, robbery, forcible rape, and homicide. Model coefficients were exponentiated to produce relative risks (RR) and the corresponding 95\% credible intervals (the Bayesian equivalent to 'confidence intervals'). For ease of interpretation, lead coefficients were multiplied by100 prior to exponentiating to represent an effect per every 100-unit increase in mean topsoil lead levels.

Additionally, principle component scores were standardized to have mean zero and unit standard deviation. Finally, point estimates and $95 \%$ credible intervals will be reported to reflect at least two significant digits. 


\section{RESULTS}

\section{Specific Aim 1 Results: Use Geographic Information Systems (GIS) to Examine the Geospatial Distribution of Violent Crime throughout Jefferson County, KY}

Crime data received from the Louisville Metro Police Department Crime Information Center showed 21,097 FBI designated violent crimes between January 1, 2012 and December 31, 2016. The most common violent crime during this time period was aggravated assault. The least common violent crime during this time period was homicide. Descriptive statistics for the number and type of violent crimes per census tract in Jefferson County can be found in Table 1. Due to the zero counts for some census tracts, the geometric mean is calculated using $\exp \left(\mathrm{n}^{\wedge}\{-1\} \operatorname{sum} \log (\mathrm{xi}+1)\right)-1$.

Table 1. FBI Violent Crimes per Jefferson County Census Tracts between January 1, 2012 and December 31, 2016

\begin{tabular}{lccccccc}
\hline Crime Type & N (\%) & $\begin{array}{c}\text { Geometric } \\
\text { Mean }\end{array}$ & Min & P25 & Med & P75 & Max \\
\hline $\begin{array}{l}\text { Aggravated } \\
\text { Assault }\end{array}$ & $12,050(57.1 \%)$ & 33.63 & 0 & 13 & 40 & 91 & 549 \\
Robbery & $7,465(35.3 \%)$ & 19.42 & 0 & 7 & 24 & 56 & 294 \\
$\begin{array}{l}\text { Forcible } \\
\text { Rape }\end{array}$ & $1,215(5.7 \%)$ & 4.28 & 0 & 2 & 5 & 9 & 54 \\
Homicide & $367(1.7 \%)$ & 1.01 & 0 & 0 & 1 & 3 & 18 \\
\hline $\begin{array}{l}\text { All Crime } \\
\text { Events }\end{array}$ & 21,097 & 60.11 & 0 & 22 & 75 & 152.5 & 905 \\
\hline
\end{tabular}

Min, minimum; $\mathrm{P} 25,25^{\text {th }}$ percentile; Med, median; $\mathrm{P} 75,75^{\text {th }}$ percentile; Max, maximum count 
FBI designated violent crime is non-randomly distributed throughout Jefferson County, Kentucky. The Kulldorff spatial scan statistic identified multiple statistically significant clusters of aggravated assault, robbery, forcible rape, and homicide, while controlling for census-tract-level population density. These non-uniform distributions of violent crime were disproportionately located in the northwestern census tracts of Jefferson County. Additionally, among the multiple areas of increased risk identified by the Kulldorff spatial scan statistic for each crime type, the highest areas of increased risk (i.e. Relative Risk) were also spatially correlated in the northwestern census tracts of Jefferson County (Illustrations 1-4). The shared space of the highest areas of risk for each violent crime type was designated the Study Area, while areas without any increased risk for violent crime became the Control Areas (Illustration 5). 
Illustration 1.

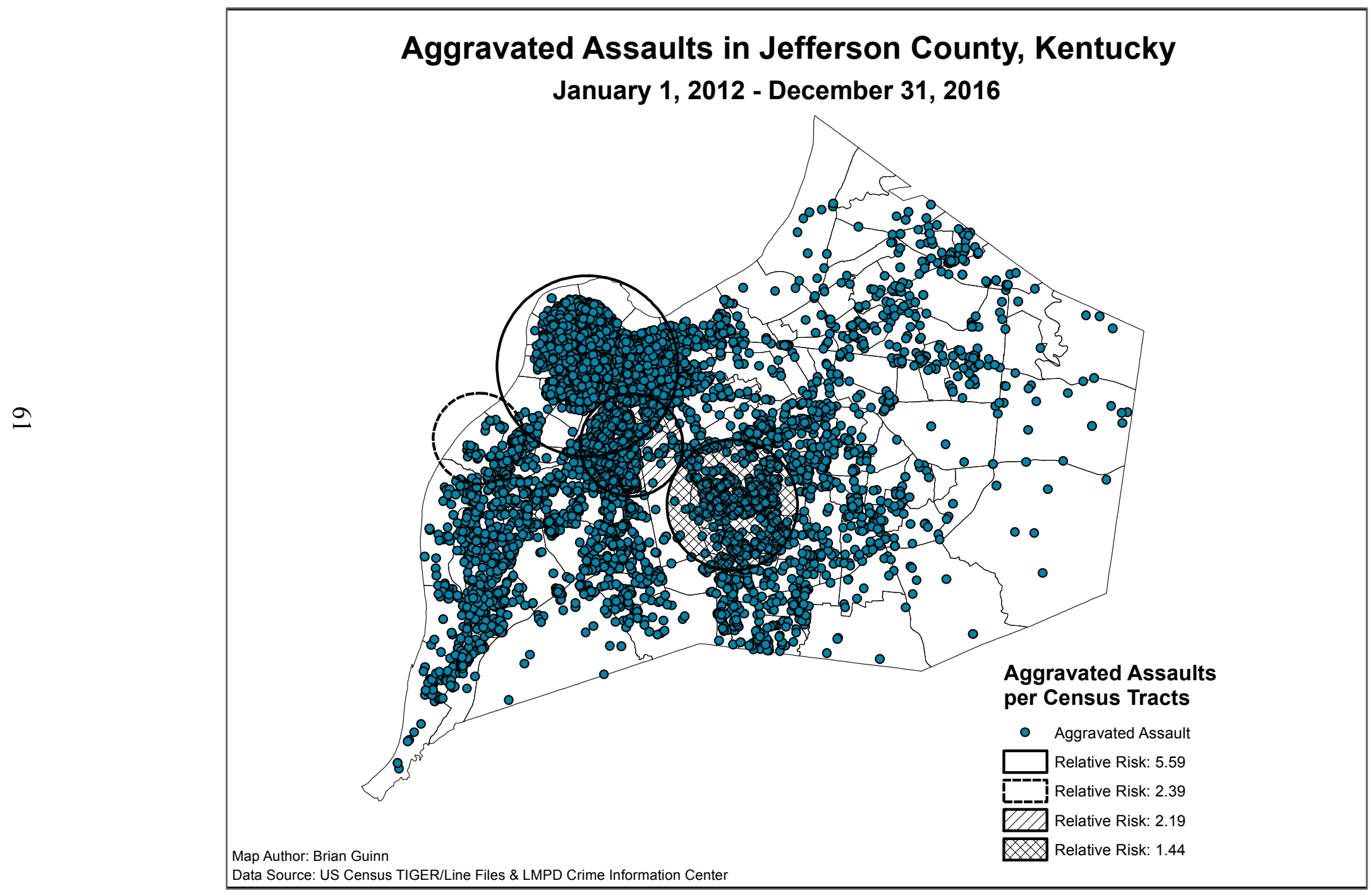


Illustration 2.

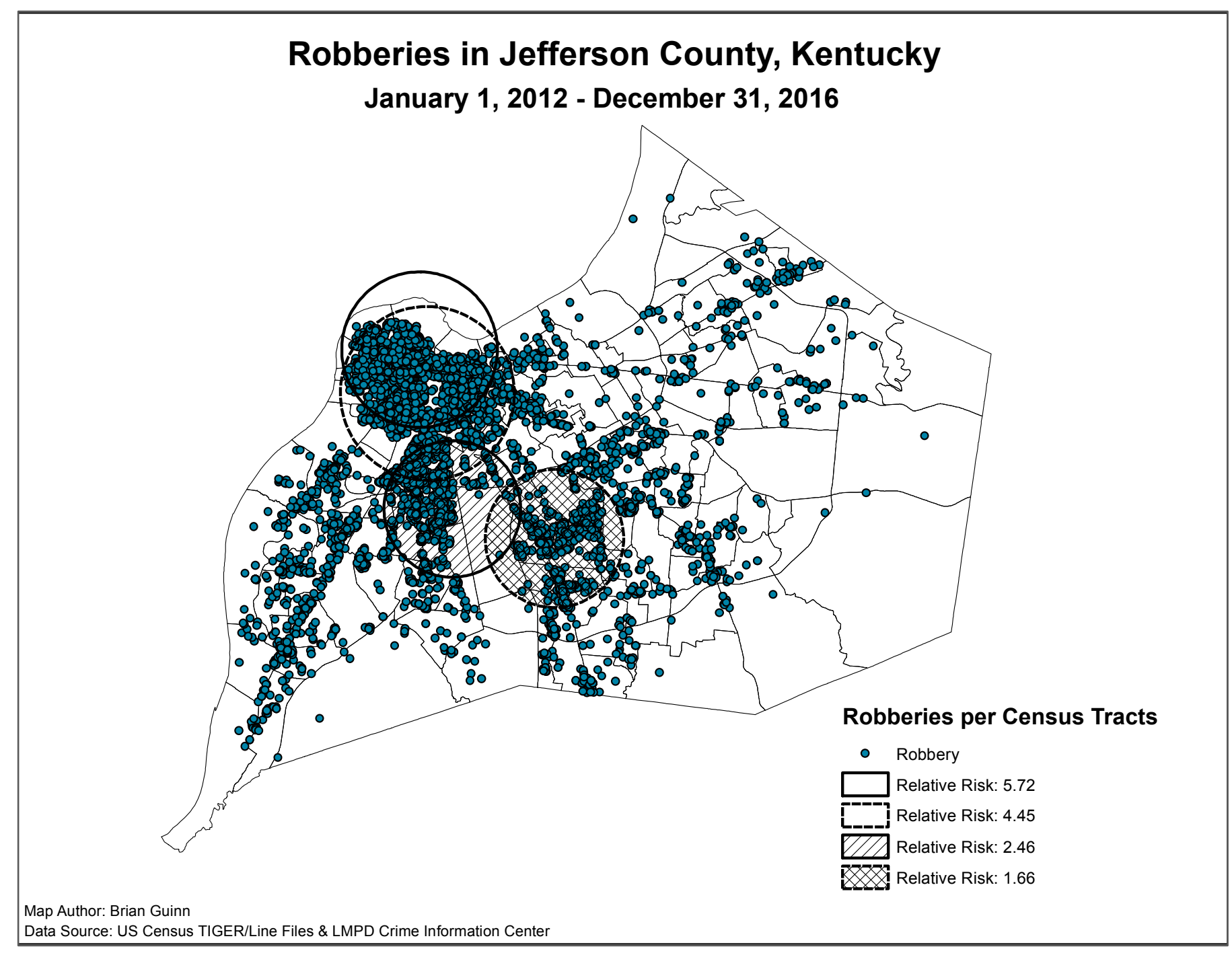


Illustration 3.

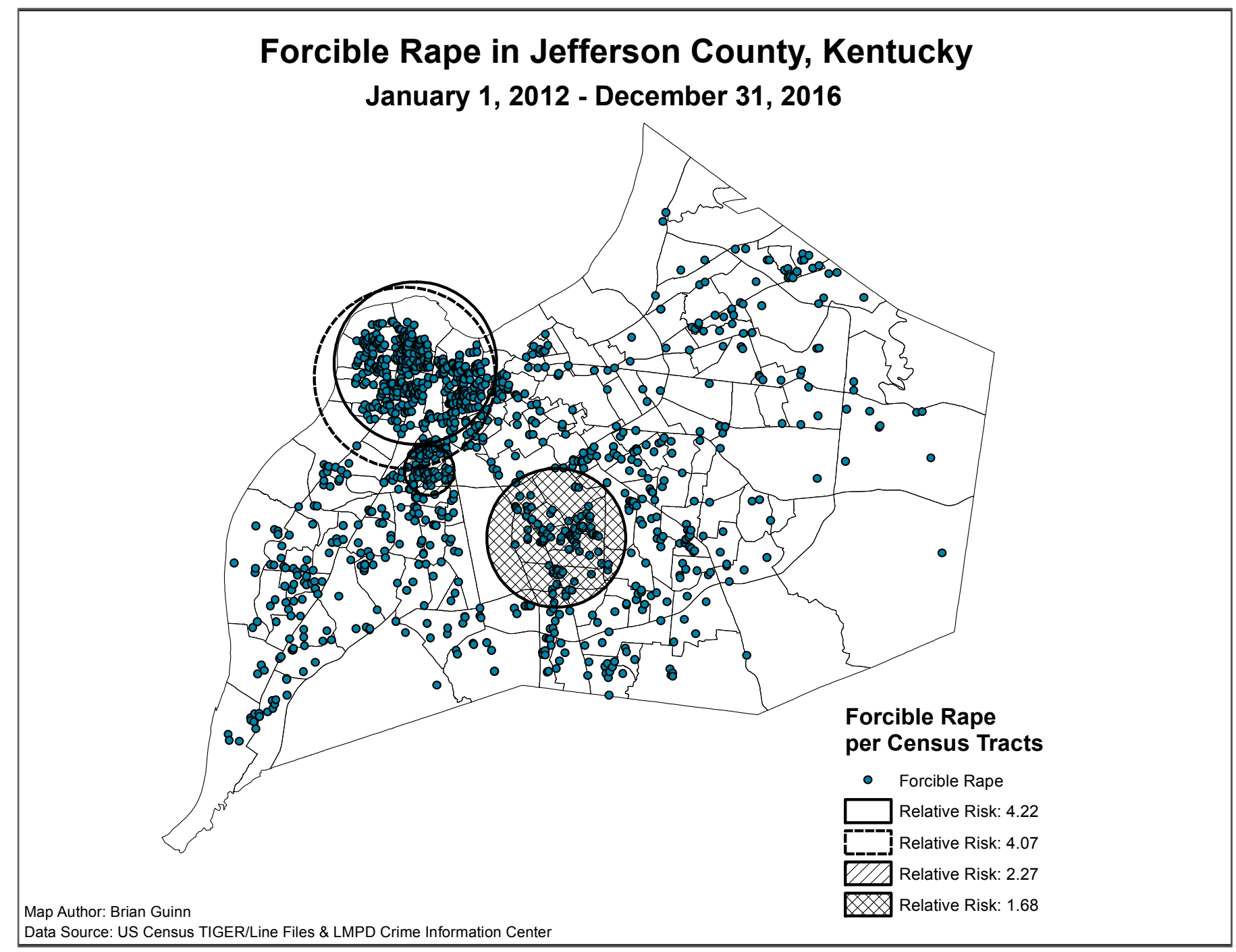


Illustration 4.

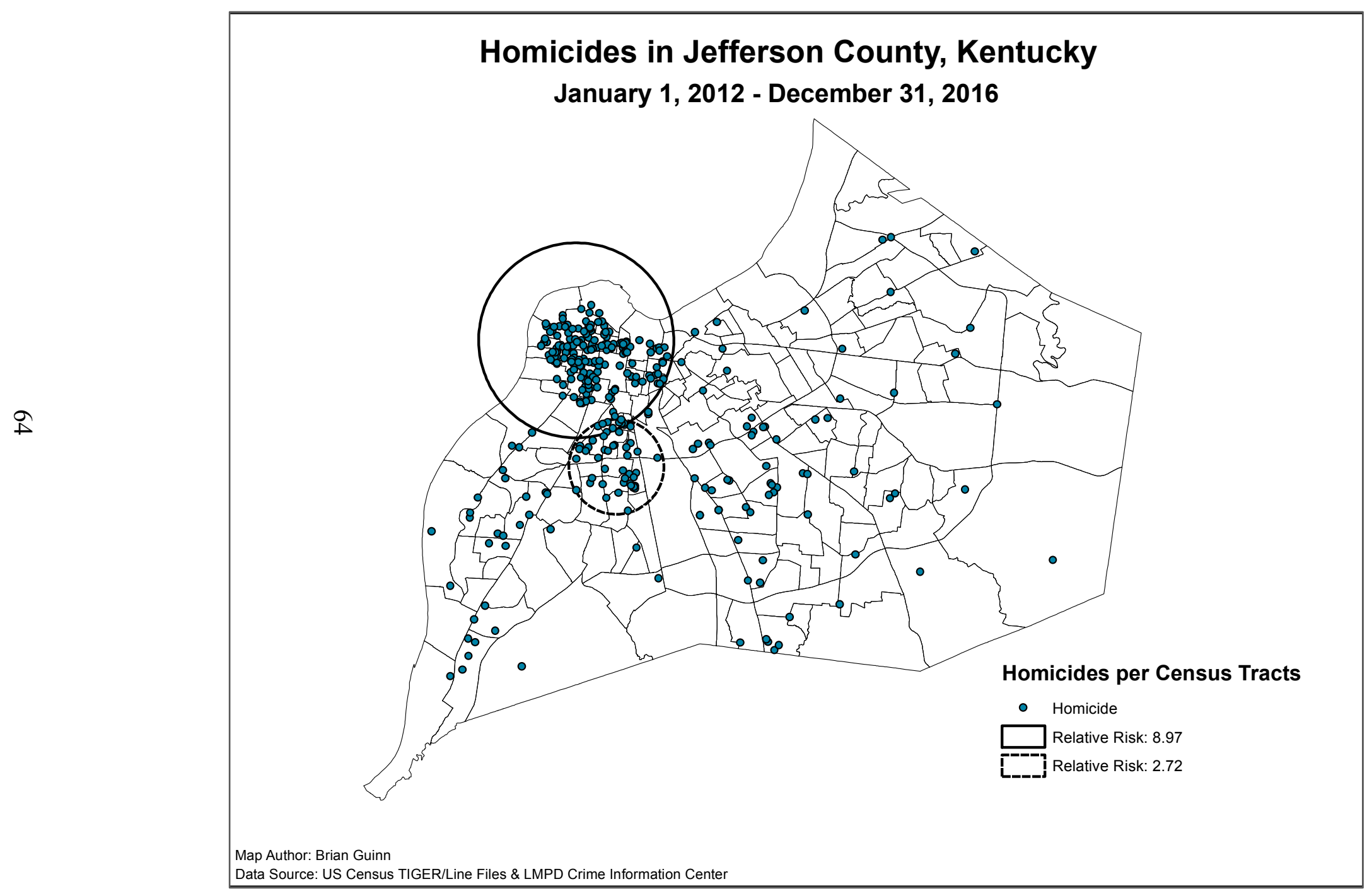


Illustration 5.

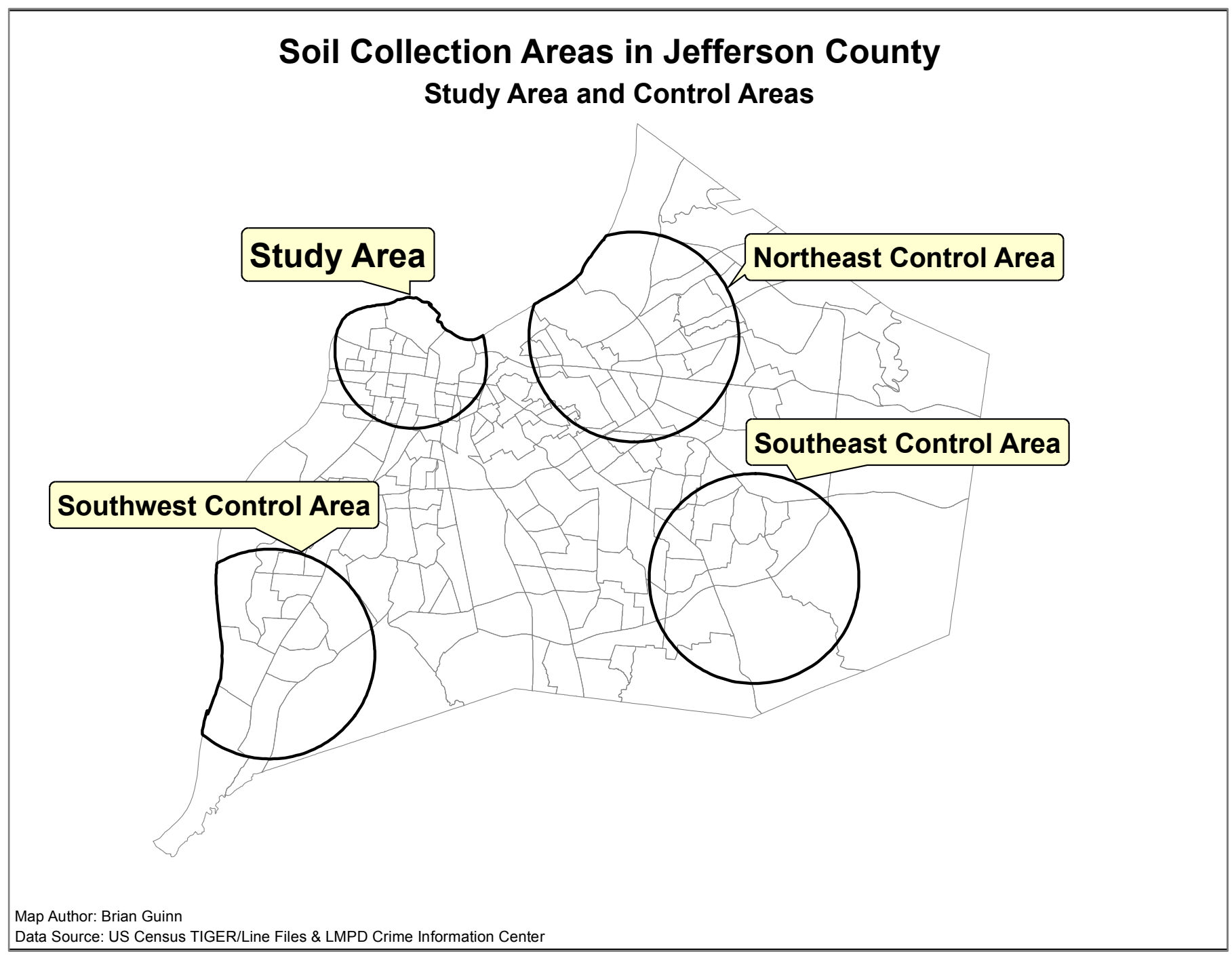




\section{Specific Aim 2 Results: Quantify and Record Topsoil Lead Concentrations in}

Neighborhoods of Jefferson County, KY with High Crime Rates, and Low to Normal

\section{Crime Rates}

Results from ICP-MS showed that Edge Zone topsoil samples from the Study Area had a higher median soil lead content compared to Edge Zone topsoil samples from the three Control Areas. The geometric mean topsoil lead content for the Study Area was $157.28 \mathrm{mg} / \mathrm{kg}$. The Northeast control area had the next highest geometric mean topsoil lead content of $43.34 \mathrm{mg} / \mathrm{kg}$. Descriptive statistics for Edge Zone topsoil lead content by collection area are reported in Table 2.

Table 2. $\quad$ Edge Zone Topsoil Lead Content by Collection Area

\begin{tabular}{lccccccc}
\hline $\begin{array}{c}\text { Collection } \\
\text { Area }\end{array}$ & $\mathbf{n}$ & $\begin{array}{c}\text { Geometric } \\
\text { Mean }\end{array}$ & Min & P25 & Med & P75 & Max \\
\hline Study & 120 & 157.28 & 16 & 97.5 & 180 & 262 & 4000 \\
Northeast & 60 & 43.34 & 9.7 & 26.50 & 44 & 68.25 & 620 \\
Southeast & 60 & 17.30 & 3.2 & 11.74 & 14 & 24 & 170 \\
Southwest & 60 & 24.44 & 3.2 & 10 & 25 & 56 & 270 \\
\hline
\end{tabular}

Min, minimum; $\mathrm{P} 25,25^{\text {th }}$ percentile; Med, median; $\mathrm{P} 75,75^{\text {th }}$ percentile; Max, maximum count Table values reported in $\mathrm{mg} / \mathrm{kg}$

ICP-MS also showed that the mean topsoil lead content from the Louisville Metro Parks was higher in the Study Area compared to the three Control Areas. The geometric mean topsoil lead content for the Study Area parks was $103.05 \mathrm{mg} / \mathrm{kg}$. The Northeast control area had the next highest geometric mean topsoil lead content of $23.62 \mathrm{mg} / \mathrm{kg}$. Descriptive statistics for Louisville Metro Parks topsoil lead content by collection area are reported in Table 3. 
Table 3. Louisville Metro Parks Topsoil Lead Content by Collection Area

\begin{tabular}{lccccccc}
\hline Collection Area & $\mathbf{n}$ & $\begin{array}{c}\text { Geometric } \\
\text { Mean }\end{array}$ & Min & P25 & Med & P75 & Max \\
\hline Study & 40 & 103.05 & 34 & 12 & 14.5 & 20 & 670 \\
Northeast & 36 & 23.62 & 7.7 & 15 & 21 & 35.25 & 71 \\
Southeast & 12 & 12.91 & 7.7 & 11.75 & 13 & 14.25 & 22 \\
Southwest & 20 & 15.72 & 9.5 & 12 & 14.5 & 20 & 48 \\
\hline
\end{tabular}

Min, minimum; $\mathrm{P} 25,25^{\text {th }}$ percentile; Med, median; $\mathrm{P} 75,75^{\text {th }}$ percentile; Max, maximum count Table values reported in $\mathrm{mg} / \mathrm{kg}$

Results from the spatial error model showed that the mean topsoil lead content from the Edge Zones data was statistically significantly higher in the Study Area compared to the mean topsoil lead content in the referent Southeast Control Area. Model results estimated an 8-fold increase in Study Area topsoil lead content compared to the referent Control Area (Study Area exponentiated results: $\beta=8.25,95 \% \mathrm{CI}=(5.12$, 13.27), p-value <0.001). Model results also estimated a 2.4-fold increase in Northeast topsoil lead content compared to the referent Control Area (Northeast Area exponentiated results: $\beta=2.43,95 \% \mathrm{CI}=(1.55,3.81)$, $\mathrm{p}$-value $<0.001)$.

Spatial error modeling also showed that the mean topsoil lead content from the Louisville Metro Parks was statistically significantly higher in the Study Area compared to the mean topsoil lead content in the referent Southeast Control Area. Model results also estimated an 8-fold increased difference in Study Area topsoil lead content compared to the referent Control Area (Study Area exponentiated results: $\beta=8.06,95 \% \mathrm{CI}=(4.76$, 13.67), p-value $<0.001)$. 
The spatial error model results for both the Edge Zones and Louisville Metro

Parks can be found in Table 4. The relationship between topsoil collection location and soil lead content is further demonstrated in Illustrations 6 and 7. 
Table 4. $\quad$ Results Spatial Error Models for Edge Zone and Louisville Metro Parks Soil Samples

\begin{tabular}{|c|c|c|c|c|c|c|}
\hline & \multicolumn{3}{|c|}{ Edge Zone Soil Samples } & \multicolumn{3}{|c|}{ Louisville Metro Parks Soil Samples } \\
\hline & Coefficients & $95 \% \mathrm{CI}$ & P-value & Coefficients & $95 \% \mathrm{CI}$ & P-value \\
\hline Intercept & 16.79 & $(10.49,26.88)$ & $<2.2 \mathrm{e}-16$ & 12.70 & $(8.02,20.09)$ & $<2.2 \mathrm{e}-16$ \\
\hline \multicolumn{4}{|c|}{ Locations (multiplicative effect) } & \multicolumn{3}{|c|}{ Locations (multiplicative effect) } \\
\hline Southeast & ref & -- & -- & ref & -- & -- \\
\hline Southwest & 1.35 & $(0.80,2.29)$ & 0.2551 & 1.27 & $(0.69,2.32)$ & 0.43068 \\
\hline Northeast & 2.43 & $(1.55,3.81)$ & 0.0001 & 1.72 & $(1.03,2.89)$ & 0.03763 \\
\hline Study & 8.24 & $(5.12,13.27)$ & $<2.2 \mathrm{e}-16$ & 8.06 & $(4.76,13.67)$ & $8.66 \mathrm{e}-15$ \\
\hline
\end{tabular}

* Table coefficients have been exponentiated back to their original measurement scale 95\% CI, 95\% confidence interval 
Illustration 6.

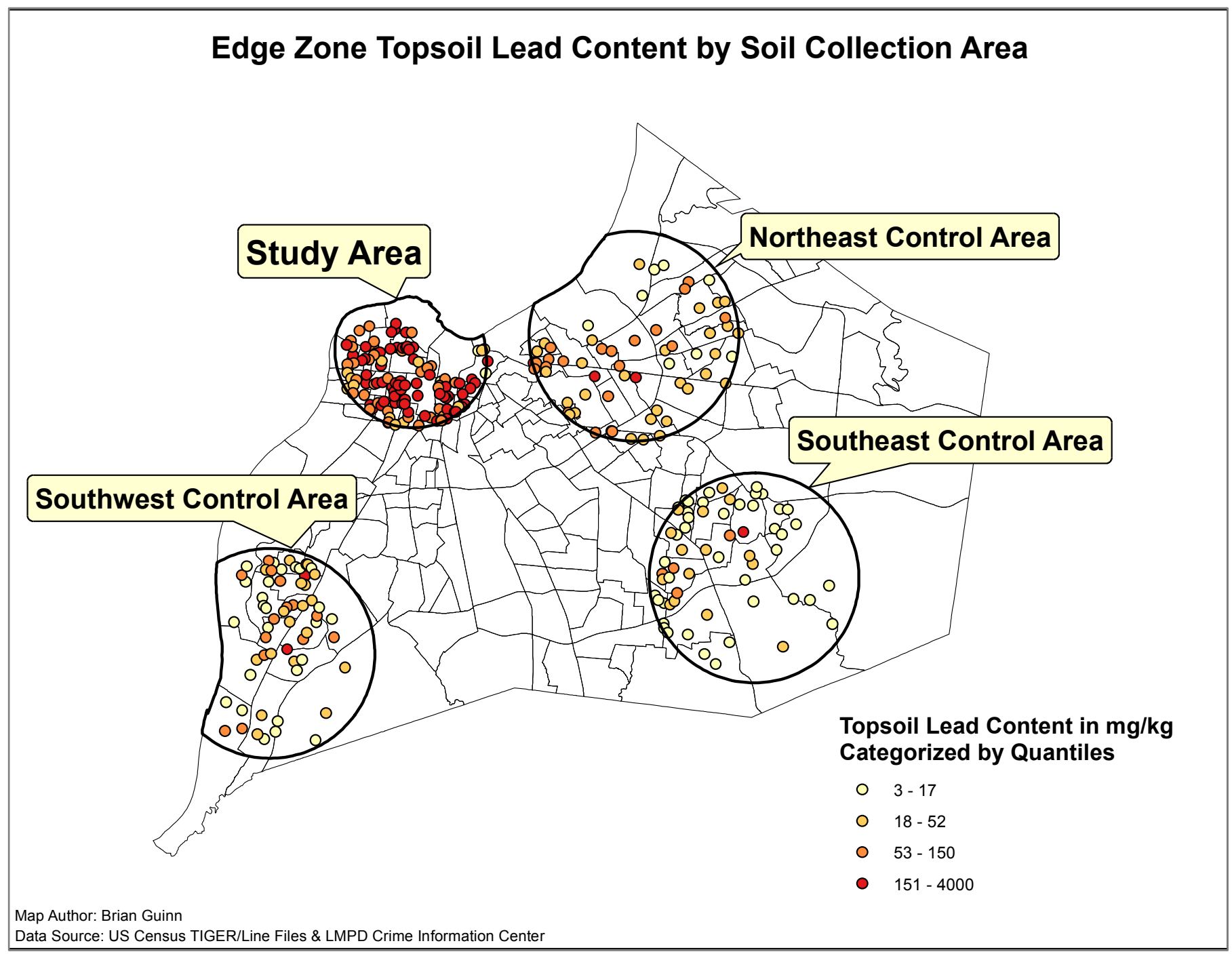


Illustration 7.

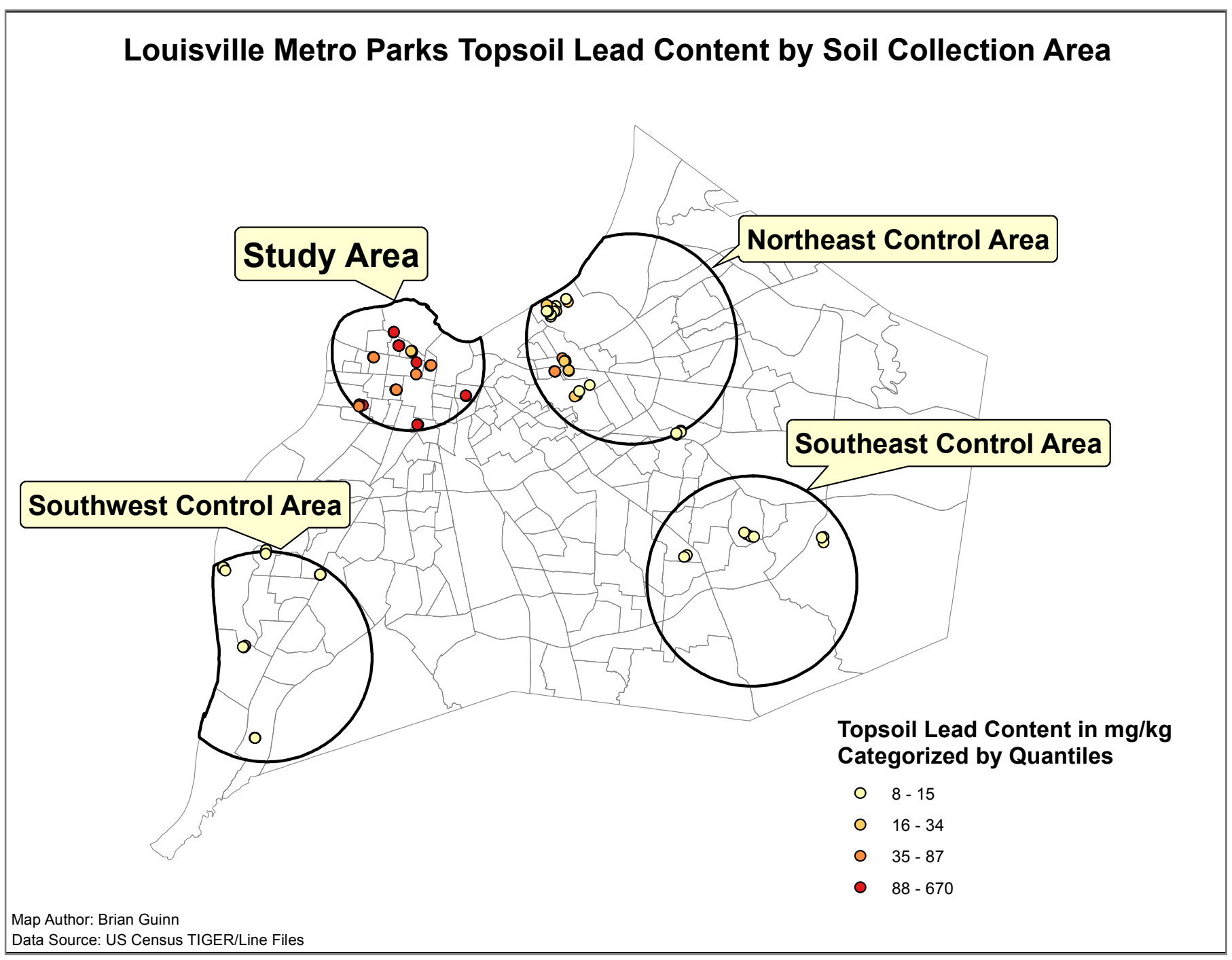


Additional investigation of samples exceeding $400 \mathrm{mg} / \mathrm{kg}$, the EPA threshold for soil lead content in designated play areas, was considered (179). Within the Study Area, these 15 high lead measurements represent $9.4 \%$ of the 160 samples collected, in comparison to $1.04 \%$ of the 96 samples collected in the Northeast Control Area. The Southwest and Southeast Control Areas had zero samples exceeding $400 \mathrm{mg} / \mathrm{kg}$. (Table 5 and Illustration 8).

Table 5.

Topsoil Samples Exceeding 400 mg/kg

\begin{tabular}{lccc}
\hline Sample & Collection Area & Soil Lead Level & Edge Zone / Park \\
\hline Sample 1 & Study & $4000 \mathrm{mg} / \mathrm{kg}$ & Edge Zone \\
Sample 2 & Study & $2300 \mathrm{mg} / \mathrm{kg}$ & Edge Zone \\
Sample 3 & Study & $1000 \mathrm{mg} / \mathrm{kg}$ & Edge Zone \\
Sample 4 & Study & $870 \mathrm{mg} / \mathrm{kg}$ & Edge Zone \\
Sample 5 & Study & $740 \mathrm{mg} / \mathrm{kg}$ & Edge Zone \\
Sample 6 & Study & $690 \mathrm{mg} / \mathrm{kg}$ & Edge Zone \\
Sample 7 & Study & $670 \mathrm{mg} / \mathrm{kg}$ & Park \\
Sample 8 & Study & $650 \mathrm{mg} / \mathrm{kg}$ & Edge Zone \\
Sample 9 & Northeast & $620 \mathrm{mg} / \mathrm{kg}$ & Edge Zone \\
Sample 10 & Study & $590 \mathrm{mg} / \mathrm{kg}$ & Edge Zone \\
Sample 11 & Study & $540 \mathrm{mg} / \mathrm{kg}$ & Edge Zone \\
Sample 12 & Study & $470 \mathrm{mg} / \mathrm{kg}$ & Edge Zone \\
Sample 13 & Study & $460 \mathrm{mg} / \mathrm{kg}$ & Edge Zone \\
Sample 14 & Study & $460 \mathrm{mg} / \mathrm{kg}$ & Edge Zone \\
Sample 15 & Study & $420 \mathrm{mg} / \mathrm{kg}$ & Edge Zone \\
Sample 16 & Study & $420 \mathrm{mg} / \mathrm{kg}$ & Edge Zone \\
\hline
\end{tabular}


Illustration 8.

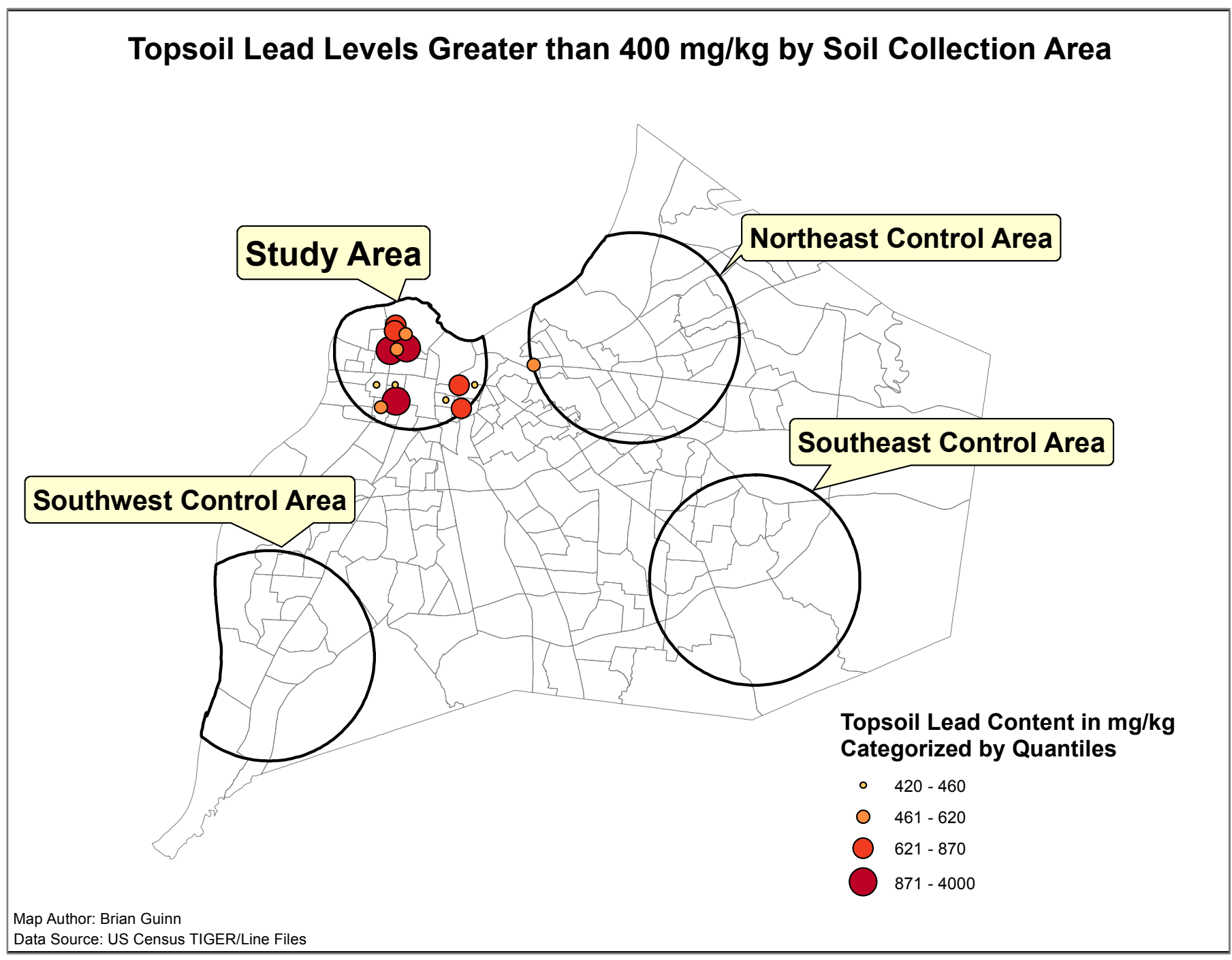




\section{Specific Aim 3 Results: Examine the Statistical Relationship Between the Spatial}

Distribution of FBI Designated Violent Crime and Topsoil Lead Concentrations, Adjusting for Pertinent Census-Tract-Level Variables in Jefferson County, Kentucky.

Results of the marginal Poisson based sparse SGLMM showed that for every 100unit increase in mean topsoil lead content, there was a $1.62(95 \%$ CI: 1.59, 1.68) times increase in the risk of FBI designated violent crime. Results from the full model showed that for every 100-unit increase in mean topsoil lead content, there was a 1.05 (95\% CI: $1.03,1.08)$ times increase in the risk of FBI designated violent crime, after adjusting for the percent of young males 15-24 years of age, as well as the first three principal components of the census-tract features index (Table 6).

Model results also showed that for every one percentage point increase in the population of males 15-24 years of age per census tract, there was a non-significant 1.003 (95\% CI: $0.99,1.01)$ times increase in the risk of FBI designated violent crime, controlling for all other independent variables. Additionally, the census-tract features index showed that for every one standard deviation increase in PC1-neighborhood advantage, there was a $0.32(95 \% \mathrm{CI}: 0.30,0.33)$ times reduction in the risk of FBI designated violent crime, after controlling for all other independent variables. Similarly, model results showed that a one standard deviation increase in PC2-family neighborhoods resulted in a $0.70(95 \% \mathrm{CI}: 0.68,0.72)$ times reduction in the risk of FBI designated violent crime, after controlling for all other independent variables. Finally, model results showed that a one standard deviation increase in PC3-low college graduates, resulted in a $1.09(95 \% \mathrm{CI}: 1.06,1.12)$ times increase in the risk of FBI designated violent crime, after controlling for all other independent variables (Table 6). 
Table 6.

All Crime Events

\begin{tabular}{|c|c|c|}
\hline & $\mathbf{R R}$ & $95 \% \mathrm{CI}$ \\
\hline $\begin{array}{l}\text { Marginal Model Characteristic } \\
{ }^{\dagger} \text { Mean topsoil lead level }\end{array}$ & 1.62 & $(1.59,1.68)$ \\
\hline Full Model Characteristics & & \\
\hline †Mean topsoil lead level & 1.05 & $(1.03,1.08)$ \\
\hline Males $15-24$ years of age & 1.00 & $(0.99,1.01)$ \\
\hline Census-tract features index & & \\
\hline PC1 - Neighborhood advantage & 0.32 & $(0.30,0.33)$ \\
\hline PC2 - Family neighborhoods & 0.70 & $(0.68,0.72)$ \\
\hline PC3 - Low college graduates & 1.09 & $(1.06,1.12)$ \\
\hline
\end{tabular}

Sub-analysis was then performed to evaluate the effect of the mean topsoil lead content on the incidence of each violent crime type: aggravated assault, robbery, forcible rape, and homicide. Results from the marginal models showed that every 100 -unit increase in mean topsoil lead content was associated with a 1.63 (95\% CI: $1.58,1.69)$ times increase in the risk of aggravated assault, a $1.61(95 \% \mathrm{CI}: 1.56,1.68)$ times increase in the risk of robbery, a $1.55(95 \% \mathrm{CI}: 1.46,1.65)$ times increase in the risk of forcible rape, and a 1.75 (95\% CI: $1.63,1.89)$ times increase in the risk of homicide. After controlling for the census-tract features index and percent males 15-24 years of age, results from the full models showed that every 100 -unit increase in mean topsoil lead content was associated with a $1.04(95 \% \mathrm{CI}: 1.01,1.07)$ times increase in the risk of aggravated assault, a 1.05 (95\% CI: $1.01,1.10)$ times increase in the risk of robbery, a $1.12(95 \% \mathrm{CI}: 1.04,1.23)$ times increase in the risk of forcible rape, and a 1.20 (95\% CI: 1.07, 1.34) times increase in the risk of homicide (Table 7). The effects of the other predictors are relatively similar across crime-type and consistent with the results from the analysis using all crime events (Table 6). 
Table 7.

Aggravated Assault

Robbery

Forcible Rape

Homicide

\begin{tabular}{|c|c|c|c|c|c|c|c|c|}
\hline & $\mathbf{R R}$ & $95 \% \mathrm{CI}$ & $\mathbf{R} \mathbf{R}$ & $95 \% \mathrm{CI}$ & $\mathbf{R} \mathbf{R}$ & $95 \% \mathrm{CI}$ & $\mathbf{R R}$ & $95 \% \mathrm{CI}$ \\
\hline \multicolumn{9}{|l|}{ Marginal Model } \\
\hline †Mean topsoil lead level & 1.63 & $(1.58,1.69)$ & 1.61 & $(1.56,1.68)$ & 1.55 & $(1.46,1.65)$ & 1.75 & $(1.63,1.89)$ \\
\hline \multicolumn{9}{|l|}{ Full Model } \\
\hline †Mean topsoil lead level & 1.04 & $(1.01,1.07)$ & 1.05 & $(1.01,1.10)$ & 1.12 & $(1.04,1.23)$ & 1.20 & $(1.07,1.34)$ \\
\hline Males $15-24$ years of age & 0.99 & $(0.98,1.00)$ & 1.01 & $(0.99,1.01)$ & 1.02 & $(1.00,1.04)$ & 0.98 & $(0.94,1.01)$ \\
\hline \multicolumn{9}{|l|}{ Census-tract features index } \\
\hline PC1: Neighborhood advantage & 0.30 & $(0.28,0.32)$ & 0.33 & $(0.31,0.36)$ & 0.46 & $(0.40,0.52)$ & 0.34 & $(0.27,0.42)$ \\
\hline PC2: Family neighborhoods & 0.74 & $(0.72,0.77)$ & 0.63 & $(0.61,0.66)$ & 0.72 & $(0.66,0.78)$ & 0.91 & $(0.77,1.08)$ \\
\hline PC3: Low college graduates & 1.13 & $(1.09,1.17)$ & 1.06 & $(1.01,1.11)$ & 1.06 & $(0.96,1.16)$ & 1.04 & $(0.86,1.23)$ \\
\hline
\end{tabular}

RR, Relative Risk; 95\% CI, 95\% Credible Interval; PC, Principal Component

${ }^{\dagger} \mathrm{RR}$ for $100 \mathrm{mg} / \mathrm{kg}$ increase in the topsoil lead levels

Table results rounded to two decimal places 


\section{Summary}

FBI designated violent crime is not evenly distributed across Jefferson County, KY. The Kulldorff spatial scan statistic identified multiple statistically significant clusters of aggravated assault, robbery, forcible rape, and homicide, while controlling for censustract-level population density. Census tracts with higher than expected rates of violent crime were disproportionately located in the northwestern Jefferson County. The shared space of high crime census tracts was designated the Study Area, while three areas with expected to low rates for violent crime became the Control Areas

Evaluation of the topsoil lead content showed that the Study Area had an approximate 8-fold increase in topsoil lead content compared to the referent Control Area. After controlling for pertinent census-tract-level variables (median household income, percent female head of household, percent of households living in poverty, percent of households with dependents under 18-years of age, percent of households receiving food stamps, percent of the population that is black, percent of the population with a bachelor's degree, and percent of the male population 15-24 years of age), every 100-unit increase in mean topsoil lead content was associated with a 1.05 (95\% CI: 1.03 , 1.08) increased risk for violent crime events. Additionally, after controlling for the aforementioned variables, every 100-unit increase in mean topsoil lead content was associated with an a $1.04(95 \% \mathrm{CI}: 1.01,1.07)$ times increase in the risk of aggravated assault, a $1.05(95 \% \mathrm{CI}: 1.007,1.10)$ times increase in the risk of robbery, a $1.12(95 \%$ CI: $1.04,1.23)$ times increase in the risk of forcible rape, and a 1.20 (95\% CI: $1.07,1.34)$ times increase in the risk of homicide. 
Results from the Spatial error models showed an inverse soil-lead concentration gradient from the urban-to-suburban environments (i.e. Study Area to Control Areas). For example, topsoil samples collected from the Study Area (i.e. urban center) had an approximate 8-fold increase in lead content compared to the referent Southeast Control Area, whose geometric center was 23.73 kilometers from the geometric center of the Study Area. Topsoil samples collected from the Northeast Control Area, whose geometric center was 12.79 kilometers from the geometric center of the Study Area, had an approximate 2-fold increase soil lead content compared to the referent Southeast Control Area. Finally, topsoil samples collected from the Southwest Control Area, whose geometric center was 19.20 kilometers from the geometric center of the Study Area, had an a non-significant 1.35 -fold increase in soil lead content compared to the referent Southeast Control Area (Tables 4 and 5 - Appendix A). This inverse soil-lead concentration gradient from the urban-to-suburban environments can be further evaluated by the interpolated mean topsoil lead levels per soil collection areas (Illustration 9). 
Illustration 9.

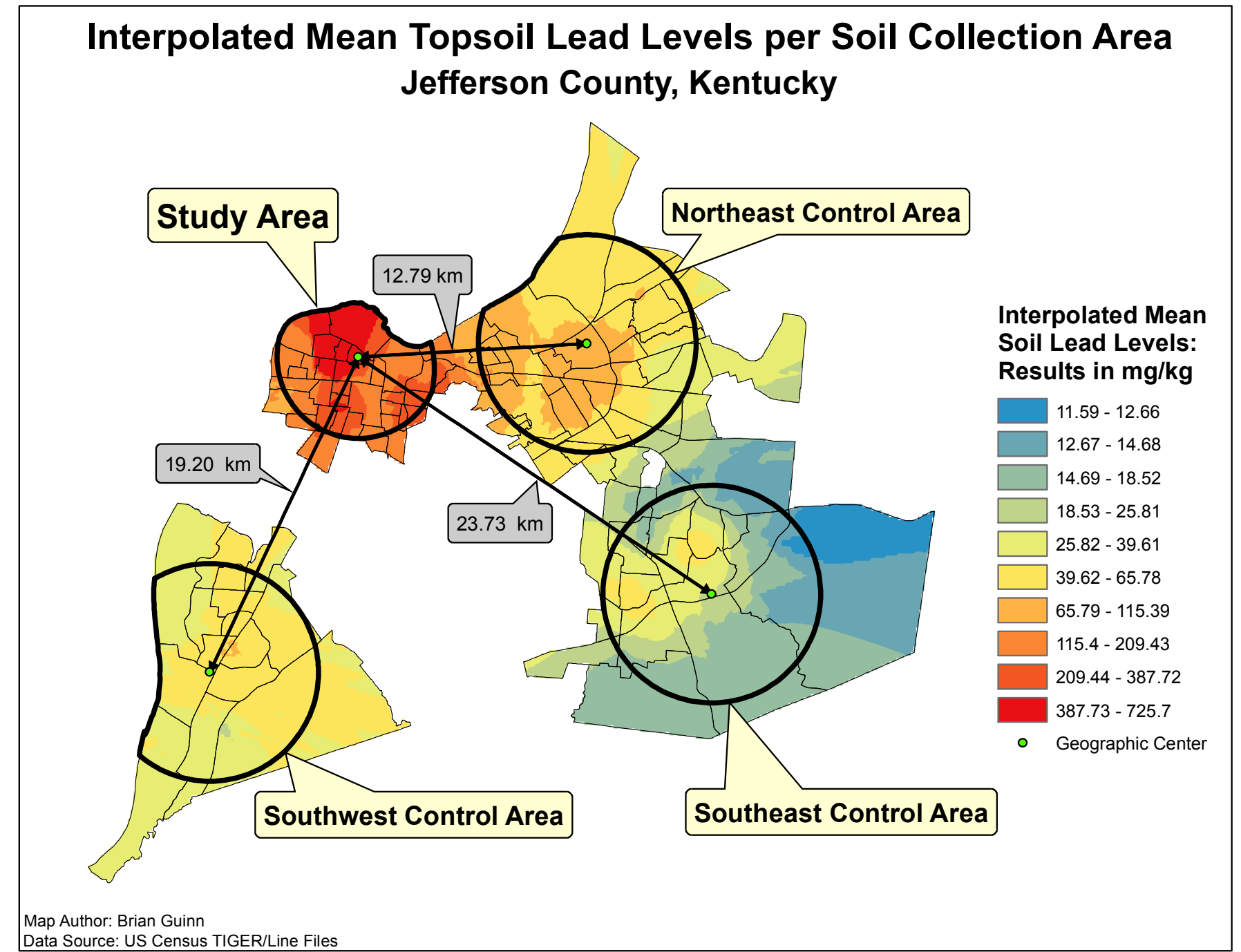




\section{DISCUSSION}

This ecological study further assessed the lead-crime hypothesis by evaluating the association between topsoil lead content and FBI designated violent crime. Specifically, the primary objective of this study was to assess whether there is a geospatial association between lead contaminated topsoil and the incidence of FBI designated violent crime in Jefferson County, KY. While this study produced numerous maps, and found statistically significant relationships between crime, topsoil lead content, and measures of socioeconomic deprivation, all results should be interpreted with caution. The ecological nature of this study merely provides evidence in support for continued research on the impact of environmental lead exposure and violent crime.

\section{The Distribution of Violent Crime in Jefferson County, Kentucky}

Specific Aim 1 was designed to evaluate the geospatial distribution of FBI designated violent crime in Jefferson County, KY. To do this, crime data was obtained from the Louisville Metro Police Department, then analyzed using ArcGIS and SaTScan's Poisson based Kulldorff spatial scan statistic. The highest risk area associated with each violent crime type overlapped substantially in the northwestern census tracts of Jefferson County. The shared geographic areas of highest risk for each violent crime type, designated the Study Area, was comprised of census tracts located in or around the commercial center of downtown Louisville, the county seat. The non-uniform distribution of FBI designated violent crime in Jefferson County is not unexpected given evidence 
from prior research which has shown that violent crime typically clusters in the urban center of a city $(245,252)$. Urban violence has been associated with demographic measures of socioeconomic deprivation, as well as the proportion of young males 15-24 years of age, the demographic most at-risk for perpetrating violence (253-255).

In Jefferson County, the top quantiles for census-tract-level measures of socioeconomic deprivation and violence, such as percent of households in poverty, percent female head of household, and percent young males 15-24 years of age, are predominantly located in the northwestern side of the county, many of which make up the census tracts of the Study Area (Illustrations 2-4 - Appendix B). Conversely, the top quantiles for census-tract-level measures of socioeconomic advantage, such as percent of the population with a bachelor's degree, and median household income, are predominantly located on the northeastern and southeastern side of the county, almost entirely outside of the Study Area (Illustrations 5 and 6 - Appendix B).

While there are likely many unknown reasons for the distribution of violence in Jefferson County, there appears to be a spatial correlation between areas of increased risk for violent crime and demographic measures of socioeconomic deprivation. The following subsections will further describe the statistical relationships between topsoil lead content, measures of socioeconomic deprivation, and the incidence of violent crime in Jefferson County, KY.

\section{The Distribution of Lead Contaminated Topsoil in Jefferson County, Kentucky}

Specific Aim 2 was designed to evaluate topsoil lead content between the Study Area, which had higher than expected rates of FBI designated violent crime, and the three 
Control Areas, which had low to expected rates of FBI designated violent crime, while controlling for spatial autocorrelation. Results from the spatial error models used to evaluate topsoil lead content between study collection areas, showed an inverse soil-lead concentration gradient from the urban-to-suburban environments (i.e. Study Area to Control Areas). This apparent concentration gradient of topsoil lead content from the Study Area to the Control Areas may be explained by the phenomenon of atmospheric lead diffusion from urban-to-suburban environments during the leaded gasoline era. Prior research has shown that the majority of leaded car exhaust fell within 10 meters of the roadway. However, smaller exhausted lead particles had the potential to travel on prevailing winds. The ability of smaller lead particles to be carried by wind explains the diffusion of atmospheric lead from densely populated urban environments to the less populated suburban environments $(196,197)$.

The apparent concentration gradient of topsoil lead content from the Study Area to the Control Areas may also be explained by the distribution of pre-1950 housing, a known risk factor for environmental lead exposure (191). In Jefferson County, there are 191 census tracts, 52 of which are in the top quantile for percent pre-1950 housing. The top quantile for percent pre-1950 housing in Jefferson County is defined as census tracts where more than 53 percent of housing units were constructed prior to 1950 (256). Of the 52 census tracts in the top quantile of pre-1950 housing, 25 (48\%) are located in the Study Area, 6 (12\%) in the Northeast control area, and the remaining $21(40 \%)$ are census tracts outside of our areas of collection. The Southwest and Southeast Control Areas had zero census tracts in the top quantile for pre-1950 housing (Table 6 - Appendix A). Out of 33 census tracts in the Study Area, 25 (75\%) have residential areas where more than 53 
percent of the housing units are at risk for lead contamination from remnant lead paint. This is in comparison to the Northeast Control Area where $6(15 \%)$ out of the 40 census tracts have residential areas where more than 53 percent of the housing units are at risk for lead contamination.

The urban-to-suburban concentration gradient in topsoil lead levels has been observed in numerous studies (237-239). The prevailing theory is that densely populated urban centers during the first half of the $20^{\text {th }}$ century consumed more leaded gasoline, and used more leaded paint, compared to less populated suburban environments (236). These phenomena, the atmospheric diffusion of leaded gasoline exhaust from the urban center, and the distribution of pre-1950 housing in Jefferson County, may explain why the urban Study Area and nearby Northeast Control Area had a respective 8.24-fold and a 2.43-fold increase in topsoil lead levels compared to the suburban referent Southeast Control Area.

This urban-to-suburban concentration gradient in topsoil lead levels may also explain the non-uniform distribution of FBI designated violent crime in Jefferson County. Review of the literature suggests that lead contaminated topsoil is a known risk factor for elevated blood lead levels, especially among the pediatric population (199). Madhavan and colleagues (1989) found that topsoil lead levels of $250 \mathrm{mg} / \mathrm{kg}$ could raise serum blood lead levels by $2 \mathrm{mcg} / \mathrm{dL}$ (257). A report by the CDC (1991) found that for every $1,000 \mathrm{mg} / \mathrm{kg}$ of topsoil lead, there is a rise in pediatric blood lead levels of $3-7 \mathrm{mcg} / \mathrm{dL}$ (258). Mielke and colleagues (2007) found that topsoil lead levels $\geq 1,200 \mathrm{mg} / \mathrm{kg}$ predicted a pediatric blood level of $8 \mathrm{mcg} / \mathrm{dL}(199)$.

The literature also suggests that elevated blood lead levels are associated with reductions in IQ, which has been previously shown to have an inverse relationship with 
criminality among all socioeconomic positions $(127,158)$. Miranda and colleagues (2007) found that blood lead levels as low as $2 \mathrm{mcg} / \mathrm{dL}$ could produce discernible reductions in academic performance $(127,182)$. These findings are supported by other studies which found statistically significant associations in IQ decrement and blood lead levels $<5 \mathrm{mcg} / \mathrm{dL}$. For example, Bellinger and colleagues (1992) found that over a range of $0-25 \mathrm{mcg} / \mathrm{dL}$, every $10 \mathrm{mcg} / \mathrm{dL}$ increase in blood lead at 24 months of age, resulted in a long-term 5.8 point reduction in the WISC-R Full-Scale IQ (259). Lanphear and colleagues (2000) found that for every $1 \mathrm{mcg} / \mathrm{dL}$ increase in blood lead level there was a 0.7-point reduction in average math scores, and a 1-point reduction in average reading scores as measured by the Wide Range Achievement Test - Revised (260). Results from Bellinger and colleagues (1992) and Lanphear and colleagues (2000), showed that the sharpest decline in IQ was associated with blood lead levels within the first $5-10 \mathrm{mcg} / \mathrm{dL}$, which suggests that mildly elevated blood levels are sufficient to reduce intelligence $(259,260)$.

Ttofi and colleagues (2016) published a meta-analysis of prospective longitudinal studies which found an inverse relationship between intelligence and criminality, even among high at-risk populations (127). Satterfield and colleagues (2007) found that IQ was protective against adult criminality among all socioeconomic positions (158). Wilson and Herrnstein (1985) and Hirschi and Hindelang (1977) found that the average difference in IQ between criminals and non-criminals was 8-10 points $(156,261)$. This estimated difference in IQ was also found between one-time criminal offenders and chronic criminal offenders (262). These findings suggest that intelligence has a protective effect against criminality. 
The published literature regarding lead contaminated topsoil, reduced IQ and subsequent violence raises concern regarding the magnitude of lead contamination in Jefferson County, specifically within the high crime Study Area. A total of 160 topsoil samples were taken from the Study Area (edge zones plus parks). Of these 160 samples, 36 (22.5\%) had topsoil lead levels $\geq 250 \mathrm{mg} / \mathrm{kg}$, a threshold which has been shown to raise blood lead levels $2 \mathrm{mcg} / \mathrm{dL}$ (257). Additionally, of 160 samples, 14 (8.75\%) had lead levels that exceeded $400 \mathrm{mg} / \mathrm{kg}$, the current EPA threshold for safety in play areas, and $3(1.8 \%$ ) of which were $\geq 1,000 \mathrm{mg} / \mathrm{kg}$ (maximum lead level of $4,000 \mathrm{mg} / \mathrm{kg}$ ) (Table 6) (179). If the prior research concerning the relationship between topsoil lead content, elevated blood lead levels, reduced IQ, and criminality is generalizable to Jefferson County, then the known topsoil lead burden in the Study Area is sufficient to produce elevated blood lead levels associated with a significant reduction in IQ, especially among the pediatric population in high lead contaminated environments.

Reduced IQ, as a risk factor for crime, provides a plausible link between environmental lead exposure and criminal offending. This, in turn, provides a plausible explanation for the geospatial association between topsoil lead content and the incidence of FBI designated violent crime in Jefferson County. The relationship between topsoil lead content and FBI designated violent crime in Jefferson County will be further explored in the following subsection. 


\section{The Statistical Associations of Topsoil Lead Content and Measures of}

Socioeconomic Deprivation on the Incidence of FBI Designated Violent Crime in Jefferson County, $K Y$

Specific Aim 3 was designed to evaluate whether topsoil lead content was independently associated with the incidence of FBI designated violent crime in Jefferson County, KY, while controlling for spatial autocorrelation and other covariates associated with socioeconomic deprivation and/or violence. This study found that the estimated mean topsoil lead content was independently associated with the incidence of violent crime in Jefferson County, KY. These results remained significant even after controlling for eight covariates of interest (i.e. percent of young males 15-24 years of age and the census-tract features index). These findings suggest that environmental lead exposure could be an important risk factor for subsequent criminality.

The results from this study are not entirely unexpected given prior research on the lead-crime hypothesis. Numerous studies have found positive associations between early life lead exposure and subsequent criminality (5-9). For example, Wright and colleagues (2008) found a dose-response relationship between early life lead exposure and adult criminality, after controlling for maternal IQ, sex, SES, and maternal education (203). Similarly, Boutwell and colleagues (2016) found that census tracts with the highest proportion of blood lead levels greater than $5 \mathrm{mcg} / \mathrm{dL}$ had an increased incidence of violent crime compared to census tracts with lower proportions of elevated blood lead levels, after controlling for census-tract-level measures of socioeconomic disadvantage (227). Additionally, Boutwell and colleagues (2017) found that a one percentage point increase in the proportion of children with blood lead levels greater than $5 \mathrm{mcg} / \mathrm{dL}$ per 
census tract was associated with a three percent increase in the risk for gun crime, aggravated assault, robbery, and homicide, after adjusting for census-tract-level measures of concentrated disadvantage (8).

The plausible mechanism behind the lead-crime hypothesis is lead's innate neurotoxic effects. Prior research has shown that pre-natal and early life lead exposure may disrupt brain organogenesis, leading to alterations of the serotonergic system, and an attenuation of the pre-frontal cortex $(10,11,204)$. Alterations of the serotonergic system and the pre-frontal cortex have been associated with conduct disorder, impulse inhibition, cognitive reappraisal, empathetic concern, moral decision making, and intelligence; all risk factors for violence $(48,51,204)$.

While there are likely many unknown risk factors for the distribution of violent crime in Jefferson County, results from this study found a spatial relationship between estimated mean topsoil lead content, demographic measures of socioeconomic deprivation, and the incidence of FBI designated violent crime. These results suggest that topsoil lead content may be an important pathway for early life lead exposure, an environmental exposure associated with subsequent violent behavior (5-9).

\section{Strengths and Limitations}

This study has several strengths worth mentioning. To the best of our knowledge, this is the only study that has evaluated the relationship between topsoil lead levels and the incidence of FBI designated crime. While the design of this study is ecological in nature, and therefore prohibits causal inferences about individuals, the underlying leadcrime hypothesis is underpinned by a litany of scientific evidence that has demonstrated 
the neurotoxic effects of lead $(10,11)$. Additionally, there is a growing body of epidemiological evidence that has found positive associations between early life lead exposure and subsequent violent behavior (5-9).

A second strength of this study includes the methods that were used for specifying the Study Area and the Control Areas. The LMPD - Crime Information Center was able to provide the exact latitude and longitude of every crime location in Jefferson County. The availability of this information enhanced the precision of crime cluster specification via the Kulldorff spatial scan statistic. This in turn allowed for larger control areas, which by default, were more socioeconomically heterogenous. Additionally, the use of the Kulldorff spatial scan statistic is a validated method for spatial-temporal cluster analysis.

A third strength of this study includes methods for topsoil selection and analysis. Randomization for sample locations among the edge zone and park topsoil collection sites was achieved by using the R sample function. This prohibited topsoil collection selection bias based upon a priori knowledge from the background investigation of pediatric serum lead levels procured from the Louisville Metro Department of Health and Wellness. Additionally, the use of the ESS Lock N' Load ${ }^{\mathrm{TM}}$ topsoil collection system produced depth and volumetric consistency between all 412 samples. Finally, topsoil lead content was evaluated by ICP-MS, a validated method for topsoil metallurgical analysis (232).

A fourth strength of this study includes the methods of statistical analyses. This study used spatial error modeling and Bayesian sparse spatial generalized linear mixed modeling (SGLMM), to evaluate topsoil lead content and crime, while controlling for spatial autocorrelation. The use of these models controlled for the inherent spatial 
dependency among the four topsoil collection areas, which improved regression inference compared to traditional modeling. Because the model results herein have adjusted for spatial autocorrelation, they are to some extent protected from type I error, a known statistical phenomenon when spatial autocorrelation is present but not methodologically controlled (263). Finally, the SGLMM utilized principal components analysis (PCA) to create a census-tract-features index, to simultaneously evaluate seven census-tract-level measures of socioeconomic deprivation, while controlling for multicollinearity (264).

The fifth and final strength of this study includes the agreement among the results. The results of this study used both actual and estimated mean topsoil lead levels per census tract. The relationship between topsoil lead content, whether actual or estimated, remained statistically significant across their respective models (Table 5 and 7). Subanalysis regarding the estimated mean topsoil lead content and each specific crime type, remained statistically significant even after adjusting for the census tract features index and percent of the male population 15-24 years of age (Table 8). The consistent agreement between models lends evidence in support for further research into the leadcrime hypothesis.

Although there are several strengths worth mentioning, this study was not without its limitations. The primary limitation of this study is its ecological design, which prohibits inferring a direct causal relationship between individual perpetrators of violence and their prior environmental lead exposure. The results of this study merely suggest a plausible relationship between topsoil lead content and the incidence of FBI designated violent crime. 
The second limitation of this study is that it only had access to the known crime events reported by the LMPD. While the LMPD crime dataset contained 21,097 individual crime events reported between 2012-2016, it is possible that some violent crimes were not reported to the police. For example, a report from the U.S. Department of Justice found that up to 65 percent of rapes and sexual assaults go unreported each year (265). Additionally, Sumner and colleagues (2015) estimated that 7 million cases of child maltreatment including forms of physical and sexual assault go unreported each year in the United States (266). If these findings are generalizable to Jefferson County, then the 'true' distribution of FBI designated violent crime may be different compared to the Kulldorff spatial scan statistics that were used to establish the Study and Control Areas for topsoil collection. While these unreported crimes will impact our estimates of the overall number and rate of crime events, the impact on our estimates of the relationship between crime rates and soil lead level will be determined by differences in the reporting rates across the census tracts. If the reporting rate is similar across all tracts (as would be expected for homicides), our estimates of lead level effects should be fairly accurate.

The third limitation of this study deals with the topsoil samples. While 412 topsoil samples were collected for this study, they may be a poor estimation of the actual lead burden in Jefferson County. For example, Jefferson County is approximately 1,030 square kilometers (267). The total actual area sampled from all 412 topsoil samples is less than one square meter. Another limitation of this study is that the edge zone soil samples might not represent the true environmental hazard from residential lead contaminated topsoil. This might be especially true among pre-1950 housing where 
contaminated topsoil from remnant lead paint may more closely approximate to play areas and/or entry ways, compared to edge zone lead contaminated topsoil.

The fourth limitation of this study is the lack of a sensitivity analysis concerning the modifiable areal unit problem (MAUP) as described by Openshaw (1984)(268). While all analyses conducted in this study were consistent at the census-tract-level, it is possible to aggregate data by a different areal unit. For example, census block groups or other grid-cell modeling could have been used in addition to census tracts (269). Although other areal units are available, census tracts were used throughout this study due to their ease of interpretation within county boundaries, shape consistency over time, and increased precision (i.e. smaller standard errors) relative to their composite census block groups $(270,271)$.

The fifth and final limitation of this study includes the absence of a Gini coefficient. While the SGLMM included a census tract features index which included the median household income as part of the adjustment for socioeconomic deprivation, this index did not directly control for the distribution of wealth, as evaluated by the Gini coefficient. Prior research has shown that the Gini coefficient may be a better predictor of violence and/or criminal behavior compared to poverty $(272,273)$.

\section{Conclusions}

Environmental lead exposure remains an important public health hazard. Lead contaminated topsoil along residential edge zones may be an under-appreciated environmental risk factor associated with violent behavior. This study utilized several statistical methods, including spatial error modeling, empirical Bayesian kriging, and 
SGLMM, to further evaluate the spatial association of lead contaminated topsoil and the incidence of FBI designated violent crime.

Findings from this study suggest that lead contaminated topsoil is spatially associated with the incidence of FBI designated violent crime in Jefferson County, KY. Results from this study found an approximate 8-fold increase in topsoil lead levels from the high crime Study Area, to the low to expected crime rate referent Control Area. After controlling for eight covariates of interest, topsoil lead content remained a statistically significant predictor of violent crime. The spatial association of topsoil lead content and violent crime, along with the plausible biological mechanisms that underpin the leadcrime hypothesis, suggests that lead contaminated topsoil may be an important early life risk factor for violent behavior. Future studies should assess the spatial association between residential drip line topsoil lead content and/or elevated pediatric blood lead levels to the incidence of FBI designated violent crime. 


\section{REFERENCES}

1. Investigation FBo. Uniform Crime Report - Crime in the United States, 2016 Violent Crime. In: Justice USDo, editor. 2016. p. 1-2.

2. United States Congress H. Statistical Abstract of the United States. 1975. 96th annual edition. Washington, DC: [s.n.]; 1975. Available from:

http://docs.newsbank.com/select/serialset/12AC91585F82D560.html.

3. UCR - Data Driven, Customizable Access to Official UCR Statistics [Internet]. Federal Bureau of Investigation 2018 [cited March 13, 2018]. Available from: https://www.ucrdatatool.gov/Search/Crime/State/RunCrimeOneYearofData.cfm.

4. Reyes JW. ENVIRONMENTAL POLICY AS SOCIAL POLICY? THE IMPACT OF CHILDHOOD LEAD EXPOSURE ON CRIME. Working paper series. 2007(13097):ALL.

5. Needleman HL, Riess JA, Tobin MJ, Biesecker GE, Greenhouse JB. Bone lead levels and delinquent behavior. Jama. 1996;275(5):363-9.

6. Stretesky PB, Lynch MJ. The relationship between lead exposure and homicide. Archives of pediatrics \& adolescent medicine. 2001;155(5):579-82.

7. Mielke $\mathrm{HW}$, Zahran $\mathrm{S}$. The urban rise and fall of air lead $(\mathrm{Pb})$ and the latent surge and retreat of societal violence. Environment international. 2012;43:48-55.

8. Boutwell BB, Nelson EJ, Qian Z, Vaughn MG, Wright JP, Beaver KM, et al. Aggregate-level lead exposure, gun violence, homicide, and rape. PloS one. 2017;12(11):e0187953.

9. Pihl RO, Ervin F. Lead and cadmium levels in violent criminals. Psychological reports. 1990;66(3 Pt 1):839-44.

10. Sanders T, Liu Y, Buchner V, Tchounwou PB. Neurotoxic effects and biomarkers of lead exposure: a review. Reviews on environmental health. 2009;24(1):15-45.

11. Mason LH, Harp JP, Han DY. Pb neurotoxicity: neuropsychological effects of lead toxicity. BioMed research international. 2014;2014:840547.

12. Cameron CD, Reber J, Spring VL, Tranel D. Damage to the ventromedial prefrontal cortex is associated with impairments in both spontaneous and deliberative moral judgments. Neuropsychologia. 2018;111:261-8 
13. Raine A, Lencz T, Bihrle S, LaCasse L, Colletti P. Reduced prefrontal gray matter volume and reduced autonomic activity in antisocial personality disorder. Archives of general psychiatry. 2000;57(2):119-27; discussion 28-9.

14. Zarka YC. The foundations of natural law. British journal for the history of philosophy : BJHP : the journal of the British Society for the History of Philosophy. 1999;7(1):15-32.

15. Fehr E, Gachter S. Altruistic punishment in humans. Nature. 2002;415(6868):137-40.

16. DeScioli P, Kurzban R. Mysteries of morality. Cognition. 2009;112(2):281-99.

17. Hoebel EA. The law of primitive man; a study in comparative legal dynamics. Cambridge,: Harvard University Press; 1954. viii, 357 p. p.

18. Sellin JT, Wolfgang ME. The measurement of delinquency. New York,: Wiley; 1964. x, 423 p. p.

19. Akman DD, Normandeau A, Turner S. The Measurement of Delinquency in Canada. The Journal of Criminal Law, Criminology, and Police Science. 1967;58(3):330-7.

20. Velez-Diaz A, Megargee EI. An Investigation of Differences in Value Judgments between Youthful Offenders and Non-Offenders in Puerto Rico. The Journal of Criminal Law, Criminology, and Police Science. 1970;61(4):549-53.

21. Wellford CF, Wiatrowski M. On the Measurement of Delinquency. The Journal of Criminal Law and Criminology (1973-). 1975;66(2):175-88.

22. Wolfgang ME. Uniform Crime Reports: A Critical Appraisal. University of Pennsylvania Law Review. 1963;111(6):708-38.

23. Hoover JE, United States Bureau of I, United States. Department of Justice. Division of I. Uniform crime reports for the United States1930. Available from: http://purl.access.gpo.gov/GPO/LPS3082.

24. Carnis L. PITFALLS OF THE CLASSICAL SCHOOL OF CRIME. Quarterly Journal of Austrian Economics. 2004;7(4):7-17.

25. Pratt TC, Lowenkamp CT. Conflict Theory, Economic Conditions, and Homicide:A Time-Series Analysis. Homicide Studies. 2002;6(1):61-83.

26. Rafter N. THE UNREPENTANT HORSE-SLASHER: MORAL INSANITY AND THE ORIGINS OF CRIMINOLOGICAL THOUGHT*. Criminology. 2004;42(4):979-1008. 
27. Sathyanarayana Rao TS. Psychiatrist and the science of criminology:

Sociological, psychological and psychiatric analysis of the dark side. Indian journal of psychiatry. 2007;49(1):3-5.

28. Mazzarello P. Cesare Lombroso: an anthropologist between evolution and degeneration. Functional neurology. 2011;26(2):97-101.

29. Newman G, Marongiu P. PENOLOGICAL REFORM AND THE MYTH OF BECCARIA *. Criminology. 1990;28(2):325-46.

30. Lens KME, van Doorn J, Pemberton A, Lahlah E, Bogaerts S. One rule for the goose, one for the gander? Wrongfulness and harmfulness in determining reactions to offenders and victims of crime. European journal of criminology. 2017;14(2):183-99.

31. Ferrajoli L. Two hundred and fifty years since the publication of On Crimes and Punishments: The currency of Cesare Beccaria's thought. Punishment \& Society. 2014;16(5):501-19.

32. Phillipson C. Three criminal law reformers : Beccaria, Bentham, Romilly. London :: J.M. Dent \& Sons; 1923.

33. Eisenstein EL, Lessing J. Rosenwald Reference Collection (Library of Congress). The printing press as an agent of change : communications and cultural transformations in early modern Europe. Cambridge Eng. ; New York: Cambridge University Press; 1979.

34. Fitzgerald CS. Historical Theories of Crime and Delinquency. Journal of Human Behavior in the Social Environment. 2011;21(3):297-311.

35. Berrios GE. J.C. Prichard and the concept of "moral insanity". Classic text no.37. History of psychiatry. 1999;10(37):111-26.

36. Hare RD, Hart SD, Harpur TJ. Psychopathy and the DSM-IV criteria for antisocial personality disorder. Journal of abnormal psychology. 1991;100(3):391-8.

37. Augstein HF. J C Prichard's concept of moral insanity--a medical theory of the corruption of human nature. Medical history. 1996;40(3):311-43.

38. Gatti U, Verde A. Cesare Lombroso: Methodological ambiguities and brilliant intuitions. International journal of law and psychiatry. 2012;35(1):19-26.

39. Lombroso-Ferrero G, Lombroso C. Criminal man, according to the classification of Cesare Lombroso. Montclair, N.J.,: Patterson Smith; 1972. xxxvii, 322 p. p.

40. Munthe C, Radovic S. The Return of Lombroso? Ethical Aspects of (Visions of) Preventive Forensic Screening. Public health ethics. 2015;8(3):270-83. 
41. Bulmer M. The Chicago school of sociology : institutionalization, diversity, and the rise of sociological research. Chicago: University of Chicago Press; 1984. xix, 285 p. p.

42. Owens BR. Mapping the City: Innovation and Continuity in the Chicago School of Sociology, 1920-1934. The American Sociologist. 2012;43(3):264-93.

43. Shaw CR, McKay HD. Juvenile delinquency and urban areas, a study of rates of delinquents in relation to differential characteristics of local communities in American cities. Chicago, Ill.,: The University of Chicago Press; 1942. xxxii, 451 p. incl. tables, diagrs. p.

44. Bursik RJ. SOCIAL DISORGANIZATION AND THEORIES OF CRIME AND DELINQUENCY: PROBLEMS AND PROSPECTS*. Criminology. 1988;26(4):519-52.

45. Boutwell BB, Barnes JC, Beaver KM, Haynes RD, Nedelec JL, Gibson CL. A unified crime theory: The evolutionary taxonomy. Aggression and Violent Behavior. 2015;25:343-53.

46. Bernet W, Vnencak-Jones CL, Farahany N, Montgomery SA. Bad nature, bad nurture, and testimony regarding MAOA and SLC6A4 genotyping at murder trials. Journal of forensic sciences. 2007;52(6):1362-71.

47. Raine A. The anatomy of violence : the biological roots of crime. First edition. ed. New York: Pantheon Books; 2013. xv, 478 pages, four unnumbered pages of plates $\mathrm{p}$.

48. Rylands AJ, Hinz R, Jones M, Holmes SE, Feldmann M, Brown G, et al. Pre- and postsynaptic serotonergic differences in males with extreme levels of impulsive aggression without callous unemotional traits: a positron emission tomography study using (11)C-DASB and (11)C-MDL100907. Biological psychiatry. 2012;72(12):1004-11.

49. Ficks CA, Waldman ID. Candidate genes for aggression and antisocial behavior: a meta-analysis of association studies of the 5HTTLPR and MAOA-uVNTR. Behavior genetics. 2014;44(5):427-44.

50. Rosell DR, Thompson JL, Slifstein M, Xu X, Frankle WG, New AS, et al. Increased serotonin $2 \mathrm{~A}$ receptor availability in the orbitofrontal cortex of physically aggressive personality disordered patients. Biological psychiatry. 2010;67(12):1154-62.

51. Reif A, Rosler M, Freitag CM, Schneider M, Eujen A, Kissling C, et al. Nature and nurture predispose to violent behavior: serotonergic genes and adverse childhood environment. Neuropsychopharmacology : official publication of the American College of Neuropsychopharmacology. 2007;32(11):2375-83. 
52. Rosell DR, Siever LJ. The neurobiology of aggression and violence. CNS spectrums. 2015;20(3):254-79.

53. Cases O, Seif I, Grimsby J, Gaspar P, Chen K, Pournin S, et al. Aggressive behavior and altered amounts of brain serotonin and norepinephrine in mice lacking MAOA. Science (New York, NY). 1995;268(5218):1763-6.

54. Yu Q, Teixeira CM, Mahadevia D, Huang Y, Balsam D, Mann JJ, et al. Dopamine and serotonin signaling during two sensitive developmental periods differentially impact adult aggressive and affective behaviors in mice. Molecular psychiatry. 2014;19(6):688-98.

55. Liu Z, Huang L, Luo XJ, Wu L, Li M. MAOA Variants and Genetic Susceptibility to Major Psychiatric Disorders. Molecular neurobiology. 2016;53(7):4319-27.

56. Brunner HG, Nelen M, Breakefield XO, Ropers HH, van Oost BA. Abnormal behavior associated with a point mutation in the structural gene for monoamine oxidase A. Science (New York, NY). 1993;262(5133):578-80.

57. Scott AL, Bortolato M, Chen K, Shih JC. Novel monoamine oxidase A knock out mice with human-like spontaneous mutation. Neuroreport. 2008;19(7):739-43.

58. Manuck SB, Flory JD, Ferrell RE, Mann JJ, Muldoon MF. A regulatory polymorphism of the monoamine oxidase-A gene may be associated with variability in aggression, impulsivity, and central nervous system serotonergic responsivity. Psychiatry research. 2000;95(1):9-23.

59. Kuepper Y, Grant P, Wielpuetz C, Hennig J. MAOA-uVNTR genotype predicts interindividual differences in experimental aggressiveness as a function of the degree of provocation. Behavioural brain research. 2013;247:73-8.

60. Stetler DA, Davis C, Leavitt K, Schriger I, Benson K, Bhakta S, et al. Association of low-activity MAOA allelic variants with violent crime in incarcerated offenders. Journal of psychiatric research. 2014;58:69-75.

61. Wensley D, King M. Scientific responsibility for the dissemination and interpretation of genetic research: lessons from the "warrior gene" controversy. Journal of medical ethics. 2008;34(6):507-9.

62. Heils A, Teufel A, Petri S, Stober G, Riederer P, Bengel D, et al. Allelic variation of human serotonin transporter gene expression. Journal of neurochemistry. 1996;66(6):2621-4.

63. Hallikainen T, Saito T, Lachman HM, Volavka J, Pohjalainen T, Ryynanen OP, et al. Association between low activity serotonin transporter promoter genotype and early onset alcoholism with habitual impulsive violent behavior. Molecular psychiatry. 1999;4(4):385-8. 
64. Retz W, Retz-Junginger P, Supprian T, Thome J, Rosler M. Association of serotonin transporter promoter gene polymorphism with violence: relation with personality disorders, impulsivity, and childhood ADHD psychopathology. Behavioral sciences \& the law. 2004;22(3):415-25.

65. Haberstick BC, Smolen A, Hewitt JK. Family-based association test of the 5HTTLPR and aggressive behavior in a general population sample of children. Biological psychiatry. 2006;59(9):836-43.

66. Beitchman JH, Baldassarra L, Mik H, De Luca V, King N, Bender D, et al. Serotonin transporter polymorphisms and persistent, pervasive childhood aggression. The American journal of psychiatry. 2006;163(6):1103-5.

67. Foley DL, Eaves LJ, Wormley B, Silberg JL, Maes HH, Kuhn J, et al. Childhood adversity, monoamine oxidase a genotype, and risk for conduct disorder. Archives of general psychiatry. 2004;61(7):738-44.

68. Haberstick BC, Lessem JM, Hopfer CJ, Smolen A, Ehringer MA, Timberlake D, et al. Monoamine oxidase A (MAOA) and antisocial behaviors in the presence of childhood and adolescent maltreatment. American journal of medical genetics Part B, Neuropsychiatric genetics : the official publication of the International Society of Psychiatric Genetics. 2005;135b(1):59-64.

69. Sadeh N, Javdani S, Jackson JJ, Reynolds EK, Potenza MN, Gelernter J, et al. Serotonin transporter gene associations with psychopathic traits in youth vary as a function of socioeconomic resources. Journal of abnormal psychology. 2010;119(3):604-9.

70. Aslund C, Comasco E, Nordquist N, Leppert J, Oreland L, Nilsson KW. Selfreported family socioeconomic status, the 5-HTTLPR genotype, and delinquent behavior in a community-based adolescent population. Aggressive behavior. 2013;39(1):52-63.

71. Tielbeek JJ, Karlsson Linner R, Beers K, Posthuma D, Popma A, Polderman TJ. Meta-analysis of the serotonin transporter promoter variant (5-HTTLPR) in relation to adverse environment and antisocial behavior. American journal of medical genetics Part B, Neuropsychiatric genetics : the official publication of the International Society of Psychiatric Genetics. 2016;171(5):748-60.

72. Rogers JC, De Brito SA. Cortical and Subcortical Gray Matter Volume in Youths With Conduct Problems: A Meta-analysis. JAMA psychiatry. 2016;73(1):64-72.

73. Shamay-Tsoory SG, Harari H, Aharon-Peretz J, Levkovitz Y. The role of the orbitofrontal cortex in affective theory of mind deficits in criminal offenders with psychopathic tendencies. Cortex; a journal devoted to the study of the nervous system and behavior. 2010;46(5):668-77. 
74. Shamay-Tsoory SG, Tomer R, Berger BD, Aharon-Peretz J. Characterization of empathy deficits following prefrontal brain damage: the role of the right ventromedial prefrontal cortex. Journal of cognitive neuroscience. 2003;15(3):324-37.

75. Brower MC, Price BH. Neuropsychiatry of frontal lobe dysfunction in violent and criminal behaviour: a critical review. Journal of neurology, neurosurgery, and psychiatry. 2001;71(6):720-6.

76. Bufkin JL, Luttrell VR. Neuroimaging studies of aggressive and violent behavior: current findings and implications for criminology and criminal justice. Trauma, violence \& abuse. 2005;6(2):176-91.

77. Siddiqui SV, Chatterjee U, Kumar D, Siddiqui A, Goyal N. Neuropsychology of prefrontal cortex. Indian journal of psychiatry. 2008;50(3):202-8.

78. Moll J, de Oliveira-Souza R, Bramati IE, Grafman J. Functional networks in emotional moral and nonmoral social judgments. NeuroImage. 2002;16(3 Pt 1):696-703.

79. Solbakk AK, Lovstad M. Effects of focal prefrontal cortex lesions on electrophysiological indices of executive attention and action control. Scandinavian journal of psychology. 2014;55(3):233-43.

80. Kral TRA, Solis E, Mumford JA, Schuyler BS, Flook L, Rifken K, et al. Neural correlates of empathic accuracy in adolescence. Social cognitive and affective neuroscience. 2017;12(11):1701-10.

81. Winter K, Spengler S, Bermpohl F, Singer T, Kanske P. Social cognition in aggressive offenders: Impaired empathy, but intact theory of mind. Scientific reports. 2017;7(1):670.

82. Bao P, Jing J, Yang WH, Li XH, Cai YS. Violence-related behaviors among adolescents and its association with cognitive emotion regulation strategies. World journal of pediatrics : WJP. 2016;12(1):82-7.

83. Heekeren HR, Wartenburger I, Schmidt H, Schwintowski HP, Villringer A. An fMRI study of simple ethical decision-making. Neuroreport. 2003;14(9):1215-9.

84. Guidotti TL. Phineas Gage and his frontal lobe-the "American Crowbar Case". Archives of environmental \& occupational health. 2012;67(4):249-50.

85. Volkow ND, Tancredi L. Neural substrates of violent behaviour. A preliminary study with positron emission tomography. The British journal of psychiatry : the journal of mental science. 1987;151:668-73.

86. Raine A, Buchsbaum M, LaCasse L. Brain abnormalities in murderers indicated by positron emission tomography. Biological psychiatry. 1997;42(6):495-508. 
87. Weiger WA, Bear DM. An approach to the neurology of aggression. Journal of psychiatric research. 1988;22(2):85-98.

88. Damasio H, Grabowski T, Frank R, Galaburda AM, Damasio AR. The return of Phineas Gage: clues about the brain from the skull of a famous patient. Science (New York, NY). 1994;264(5162):1102-5.

89. Camprodon JA, Stern TA. Selecting neuroimaging techniques: a review for the clinician. The primary care companion for CNS disorders. 2013;15(4).

90. Yang Y, Raine A. Prefrontal structural and functional brain imaging findings in antisocial, violent, and psychopathic individuals: a meta-analysis. Psychiatry research. 2009;174(2):81-8.

91. Amen DG, Stubblefield M, Carmicheal B, Thisted R. Brain SPECT findings and aggressiveness. Annals of clinical psychiatry : official journal of the American Academy of Clinical Psychiatrists. 1996;8(3):129-37.

92. House TH, Milligan WL. Autonomic responses to modeled distress in prison psychopaths. Journal of personality and social psychology. 1976;34(4):556-60.

93. Cohn MD, Popma A, van den Brink W, Pape LE, Kindt M, van Domburgh L, et al. Fear conditioning, persistence of disruptive behavior and psychopathic traits: an fMRI study. Translational psychiatry. 2013;3:e319.

94. Valois RF, Zullig KJ, Revels AA. Aggressive and Violent Behavior and Emotional Self-Efficacy: Is There a Relationship for Adolescents? The Journal of school health. 2017;87(4):269-77.

95. Cutuli D. Cognitive reappraisal and expressive suppression strategies role in the emotion regulation: an overview on their modulatory effects and neural correlates. Frontiers in systems neuroscience. 2014;8:175.

96. Ochsner KN, Bunge SA, Gross JJ, Gabrieli JD. Rethinking feelings: an FMRI study of the cognitive regulation of emotion. Journal of cognitive neuroscience. 2002;14(8):1215-29.

97. Vanderhasselt MA, Baeken C, Van Schuerbeek P, Luypaert R, De Raedt R. Interindividual differences in the habitual use of cognitive reappraisal and expressive suppression are associated with variations in prefrontal cognitive control for emotional information: an event related fMRI study. Biological psychology. 2013;92(3):433-9.

98. Riess H. The Science of Empathy. Journal of patient experience. 2017;4(2):74-7.

99. Seidel EM, Pfabigan DM, Keckeis K, Wucherer AM, Jahn T, Lamm C, et al. Empathic competencies in violent offenders. Psychiatry research. 2013;210(3):1168-75. 
100. Baez S, Morales JP, Slachevsky A, Torralva T, Matus C, Manes F, et al. Orbitofrontal and limbic signatures of empathic concern and intentional harm in the behavioral variant frontotemporal dementia. Cortex; a journal devoted to the study of the nervous system and behavior. 2016;75:20-32.

101. Pera-Guardiola V, Contreras-Rodriguez O, Batalla I, Kosson D, Menchon JM, Pifarre J, et al. Brain Structural Correlates of Emotion Recognition in Psychopaths. PloS one. 2016;11(5):e0149807.

102. Dominguez DJ, van Nunspeet F, Gupta A, Eres R, Louis WR, Decety J, et al. Lateral orbitofrontal cortex activity is modulated by group membership in situations of justified and unjustified violence. Social neuroscience. 2017:1-17.

103. Fabian JM. Neuropsychological and neurological correlates in violent and homicidal offenders: A legal and neuroscience perspective. AGGRESSION AND VIOLENT BEHAVIOR. 2010;15(3):209-23.

104. Seo D, Lacadie CM, Sinha R. Neural Correlates and Connectivity Underlying Stress-Related Impulse Control Difficulties in Alcoholism. Alcoholism, clinical and experimental research. 2016;40(9):1884-94.

105. Thompson BL, Levitt P, Stanwood GD. Prenatal exposure to drugs: effects on brain development and implications for policy and education. Nature reviews Neuroscience. 2009;10(4):303-12.

106. Scott-Goodwin AC, Puerto M, Moreno I. Toxic effects of prenatal exposure to alcohol, tobacco and other drugs. Reproductive toxicology (Elmsford, NY). 2016;61:120-30.

107. de Zeeuw P, Zwart F, Schrama R, van Engeland H, Durston S. Prenatal exposure to cigarette smoke or alcohol and cerebellum volume in attentiondeficit/hyperactivity disorder and typical development. Translational psychiatry. 2012;2:e84.

108. National Institutes of H. Fetal alcohol spectrum disorders. [Bethesda, Md.] :: National Institutes of Health, Dept. of Health and Human Services; 2007. Available from: http://purl.access.gpo.gov/GPO/LPS107889.

109. Salmasi G, Grady R, Jones J, McDonald SD. Environmental tobacco smoke exposure and perinatal outcomes: a systematic review and meta-analyses. Acta obstetricia et gynecologica Scandinavica. 2010;89(4):423-41.

110. Ferrante G, Antona R, Malizia V, Montalbano L, Corsello G, La Grutta S. Smoke exposure as a risk factor for asthma in childhood: a review of current evidence. Allergy and asthma proceedings. 2014;35(6):454-61. 
111. Nomura Y, Marks DJ, Halperin JM. Prenatal exposure to maternal and paternal smoking on attention deficit hyperactivity disorders symptoms and diagnosis in offspring. J Nerv Ment Dis. 2010;198(9):672-8.

112. Cornelius MD, De Genna NM, Leech SL, Willford JA, Goldschmidt L, Day NL. Effects of prenatal cigarette smoke exposure on neurobehavioral outcomes in 10year-old children of adolescent mothers. Neurotoxicology and teratology. 2011;33(1):137-44.

113. Cornelius MD, Goldschmidt L, De Genna NM, Larkby C. Long-term effects of prenatal cigarette smoke exposure on behavior dysregulation among 14-year-old offspring of teenage mothers. Maternal and child health journal. 2012;16(3):694705 .

114. Toro R, Leonard G, Lerner JV, Lerner RM, Perron M, Pike GB, et al. Prenatal exposure to maternal cigarette smoking and the adolescent cerebral cortex. Neuropsychopharmacology : official publication of the American College of Neuropsychopharmacology. 2008;33(5):1019-27.

115. Coles C. Critical Periods for Prenatal Alcohol Exposure: Evidence From Animal and Human Studies. ALCOHOL HEALTH AND RESEARCH WORLD. 1994;18(1):22.

116. Zhu Y, Wang L, Yin F, Yu Y, Wang Y, Shepard MJ, et al. Probing impaired neurogenesis in human brain organoids exposed to alcohol. Integrative biology : quantitative biosciences from nano to macro. 2017;9(12):968-78.

117. Tobena A. The wicked in court: a neuroscientific primer. Annals of the New York Academy of Sciences. 2013;1299:1-10.

118. Ornoy A, Ergaz Z. Alcohol abuse in pregnant women: effects on the fetus and newborn, mode of action and maternal treatment. International journal of environmental research and public health. 2010;7(2):364-79.

119. Mattson SN, Schoenfeld AM, Riley EP. Teratogenic effects of alcohol on brain and behavior. Alcohol research \& health : the journal of the National Institute on Alcohol Abuse and Alcoholism. 2001;25(3):185-91.

120. National Institute on Alcohol A, Alcoholism. Alcohol metabolism : an update. Rockville, MD :: National Institute on Alcohol Abuse and Alcoholism Publications Distribution Center; 2007. Available from: HTML version http://pubs.niaaa.nih.gov/publications/AA72/AA72.htm PDF version http://pubs.niaaa.nih.gov/publications/AA72/AA72.pdf.

121. Cederbaum AI. Alcohol metabolism. Clinics in liver disease. 2012;16(4):667-85. 
122. Gemma S, Vichi S, Testai E. Metabolic and genetic factors contributing to alcohol induced effects and fetal alcohol syndrome. Neuroscience and biobehavioral reviews. 2007;31(2):221-9.

123. Sari Y, Zhou FC. Prenatal alcohol exposure causes long-term serotonin neuron deficit in mice. Alcoholism, clinical and experimental research. 2004;28(6):941-8.

124. Donald KA, Eastman E, Howells FM, Adnams C, Riley EP, Woods RP, et al. Neuroimaging effects of prenatal alcohol exposure on the developing human brain: a magnetic resonance imaging review. Acta neuropsychiatrica. 2015;27(5):251-69.

125. Fast DK, Conry J, Loock CA. Identifying fetal alcohol syndrome among youth in the criminal justice system. Journal of developmental and behavioral pediatrics : JDBP. 1999;20(5):370-2.

126. Streissguth AP, Bookstein FL, Barr HM, Sampson PD, O'Malley K, Young JK. Risk factors for adverse life outcomes in fetal alcohol syndrome and fetal alcohol effects. Journal of developmental and behavioral pediatrics : JDBP. 2004;25(4):228-38.

127. Ttofi MM, Farrington DP, Piquero AR, Lösel F, DeLisi M, Murray J. Intelligence as a protective factor against offending: A meta-analytic review of prospective longitudinal studies. Journal of Criminal Justice. 2016;45:4-18.

128. Popova S, Lange S, Bekmuradov D, Mihic A, Rehm J. Fetal alcohol spectrum disorder prevalence estimates in correctional systems: a systematic literature review. Canadian journal of public health $=$ Revue canadienne de sante publique. 2011;102(5):336-40.

129. Anblagan D, Jones NW, Costigan C, Parker AJ, Allcock K, Aleong R, et al. Maternal smoking during pregnancy and fetal organ growth: a magnetic resonance imaging study. PloS one. 2013;8(7):e67223.

130. Pauly JR, Slotkin TA. Maternal tobacco smoking, nicotine replacement and neurobehavioural development. Acta paediatrica (Oslo, Norway : 1992). 2008;97(10):1331-7.

131. Blood-Siegfried J, Rende EK. The long-term effects of prenatal nicotine exposure on neurologic development. Journal of midwifery \& women's health. 2010;55(2):143-52.

132. Zhu Y, Li Z, Pang Y, Huo W, Li N, Li Z, et al. Association Between Chronic Exposure to Tobacco Smoke and Accumulation of Toxic Metals in Hair Among Pregnant Women. Biological trace element research. 2018. 
133. Piade JJ, Jaccard G, Dolka C, Belushkin M, Wajrock S. Differences in cadmium transfer from tobacco to cigarette smoke, compared to arsenic or lead. Toxicology reports. 2015;2:12-26.

134. Gundacker C, Hengstschlager M. The role of the placenta in fetal exposure to heavy metals. Wiener medizinische Wochenschrift (1946). 2012;162(9-10):201-6.

135. Jedrychowski W, Perera FP, Jankowski J, Mrozek-Budzyn D, Mroz E, Flak E, et al. Very low prenatal exposure to lead and mental development of children in infancy and early childhood: Krakow prospective cohort study. Neuroepidemiology. 2009;32(4):270-8.

136. Pascual L, Rodrigues P, Gallardo-Pujol D. How does morality work in the brain? A functional and structural perspective of moral behavior. Frontiers in integrative neuroscience. 2013;7:65.

137. Weitzman M, Gortmaker S, Sobol A. Maternal smoking and behavior problems of children. Pediatrics. 1992;90(3):342-9.

138. Fergusson DM, Horwood LJ, Lynskey MT. Maternal smoking before and after pregnancy: effects on behavioral outcomes in middle childhood. Pediatrics. 1993;92(6):815-22.

139. Wakschlag LS, Lahey BB, Loeber R, Green SM, Gordon RA, Leventhal BL. Maternal smoking during pregnancy and the risk of conduct disorder in boys. Archives of general psychiatry. 1997;54(7):670-6.

140. Palmstierna T. [Personality disorders, violence and criminal behaviour]. Lakartidningen. 2016;113.

141. Black DW. The Natural History of Antisocial Personality Disorder. Canadian journal of psychiatry Revue canadienne de psychiatrie. 2015;60(7):309-14.

142. Brennan PA, Grekin ER, Mednick SA. Maternal smoking during pregnancy and adult male criminal outcomes. Archives of general psychiatry. 1999;56(3):215-9.

143. Pratt TC, McGloin JM, Fearn NE. Maternal cigarette smoking during pregnancy and criminal/deviant behavior: a meta-analysis. International journal of offender therapy and comparative criminology. 2006;50(6):672-90.

144. Zhou S, Rosenthal DG, Sherman S, Zelikoff J, Gordon T, Weitzman M. Physical, behavioral, and cognitive effects of prenatal tobacco and postnatal secondhand smoke exposure. Current problems in pediatric and adolescent health care. 2014;44(8):219-41.

145. Braveman P, Gottlieb L. The social determinants of health: it's time to consider the causes of the causes. Public health reports (Washington, DC : 1974). 2014;129 Suppl 2:19-31. 
146. McEwen BS. Effects of stress on the developing brain. Cerebrum : the Dana forum on brain science. 2011;2011:14.

147. Lupien SJ, Juster RP, Raymond C, Marin MF. The effects of chronic stress on the human brain: From neurotoxicity, to vulnerability, to opportunity. Frontiers in neuroendocrinology. 2018.

148. Cote SM, Vaillancourt T, LeBlanc JC, Nagin DS, Tremblay RE. The development of physical aggression from toddlerhood to pre-adolescence: a nation wide longitudinal study of Canadian children. Journal of abnormal child psychology. 2006;34(1):71-85.

149. Wallinius M, Delfin C, Billstedt E, Nilsson T, Anckarsater H, Hofvander B. Offenders in emerging adulthood: School maladjustment, childhood adversities, and prediction of aggressive antisocial behaviors. Law and human behavior. 2016;40(5):551-63.

150. Afifi TO, Mota N, Sareen J, MacMillan HL. The relationships between harsh physical punishment and child maltreatment in childhood and intimate partner violence in adulthood. BMC public health. 2017;17(1):493.

151. Cicciola E, Foschi R, Lombardo GP. Making up intelligence scales: De Sanctis's and Binet's tests, 1905 and after. History of psychology. 2014;17(3):223-36.

152. Teive HAG, Teive GMG, Dallabrida N, Gutierrez L. Alfred Binet: Charcot's pupil, a neuropsychologist and a pioneer in intelligence testing. Arquivos de neuro-psiquiatria. 2017;75(9):673-5.

153. Strenze T. Intelligence and socioeconomic success: A meta-analytic review of longitudinal research. Intelligence. 2007;35(5):401-26.

154. Deary IJ, Strand S, Smith P, Fernandes C. Intelligence and educational achievement. Intelligence. 2007;35(1):13-21.

155. Hirschi T, Hindelang MJ. Intelligence and delinquency: a revisionist review. American sociological review. 1977;42(4):571-87.

156. Wilson JQ, Herrnstein RJ. Crime and human nature. New York: Simon and Schuster; 1985. 639 p. p.

157. Koolhof R, Loeber R, Wei EH, Pardini D, D'Escury AC. Inhibition deficits of serious delinquent boys of low intelligence. Criminal behaviour and mental health : CBMH. 2007;17(5):274-92.

158. Satterfield JH, Faller KJ, Crinella FM, Schell AM, Swanson JM, Homer LD. A 30-year prospective follow-up study of hyperactive boys with conduct problems: adult criminality. Journal of the American Academy of Child and Adolescent Psychiatry. 2007;46(5):601-10. 
159. McDowall D, Loftin C. Do US City Crime Rates Follow a National Trend? The Influence of Nationwide Conditions on Local Crime Patterns. Journal of Quantitative Criminology. 2009;25(3):307-24.

160. Tsai PL, Hatfield TH. Global Benefits From the Phaseout of Leaded Fuel. Journal of Environmental Health. 2011;74(5):8-14.

161. Warren C. Brush with death : a social history of lead poisoning. Baltimore, MD: Johns Hopkins University Press; 2000. xiv, 362 p. p.

162. Hernberg S. Lead poisoning in a historical perspective. American Journal of Industrial Medicine. 2000;38(3):244-54.

163. National Research Council Committee on Measuring Lead in Critical P. Measuring Lead Exposure in Infants, Children, and Other Sensitive Populations. Washington (DC): National Academies Press (US) Copyright 1993 by the National Academy of Sciences. All rights reserved.; 1993.

164. Eisinger J. Lead and wine. Eberhard Gockel and the colica Pictonum. Medical history. 1982;26(3):279-302.

165. Beritic T. Spinal origin of human lead neuropathy: this paper marks the 150th anniversary of Paralysie de Plomb ou Saturnine by L. Tanquerel des Planches. Am J Ind Med. 1989;15(6):643-56.

166. O'Carroll J. Saturnine encephalopathy. Dublin Journal of Medical Science (18721920). 1893;95(1):1-17.

167. S. KB. Environmental Lead Contamination:: A Metaphor for Destructive Industrial Practices; Lead Abatement: A Model for Ineffective Societal Responses. Structural Survey. 1994;12(3):13-23.

168. Gibson JL. A plea for painted railings and painted walls of rooms as the source of lead poisoning amongst Queensland children. 1904. Public health reports (Washington, DC : 1974). 2005;120(3):301-4.

169. D BK. LEAD POISONING IN CHILDREN WITH ESPECIAL REFERENCE TO LEAD AS A CAUSE OF CONVULSIONS. . The american journal of the medical sciences. 1917;153(6):877-87.

170. Flora G, Gupta D, Tiwari A. Toxicity of lead: A review with recent updates. Interdisciplinary toxicology. 2012;5(2):47-58.

171. Needleman H. Lead poisoning. Annual review of medicine. 2004;55:209-22.

172. Montgomery D. Workers' control in America : studies in the history of work, technology, and labor struggles. Cambridge Eng. ; New York: Cambridge University Press; 1979. x, 189 p. p. 
173. Fairchild AL, Rosner D, Colgrove J, Bayer R, Fried LP. The EXODUS of public health. What history can tell us about the future. American journal of public health. 2010;100(1):54-63.

174. Moawad EM, Badawy NM, Manawill M. Environmental and Occupational Lead Exposure Among Children in Cairo, Egypt: A Community-Based Cross-Sectional Study. Medicine. 2016;95(9):e2976.

175. Abelsohn AR, Sanborn M. Lead and children: clinical management for family physicians. Canadian family physician Medecin de famille canadien. 2010;56(6):531-5.

176. Shih RA, Hu H, Weisskopf MG, Schwartz BS. Cumulative lead dose and cognitive function in adults: a review of studies that measured both blood lead and bone lead. Environmental health perspectives. 2007;115(3):483-92.

177. Ericson JE, Smith DR, Flegal AR. Skeletal concentrations of lead, cadmium, zinc, and silver in ancient North American Pecos Indians. Environmental health perspectives. 1991;93:217-23.

178. Shacklette HT, Boerngen JG, Geological S. Element concentrations in soils and other surficial materials of the conterminous United States : an account of the concentrations of 50 chemical elements in samples of soils and other regoliths. Washington :: U.S. G.P.O.; 1984.

179. United States. Environmental Protection A. Federal Register. Environmental Protection Agency. Part III : 40 CFR part 745, lead; identification of dangerous levels of lead; final rule. [Washington, D.C.] :: [U.S. National Archives and Records Administration]; 2001.

180. Centers for Disease C, Prevention . Advisory Committee on Childhood Lead P. Low level lead exposure harms children : a renewed call for primary prevention. [Atlanta, GA] :: [U.S. Dept. of Health \& Human Services, Centers for Disease Control and Prevention]; 2012.

181. Vorvolakos T, Arseniou S, Samakouri M. There is no safe threshold for lead exposure: Alpha literature review. Psychiatrike = Psychiatriki. 2016;27(3):20414.

182. Miranda ML, Kim D, Galeano MA, Paul CJ, Hull AP, Morgan SP. The relationship between early childhood blood lead levels and performance on endof-grade tests. Environmental health perspectives. 2007;115(8):1242-7.

183. Needleman H. Low level lead exposure: history and discovery. Annals of epidemiology. 2009;19(4):235-8.

184. Sabin AH. Some Less Well-Known Lead Pigments. The Scientific Monthly. 1932;34(1):31-4. 
185. Montes-Santiago J. The lead-poisoned genius: saturnism in famous artists across five centuries. Progress in brain research. 2013;203:223-40.

186. United States. Louisiana purchase exposition commission. [from old catalog], United States. Department of State. Final report of the Louisiana purchase exposition commission, 1906. Washington,: Gov't print. off.; 1906. 2 p. p.

187. Korfmacher KS, Hanley ML. Are local laws the key to ending childhood lead poisoning? Journal of health politics, policy and law. 2013;38(4):757-813.

188. LaBelle SJ. Pilot study of the relationship of regional road traffic to surface-soil lead levels in Illinois. Springfield, Virginia :: U.S. Dept. of Commerce, National Technical Information Service; 2013.

189. Battelle Memorial I, United States. Environmental Protection Agency. Prevention $\mathrm{P}$, Toxic S. Sources of lead in soil : a literature review : final report. Washington, D.C. :: United States Environmental Protection Agency, Office of Pollution Prevention and Toxics ; 1996.

190. Bernard SM, McGeehin MA. Prevalence of blood lead levels $>$ or $=5$ micro g/dL among US children 1 to 5 years of age and socioeconomic and demographic factors associated with blood of lead levels 5 to 10 micro g/dL, Third National Health and Nutrition Examination Survey, 1988-1994. Pediatrics. 2003;112(6 Pt 1):1308-13.

191. Jones RL, Homa DM, Meyer PA, Brody DJ, Caldwell KL, Pirkle JL, et al. Trends in blood lead levels and blood lead testing among US children aged 1 to 5 years, 1988-2004. Pediatrics. 2009;123(3):e376-85.

192. Rosner D, Markowitz G. A 'gift of God'?: The public health controversy over leaded gasoline during the 1920s. American journal of public health. $1985 ; 75(4): 344-52$.

193. Martineau RJ, Novello DP. The Clean Air Act handbook. Chicago, Ill.: American Bar Association; 1997. xxxi, 587 p. p.

194. Gilbert SG. A small dose of toxicology : the health effects of common chemicals. Boca Raton: CRC Press; 2004. x, 266 p. p.

195. Mielke HW, Reagan PL. Soil is an important pathway of human lead exposure. Environmental health perspectives. 1998;106 Suppl 1:217-29.

196. McConnell JR, Maselli OJ, Sigl M, Vallelonga P, Neumann T, Anschutz H, et al. Antarctic-wide array of high-resolution ice core records reveals pervasive lead pollution began in 1889 and persists today. Scientific reports. 2014;4:5848. 
197. Laidlaw MAS, Filippelli GM. Resuspension of urban soils as a persistent source of lead poisoning in children: A review and new directions. Applied Geochemistry. 2008;23(8):2021-39.

198. von Lindern IH, Spalinger SM, Bero BN, Petrosyan V, von Braun MC. The influence of soil remediation on lead in house dust. The Science of the total environment. 2003;303(1-2):59-78.

199. Mielke HW, Gonzales CR, Powell E, Jartun M, Mielke PW, Jr. Nonlinear association between soil lead and blood lead of children in metropolitan New Orleans, Louisiana: 2000-2005. The Science of the total environment. 2007;388(1-3):43-53.

200. National Research Council . Committee on Lead in the Human E. Lead in the human environment : a report. Washington, D.C. :: National Academy of Sciences; 1980.

201. Brookes PS, Yoon Y, Robotham JL, Anders MW, Sheu SS. Calcium, ATP, and ROS: a mitochondrial love-hate triangle. American journal of physiology Cell physiology. 2004;287(4):C817-33.

202. Cecil KM, Brubaker CJ, Adler CM, Dietrich KN, Altaye M, Egelhoff JC, et al. Decreased brain volume in adults with childhood lead exposure. PLoS medicine. 2008;5(5):e112.

203. Wright JP, Dietrich KN, Ris MD, Hornung RW, Wessel SD, Lanphear BP, et al. Association of prenatal and childhood blood lead concentrations with criminal arrests in early adulthood. PLoS medicine. 2008;5(5):e101.

204. Brubaker CJ, Dietrich KN, Lanphear BP, Cecil KM. The influence of age of lead exposure on adult gray matter volume. Neurotoxicology. 2010;31(3):259-66.

205. Stewart WF, Schwartz BS, Davatzikos C, Shen D, Liu D, Wu X, et al. Past adult lead exposure is linked to neurodegeneration measured by brain MRI. Neurology. 2006;66(10):1476-84.

206. Apps MA, Rushworth MF, Chang SW. The Anterior Cingulate Gyrus and Social Cognition: Tracking the Motivation of Others. Neuron. 2016;90(4):692-707.

207. Hughes BL, Beer JS. Orbitofrontal cortex and anterior cingulate cortex are modulated by motivated social cognition. Cerebral cortex (New York, NY : 1991). 2012;22(6):1372-81.

208. Yokoyama C, Kaiya H, Kumano H, Kinou M, Umekage T, Yasuda S, et al. Dysfunction of ventrolateral prefrontal cortex underlying social anxiety disorder: A multi-channel NIRS study. NeuroImage Clinical. 2015;8:455-61. 
209. Brubaker CJ, Schmithorst VJ, Haynes EN, Dietrich KN, Egelhoff JC, Lindquist DM, et al. Altered myelination and axonal integrity in adults with childhood lead exposure: a diffusion tensor imaging study. Neurotoxicology. 2009;30(6):867-75.

210. Tierney AL, Nelson CA, 3rd. Brain Development and the Role of Experience in the Early Years. Zero to three. 2009;30(2):9-13.

211. Thompson-Schill SL, Ramscar M, Chrysikou EG. Cognition without control: When a little frontal lobe goes a long way. Current directions in psychological science. 2009;18(5):259-63.

212. Almond C. Children are not little adults. Australian nursing journal (July 1993). 1998;6(3):suppl 1-4.

213. Woolf AD, Goldman R, Bellinger DC. Update on the clinical management of childhood lead poisoning. Pediatric clinics of North America. 2007;54(2):271-94, viii.

214. Organization WH. Childhood Lead Poisoning. Geneva, Switzerland WHO Library Cataloguing-in-Publication Data; 2010.

215. Fitzgerald EF, Schell LM, Marshall EG, Carpenter DO, Suk WA, Zejda JE. Environmental pollution and child health in central and Eastern Europe. Environmental health perspectives. 1998;106(6):307-11.

216. Schnur J, John RM. Childhood lead poisoning and the new Centers for Disease Control and Prevention guidelines for lead exposure. Journal of the American Association of Nurse Practitioners. 2014;26(5):238-47.

217. Barltrop D. The prevalence of pica. American journal of diseases of children (1960). 1966;112(2):116-23.

218. Sabouraud S, Testud F, Descotes J, Benevent M, Soglu G. Lead poisoning following ingestion of pieces of lead roofing plates: pica-like behavior in an adult. Clinical toxicology (Philadelphia, Pa). 2008;46(3):267-9.

219. Ziegler EE, Edwards BB, Jensen RL, Mahaffey KR, Fomon SJ. Absorption and Retention of Lead by Infants. Pediatric Research. 1978;12(1):29-34.

220. Zentner LE, Rondo PH, Duran MC, Oliveira JM. Relationships of blood lead to calcium, iron, and vitamin $\mathrm{C}$ intakes in Brazilian pregnant women. Clinical nutrition (Edinburgh, Scotland). 2008;27(1):100-4.

221. Seligman HK, Laraia BA, Kushel MB. Food insecurity is associated with chronic disease among low-income NHANES participants. The Journal of nutrition. 2010;140(2):304-10. 
222. Byers RK, Lord EE. LATE EFFECTS OF LEAD POISONING ON MENTAL DEVELOPMENT. The Journal of Nervous and Mental Disease. 1944;100(4):420.

223. Markowitz GE, Rosner D. Deceit and denial : the deadly politics of industrial pollution. Berkeley, CA: University of California Press; 2002. xx, 408 p. p.

224. Dietrich KN, Ris MD, Succop PA, Berger OG, Bornschein RL. Early exposure to lead and juvenile delinquency. Neurotoxicology and teratology. 2001;23(6):5118 .

225. Needleman HL, McFarland C, Ness RB, Fienberg SE, Tobin MJ. Bone lead levels in adjudicated delinquents. A case control study. Neurotoxicology and teratology. 2002;24(6):711-7.

226. Nevin R. Understanding international crime trends: the legacy of preschool lead exposure. Environmental research. 2007;104(3):315-36.

227. Boutwell BB, Nelson EJ, Emo B, Vaughn MG, Schootman M, Rosenfeld R, et al. The intersection of aggregate-level lead exposure and crime. Environmental research. 2016;148:79-85.

228. Tang HW, Huel G, Campagna D, Hellier G, Boissinot C, Blot P. Neurodevelopmental evaluation of 9-month-old infants exposed to low levels of lead in utero: involvement of monoamine neurotransmitters. Journal of applied toxicology : JAT. 1999;19(3):167-72.

229. de Melo SN, Pereira DV, Andresen MA, Matias LF. Spatial/Temporal Variations of Crime: A Routine Activity Theory Perspective. International journal of offender therapy and comparative criminology. 2017:306624x17703654.

230. Amin R, Nabors NS, Nelson AM, Saqlain M, Kulldorff M. Geographical Clusters of Rape in the United States: 2000-2012. Statistics and public policy (Philadelphia, Pa). 2015;2(1):87-92.

231. Kulldorff M, Nagarwalla N. Spatial disease clusters: detection and inference. Statistics in medicine. 1995;14(8):799-810.

232. Ammann AA. Inductively coupled plasma mass spectrometry (ICP MS): a versatile tool. Journal of mass spectrometry : JMS. 2007;42(4):419-27.

233. Brouwers EE, Tibben M, Rosing H, Schellens JH, Beijnen JH. The application of inductively coupled plasma mass spectrometry in clinical pharmacological oncology research. Mass spectrometry reviews. 2008;27(2):67-100.

234. Team RC. R: A Language and Environment for Statistical Computing. Vienna, Austria2013. 
235. Cohen J. Statistical power analysis for the behavioral sciences. 2nd ed. ed. Hillsdale, N.J. :: L. Erlbaum Associates; 1988.

236. Filippelli GM, Laidlaw MA. The elephant in the playground: confronting leadcontaminated soils as an important source of lead burdens to urban populations. Perspectives in biology and medicine. 2010;53(1):31-45.

237. Mielke HW, Wang G, Gonzales CR, Powell ET, Le B, Quach VN. PAHs and metals in the soils of inner-city and suburban New Orleans, Louisiana, USA. Environmental toxicology and pharmacology. 2004;18(3):243-7.

238. Carey AE, Gowen JA, Forehand TJ, Tai H, Wiersma GB. Heavy metal concentrations in soils of five United States cities, 1972 urban soils monitoring program. Pesticides monitoring journal. 1980;13(4):150-4.

239. Datko-Williams L, Wilkie A, Richmond-Bryant J. Analysis of U.S. soil lead (Pb) studies from 1970 to 2012. The Science of the total environment. 2014;468469:854-63.

240. Bivand R, Pebesma EJ, Gómez-Rubio V. Applied spatial data analysis with R. New York: Springer; 2008. xiv, 374 p. p.

241. Anselin L. Lagrange Multiplier Test Diagnostics for Spatial Dependence and Spatial Heterogeneity. Geographical Analysis. 1988;20(1):1-17.

242. Bivand RS, Hauke, J., and Kossowski, T. , . Computing the Jacobian in Gaussian spatial autoregressive models: An illustrated comparison of available methods. Geographical Analysis. (2013);45(2):150-79.

243. Roger Bivand GP. Comparing Implementations of Estimation Methods for Spatial Econometrics Journal of Statistical Software. 2015;63(18):1-36.

244. Land KC, McCall PL, Cohen LE. Structural Covariates of Homicide Rates: Are There Any Invariances Across Time and Social Space? American Journal of Sociology. 1990;95(4):922-63.

245. Deane G, Messner SF, McGeever K, Stucky TD, Kubrin CE. Not 'Islands, Entire of Themselves': Exploring the Spatial Context of City-level Robbery Rates. J Quant Criminol. 2008;24(4):363-80.

246. Office of the Surgeon G, National Center for Injury P, Control, National Institute of Mental H, Center for Mental Health S. Publications and Reports of the Surgeon General. Youth Violence: A Report of the Surgeon General. Rockville (MD): Office of the Surgeon General (US); 2001.

247. STEFFENSMEIER D, HARER MD. Did Crime Rise or Fall During the Reagan Presidency? The Effects of an "Aging" U.S. Population on the Nation's Crime Rate. Journal of Research in Crime and Delinquency 2016;28(3):330-59 
248. Hahn RA, Truman BI. Education Improves Public Health and Promotes Health Equity. International journal of health services : planning, administration, evaluation. 2015;45(4):657-78.

249. Beaver K, Barnes J, Boutwell B. The Nurture Versus Biosocial Debate in Criminology: On the Origins of Criminal Behavior and Criminality: SAGE Publications; 2014.

250. Hughes J, Haran M. Dimension reduction and alleviation of confounding for spatial generalized linear mixed models. Journal of the Royal Statistical Society Series B (Statistical Methodology). 2013;75(1):139-59.

251. Earnest A, Morgan G, Mengersen K, Ryan L, Summerhayes R, Beard J. Evaluating the effect of neighbourhood weight matrices on smoothing properties of Conditional Autoregressive (CAR) models. International journal of health geographics. 2007;6:54.

252. Messner SF, Sampson RJ. The Sex Ratio, Family Disruption, and Rates of Violent Crime: The Paradox of Demographic Structure. Social Forces. 1991;69(3):693.

253. Casas A, Duell J, O'Malley T, Documet P, Garland R, Albert S, et al. Housing Relocation Policy and Violence: A Literature Review. Trauma, violence \& abuse. 2016;17(5):601-10.

254. Sampson RJ, Raudenbush SW, Earls F. Neighborhoods and violent crime: a multilevel study of collective efficacy. Science (New York, NY). 1997;277(5328):918-24.

255. Cerda M, Tracy M, Keyes KM. Reducing Urban Violence: A Contrast of Public Health and Criminal Justice Approaches. Epidemiology (Cambridge, Mass). 2018;29(1):142-50.

256. B25036 - TENURE BY YEAR STRUCTURE BUILT Universe: Occupied housing units more information 2010-2014 American Community Survey 5-Year Estimates [Internet]. United States Census Bureau. 2014. Available from: https://factfinder.census.gov/faces/tableservices/jsf/pages/productview.xhtml?pid =ACS_16_5YR_B25036\&prodType=table.

257. Madhavan S, Rosenman KD, Shehata T. Lead in soil: recommended maximum permissible levels. Environmental research. 1989;49(1):136-42.

258. Centers for Disease C. Preventing lead poisoning in young children : a statement. [4th revision]. ed. Atlanta, GA (Atlanta, 30333): U.S. Dept. of Health and Human Services, Public Health Service, Centers for Disease Control; 1991. 
259. Bellinger DC, Stiles KM, Needleman HL. Low-level lead exposure, intelligence and academic achievement: a long-term follow-up study. Pediatrics. 1992;90(6):855-61.

260. Lanphear BP, Dietrich K, Auinger P, Cox C. Cognitive deficits associated with blood lead concentrations $<10$ microg/dL in US children and adolescents. Public health reports (Washington, DC : 1974). 2000;115(6):521-9.

261. Hirschi T, Hindelang MJ. Intelligence and Delinquency: A Revisionist Review. American sociological review. 1977;42(4):571.

262. Wolfgang ME, Figlio RM, Sellin T. Delinquency in a birth cohort. Chicago: University of Chicago Press; 1972.

263. Lennon JJ. Red-Shifts and Red Herrings in Geographical Ecology. Ecography. 2000;23(1):101-13.

264. Zhang Z, Castello A. Principal components analysis in clinical studies. Annals of translational medicine. 2017;5(17):351.

265. Langton L, Berzofsky M, Krebs CP, Smiley-McDonald H, United States. Bureau of Justice S. Victimizations not reported to the police, 2006-2010. Washington, D.C.: U.S. Dept. of Justice, Office of Justice Programs, Bureau of Justice Statistics; 2012. Available from: http://www.bjs.gov/content/pub/pdf/vnrp0610.pdf.

266. Sumner SA, Mercy JA, Dahlberg LL, Hillis SD, Klevens J, Houry D. Violence in the United States: Status, Challenges, and Opportunities. Jama. 2015;314(5):47888 .

267. Commerce USDo. Jefferson County, KY - Shapefile. In: Bureau USC, editor. TIGER/Line2015.

268. Openshaw S. The modifiable areal unit problem. Norwich: Geo; 1984.

269. Moon Z, Farmer F. Population Density Surface: A New Approach to an Old Problem. Society and Natural Resources. 2001;14(1):39-51.

270. Spielman SE, Folch D, Nagle N. Patterns and causes of uncertainty in the American Community Survey. Applied geography (Sevenoaks, England). 2014;46:147-57.

271. Krieger N. A century of census tracts: health \& the body politic (1906-2006). Journal of urban health : bulletin of the New York Academy of Medicine. 2006;83(3):355-61.

272. Blau JR, Blau PM. The Cost of Inequality: Metropolitan Structure and Violent Crime. American sociological review. 1982;47(1):114-29. 
273. Fajnzylber P, Lederman D, Loayza N. Inequality and Violent Crime. The Journal of Law and Economics. 2002;45(1):1-39. 
APPENDIX A - Supplemental Tables

Table 1. Serum Lead Data from the Louisville Metro Department of Health and Wellness

\begin{tabular}{lccccccc}
\hline \multicolumn{1}{c}{$\mathbf{n}$} & $\begin{array}{c}\text { Geometric } \\
\text { Mean }\end{array}$ & Min & P25 & Med & P75 & Max \\
\hline Serum Lead & 26,027 & 1.51 & 1 & 1 & 1 & 2 & 60 \\
\hline $\begin{array}{l}\text { Serum lead measured in mcg/dL; Min, minimum; } \\
\text { Max, maximum count; }\end{array}$
\end{tabular}

\begin{tabular}{ccccccccc} 
Table 2. & \multicolumn{8}{c}{ Summary of Principle Components Analysis } \\
\cline { 2 - 9 } & PCI-1 & PCI-2 & PCI-3 & PCI-4 & PCI-5 & PCI-6 & PCI-7 \\
\hline Standard Deviation & 2.18 & 1.08 & 0.67 & 0.59 & 0.37 & 0.33 & 0.21 \\
Proportion of Variance & 0.68 & 0.17 & 0.06 & 0.05 & 0.02 & 0.02 & 0.01 \\
Cumulative Proportion & 0.68 & 0.85 & 0.91 & 0.96 & 0.98 & 0.99 & 1.00 \\
\hline PC, Principal Component & & & & & & & &
\end{tabular}


Table 3.

Principle Components Analysis -

\begin{tabular}{lccc}
\hline & \multicolumn{3}{c}{ Rotation Scores } \\
\hline Median Household Income & PCI-1 & PCI-2 & PCI-3 \\
Percent Population with Bachelor's Degree & 0.39 & 0.37 & -0.23 \\
Percent of Population that is Black & 0.38 & 0.03 & -0.78 \\
Percent Female Head of Household & -0.40 & 0.06 & -0.41 \\
Percent of Households with Dependents $<18$ years of age & -0.42 & 0.23 & -0.04 \\
Percent of Households on Food Stamps & -0.07 & 0.89 & 0.14 \\
Percent of Households Living in Poverty & -0.44 & -0.03 & -0.17 \\
\hline
\end{tabular}

PC, Principal Component; PC scores have been rounded to two decimal places

Table 4. Results Spatial Error Models for Edge Zone and Distance to Urban Core

\begin{tabular}{lcccc}
\hline \multicolumn{5}{c}{ Edge Zone Soil Samples } \\
\hline Intercept & $\begin{array}{c}\text { Coefficients } \\
16.79\end{array}$ & $\begin{array}{c}\mathbf{9 5 \%} \text { CI } \\
(10.49,26.88)\end{array}$ & $\begin{array}{c}\text { P-value } \\
<2.2 \mathrm{e}-16\end{array}$ & Distance to Urban Core \\
Study & 8.24 & $(5.12,13.27)$ & $<2.2 \mathrm{e}-16$ & -- \\
Northeast & 2.43 & $(1.55,3.81)$ & 0.0001 & 12.79 Kilometers \\
Southwest & 1.35 & $(0.80,2.29)$ & 0.2551 & 19.20 Kilometers \\
Southeast & ref & -- & -- & 23.73 Kilometers \\
\hline $95 \%$ CI, $95 \%$ confidence interval; & &
\end{tabular}

95\% CI, 95\% confidence interval;

Table coefficients have been exponentiated back to their original measurement scale;

Distances are measured from the geometric center of each Control Area to the geometric center of the Study Area 
Table 5. Results Spatial Error Models for Louisville Metro Parks and Distance to Urban Core

\begin{tabular}{lcccc}
\hline \multicolumn{5}{c}{ Edge Zone Soil Samples } \\
\hline Intercept & $\begin{array}{c}\text { Coefficients } \\
\mathbf{9 5 \%} \text { CI }\end{array}$ & $\begin{array}{c}\text { P-value } \\
(8.02,20.09)\end{array}$ & $<2.2 \mathrm{e}-16$ & Distance to Urban Core \\
Study & 8.06 & $(4.76,13.67)$ & $<8.66 \mathrm{e}-15$ & -- \\
Northeast & 1.72 & $(1.03,2.89)$ & 0.03763 & 12.79 Kilometers \\
Southwest & 1.27 & $(0.69,2.32)$ & 0.43068 & 19.20 Kilometers \\
Southeast & ref & -- & -- & 23.73 Kilometers \\
\hline
\end{tabular}

95\% CI, 95\% confidence interval;

Table coefficients have been exponentiated back to their original measurement scale;

Distances are measured from the geometric center of each Control Area to the geometric center of the Study Area

\begin{tabular}{lccc} 
Table 6. & \multicolumn{2}{c}{ Census Tracts and Pre-1950 Housing } \\
\hline Soil Collection Area & N & $\begin{array}{c}\text { Top Quantile of } \\
\text { Pre-1950 Housing }\end{array}$ & $\begin{array}{c}\text { Percent - Top Quantile } \\
\text { Pre-1950 Housing }\end{array}$ \\
\hline Study Area & 33 & 25 & $75.75 \%$ \\
Northeast Control Area & 40 & 6 & $15 \%$ \\
Southwest Control Area & 15 & 0 & $0 \%$ \\
Southeast Control Area & 21 & 0 & $0 \%$ \\
\hline
\end{tabular}

Top quantile of pre-1950 housing is defined as more than $53 \%$ of residential structures per census tract built prior to 1950 
APPENDIX B - Supplemental Illustrations 
Illustration 1.

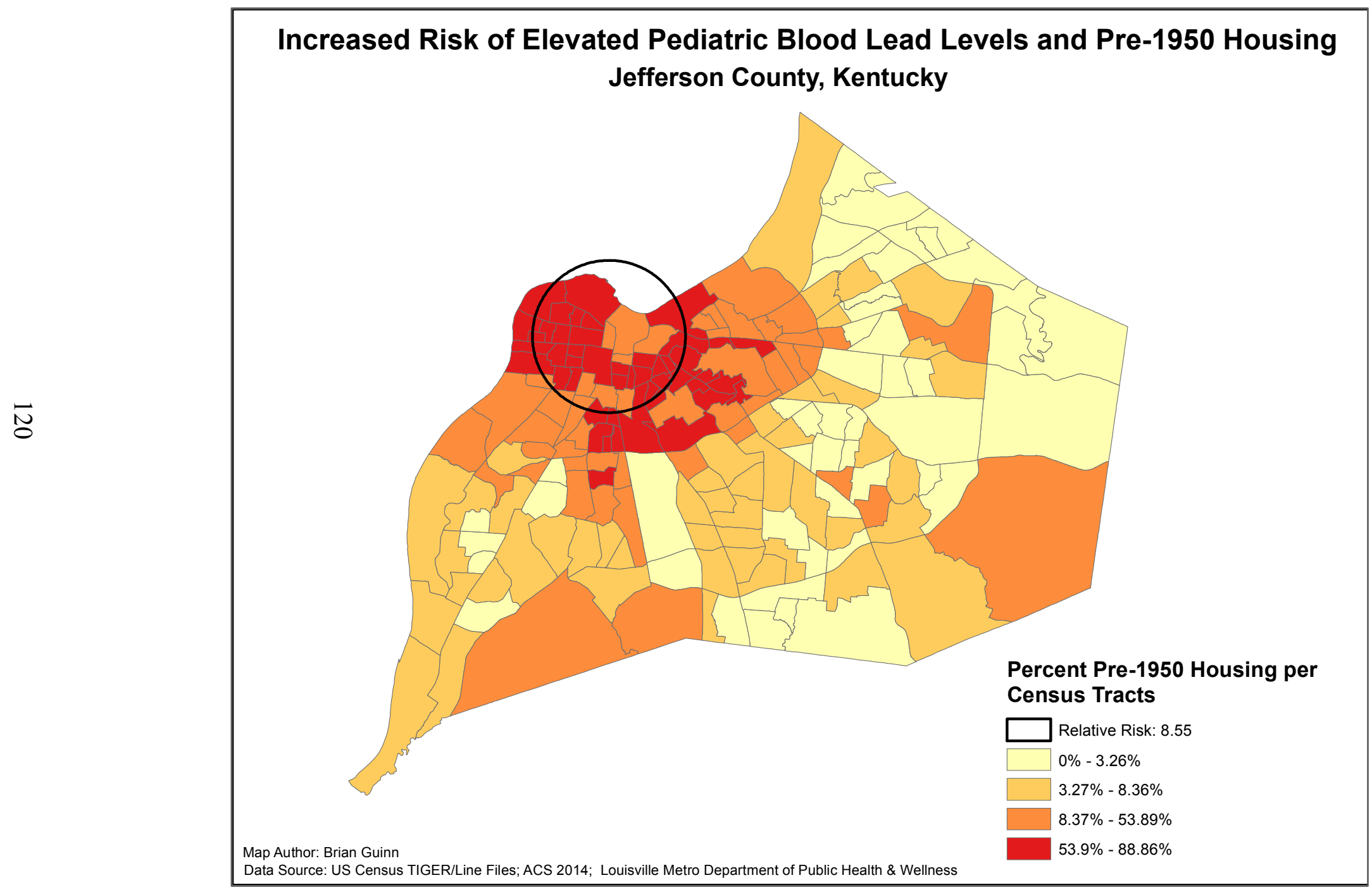


Illustration 2.

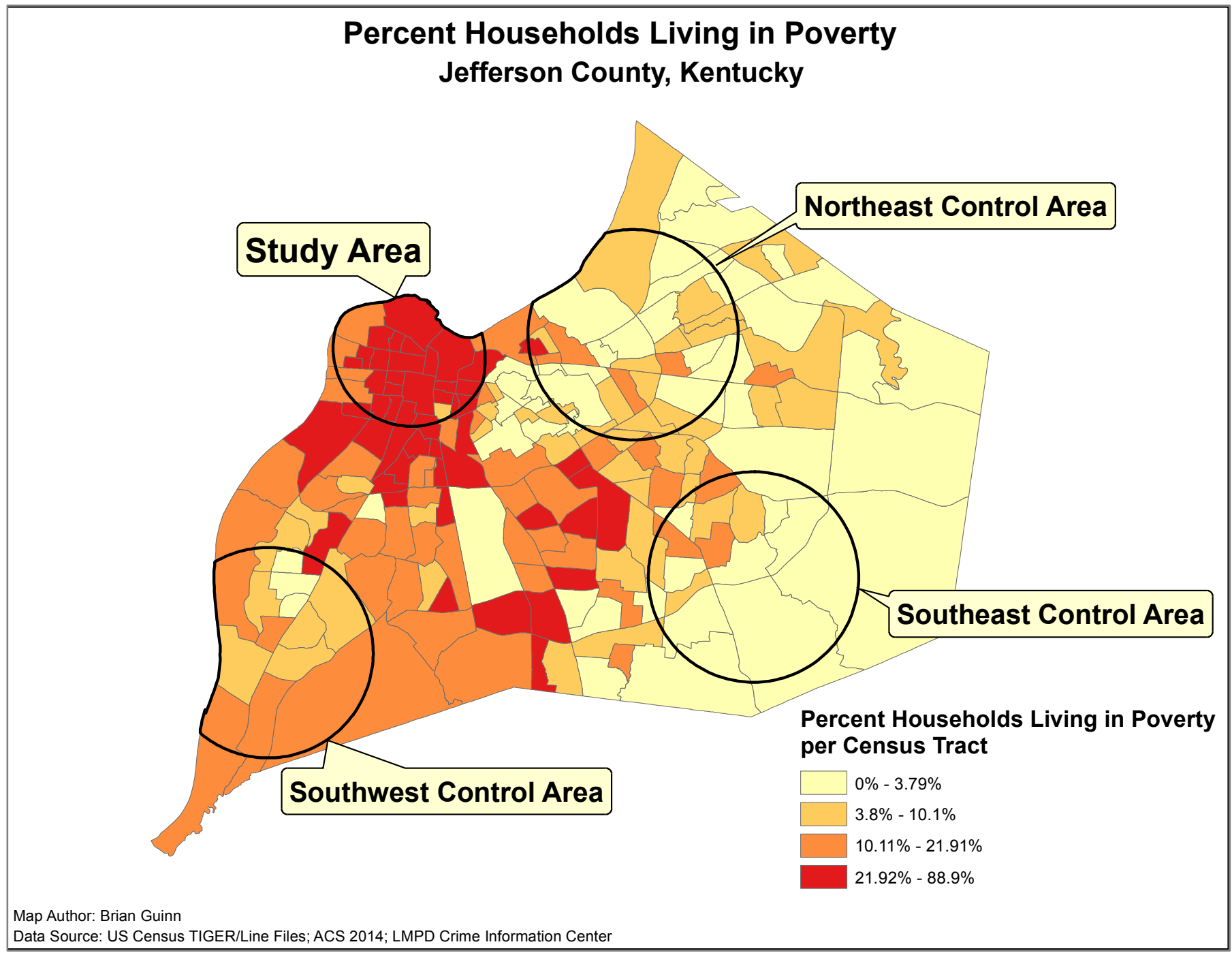


Illustration 3.

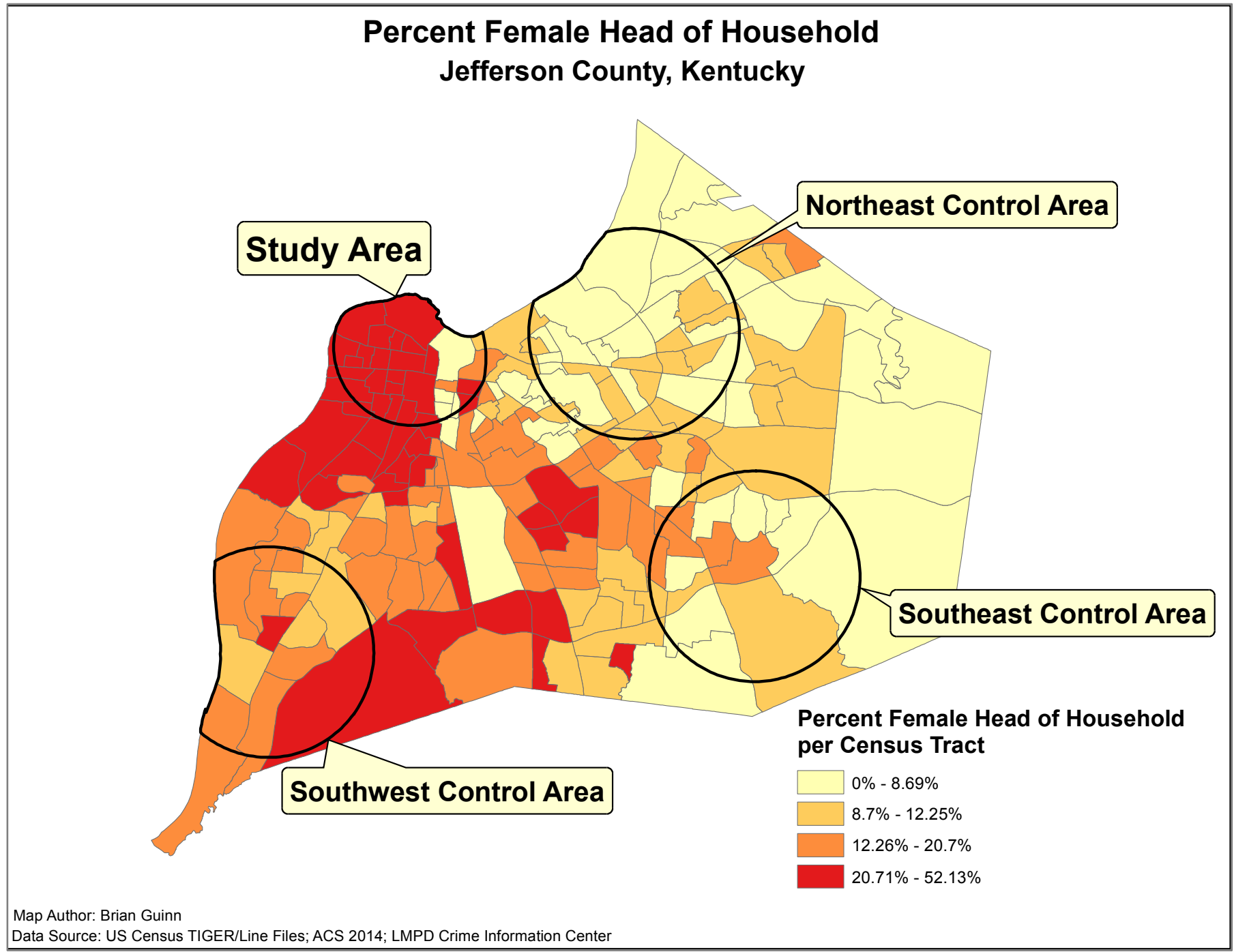


Illustration 4.

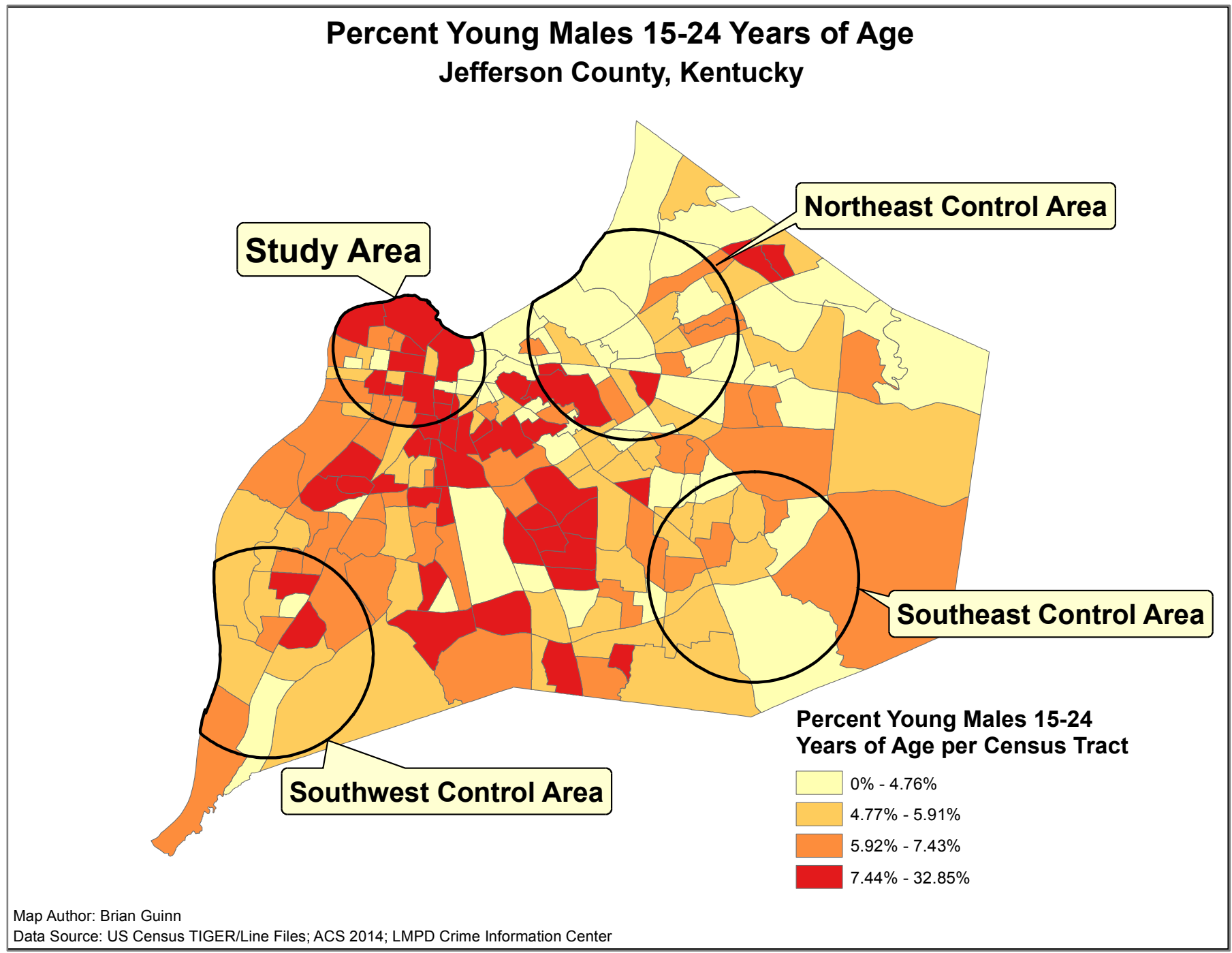


Illustration 5.

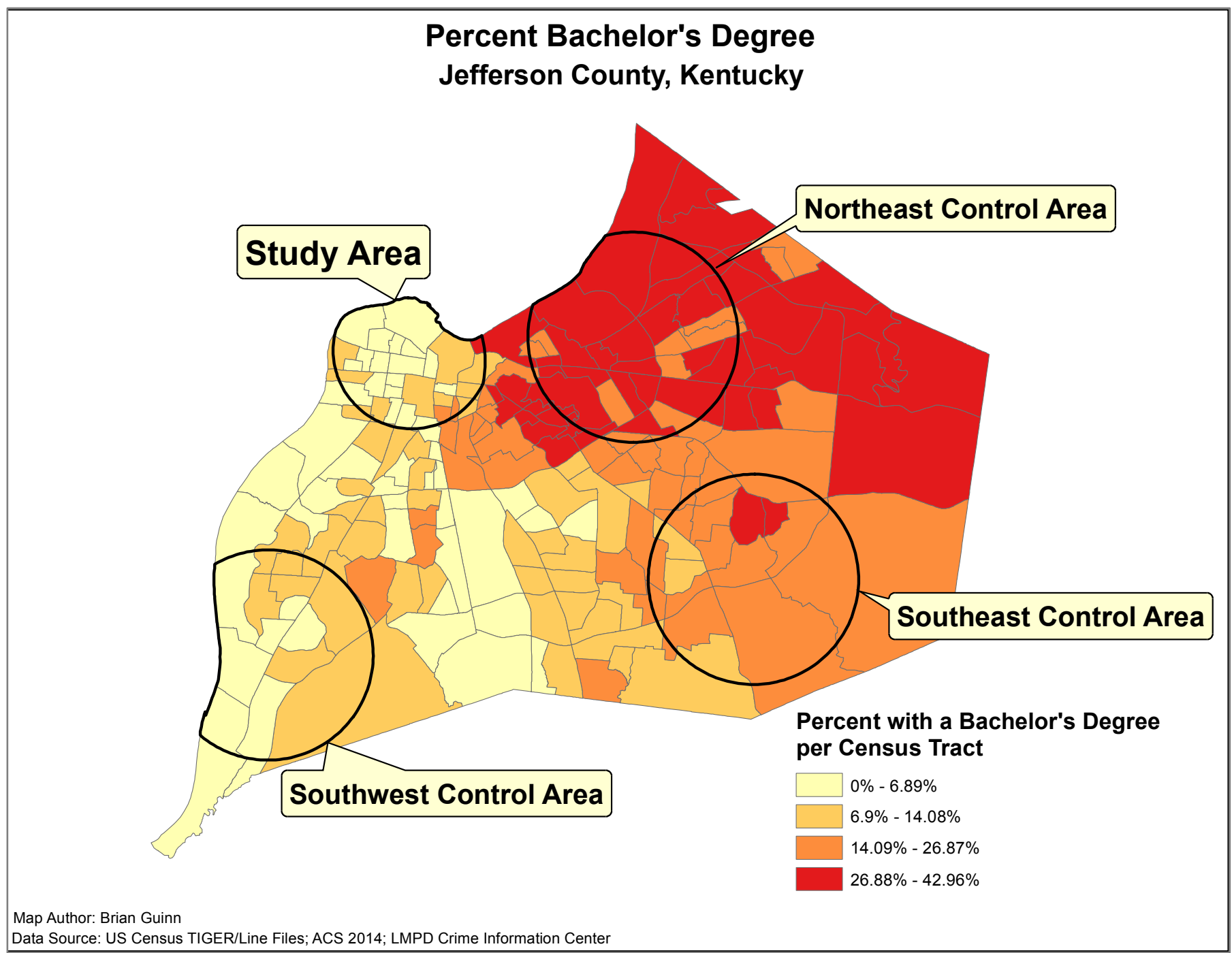


Illustration 6.

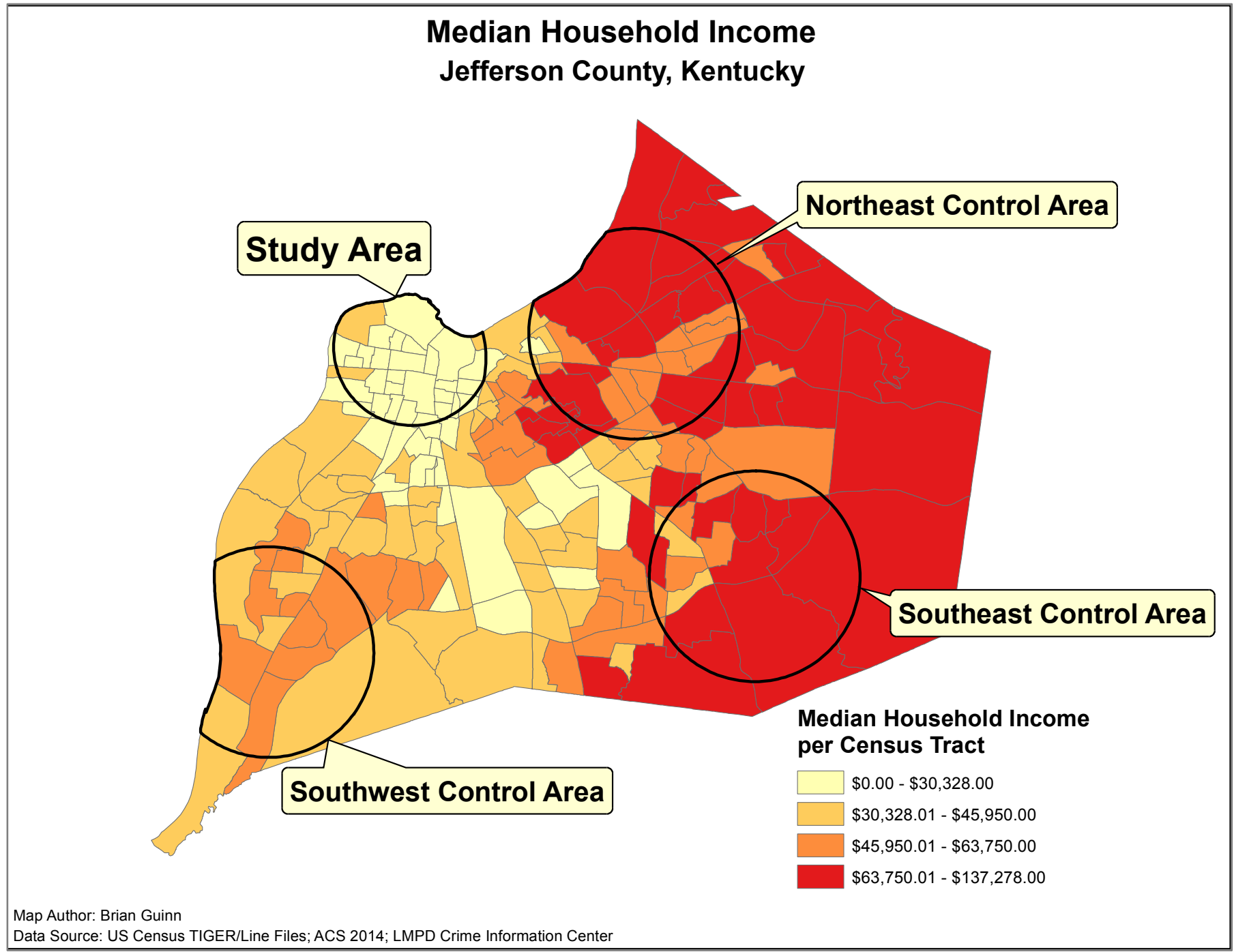




\title{
CURRICULUM VITAE
}

\author{
Brian Guinn
}

\section{$\underline{\text { EDUCATION }}$}

2015 - Present

$2013-2015$

$1997-2001$
PhD Candidate - Epidemiology

Dissertation Defense Date - November 19, 2018

Masters of Public Health, Epidemiology

University of Louisville - School of Public Health and Information Sciences

Bachelor of Science in Nursing (BSN)

Bellarmine University

\section{CERTIFICATION AND LICENSURE}

2001 - Present

2001 - Present

2009-2013

2008-2013

2001-2008

2006-2008

2006-2008

HONOR SOCIETIES

2015

2015

HONORS AND AWARDS

2013

2011

$1997 \& 2001$

1997
Registered Nurse, Kentucky

Basic Cardiac Life Support

Certified Sensitive 6 Clearance, U.S. Department of

Veterans Affairs

Certified Journey Level Rating Specialist, U.S. Department of Veterans Affairs

Advanced Cardiac Life Support

Certified in Balloon-Pump Management

Certified in Hemodynamic Monitoring
Delta Omega

Phi Kappa Phi 


\section{RELATED EXPERIENCE}

2017 - Present

$2013-2017$

$2018-2013$
Graduate Teaching Assistant

University of Louisville - School of Public Health and Information Sciences, Department of Epidemiology

Faculty Mentor: Dr. Kathy Baumgartner

- Create original lecture content for graduate students enrolled in Introduction to Epidemiology

- Grade homework assignments and examinations

- Tutor students one-on-one, as needed

- Group review sessions, as needed

Clinical Research Coordinator

University of Louisville, Division of Infectious Diseases, Clinical Translational Research Support Unit

Principle Investigator: Dr. Julio Ramirez

- Quality control team member for Pfizer UAD and HAPPI studies

- Provide support and guidance for university faculty in the development of research questionnaires/data collection forms

- Develop REDCap modules for data capture for university faculty

- Create maps as needed using ArcGIS and SaTScan Software

Journey Level Rating Veterans Service Representative (RVSR) - U.S. Department of Veterans Affairs

- Adjudicated claims for disability compensation and/or pension

- Adjudicated Dependency Indemnity Compensation claims

- Specialized team member working with a small group to adjudicate contaminated water claims made by veterans who were stationed at Camp Lejeune

- Cross trained to evaluate claims of military sexual assault, Traumatic Brain Injury, Post-Traumatic Stress Disorder, and Gulf War Illness 
- Assisted cardiologists with diagnostic and urgent cardiac catheterizations, percutaneous coronary interventions, balloon pump and pacemaker/ICD implantations

- Performed Tilt-Table studies, assisted with transesophageal echocardiograms, and assisted with electrophysiology studies/ablations

- Responded to cardiopulmonary arrest throughout the hospital as needed

- On call 108 hours a month for after-hour emergencies

- Responsible for maintaining continuous surveillance of patient cardiopulmonary status, administering medications, monitoring pertinent lab findings and informing physicians as needed

- Mentored new nurses during their training period and educated student nurses during their clinical rounds

- Relief charge nurse responsibilities

\section{PUBLICATIONS}

Ramirez JA, Wiemken TL, Peyrani P, Arnold FW, Kelley R, Mattingly WA, et al. Adults Hospitalized With Pneumonia in the United States: Incidence, Epidemiology, and Mortality. Clinical infectious diseases : an official publication of the Infectious Diseases Society of America. 2017;65(11):1806-12.

Wiemken TL, Furmanek SP, Mattingly WA, Wright MO, Persaud AK, Guinn $\mathrm{BE}$, et al. Methods for computational disease surveillance in infection prevention and control: Statistical process control versus Twitter's anomaly and breakout detection algorithms. American journal of infection control.

El-Kersh K, Jalil B, McClave SA, Cavallazzi R, Guardiola J, Guilkey K, Guinn $\mathrm{B}$, et al. Enteral nutrition as stress ulcer prophylaxis in critically ill patients: A randomized controlled exploratory study. Journal of critical care.

Wiemken TL, Kelley RR, Carrico RM, Binford LE, Guinn BE, Mattingly WA, Peyrani P, Ramirez JA. Efficacy of a novel skin antiseptic against Carbepenemresistant Enterobacteriaceae. American Journal of Infection Control. 
Pfister GJ, Burkes RM, Guinn B, Steele J, Kelley RR, Wiemken TL, Sadd M, Ramirez J, Cavallazzi R. Opioid overdose leading to intensive care unit admission: Epidemiology and outcomes. Journal of Critical Care.

Wiemken TL, Furmanek SP, Carrico RM, Mattingly WA, Persaud AK, Guinn $\mathrm{BE}$, et al. Process control charts in infection prevention: Make it simple to make it happen. American journal of infection control.

Mattingly WA, Kelley RR, Wiemken TL, Chariker JH, Peyrani P, Guinn B, Binford L, Buckner K, Ramirez J. Real-Time Enrollment Dashboard for Multisite Clinical Trials. Contemporary Clinical Trials.

\section{PRESENTATIONS}

March 14, 2017

August 6, 2016

May 20, 2016
Kentucky Hospital Association - Critically Thinking about Quality Control Measures Utilized by HIIN

University of Louisville - Division of Infectious Diseases: Measures of Association

Western Kentucky Chapter APIC: An Introduction into Descriptive and Inferential Statistics

\section{POSTER PUBLICATIONS}

B Guinn, T Wiemken, R Kelley, L Binford, F Arnold, R Carrico, P Peyrani, K Buckner, C Ackerman, J Ramirez. Levels of Air Pollution in Jefferson County Kentucky are Associated with Increased Risk for Lower Respiratory Tract Infection Hospitalization. Research Louisville. 2013.

R Rivera, B Guinn, T Wiemken, R. Kelley, M Ahmed, J Gonzalez, J Lanceta, V Salunkhe, L Binford, J Ramirez. Impact of Economic Factors on the Incidence of Hospitalization for Lower Respiratory Tract Infection in Jefferson County. Research Louisville. 2013.

J Lanceta, B Guinn, T Wiemken, R Kelley, V Salunkhe, S Pena, L Rodriguez, L Binford, C Ackerman, J Ramirez. Patients Hospitalized with Lower Respiratory Tract Infections in Jefferson County: The impact of Census Tract Level Demographic Characteristics. Research Louisville. 2013.

K Buckner, R Kelley, L Binford, B Guinn, J. Gonzalez, C Ackerman, P Peyrani, R Carrico, J Ramirez, T Wiemken. The Economic Burden of Hospitalization due to Pneumonia in Acute Care Hospitals in Jefferson County. Research Louisville. 2013. 
Pfister GJ, Burkes RM, Guinn B, Steele J, Kelley RR, Wiemken TL, Sadd M, Ramirez J, Cavallazzi R. Opioid overdose leading to intensive care unit admission: Epidemiology and outcomes. Journal of Critical Care.

W Mattingly, R Kelley, K Buckner, B Guinn, L Binford, J Lanceta, J Ramirez. Development of Applications to Facilitate Clinical Research: The Pneumonia in Jefferson County Research App. Research Louisville. 2013.

\section{ACADEMIC COMITTEES}

2018

Decanal Review Committee Student Representative for the School of Public Health and Information Sciences

\section{OTHER ACTIVITIES}

$2006-2008$

Medical Response Team Leader - U.S. Department of Veterans Affairs Regional Office 327

Workplace Safety Team Leader - Cardiac Catheterization Lab - Baptist Hospital East

Southern Middle School volunteer physical education teacher/mentor

"Kids Café" volunteer mentor - helped grades $\mathrm{K}-8$ participants with homework during study hour, and organized after school activities 